University of Louisville

ThinkIR: The University of Louisville's Institutional Repository

Electronic Theses and Dissertations

$12-2014$

\title{
Modulation of the ovarian cancer humoral response by tumor- derived exosomes.
}

Carolyn Denise Roberson

University of Louisville

Follow this and additional works at: https://ir.library.louisville.edu/etd

Part of the Microbiology Commons, and the Oncology Commons

\section{Recommended Citation}

Roberson, Carolyn Denise, "Modulation of the ovarian cancer humoral response by tumor-derived exosomes." (2014). Electronic Theses and Dissertations. Paper 1771.

https://doi.org/10.18297/etd/1771

This Doctoral Dissertation is brought to you for free and open access by ThinkIR: The University of Louisville's Institutional Repository. It has been accepted for inclusion in Electronic Theses and Dissertations by an authorized administrator of ThinkIR: The University of Louisville's Institutional Repository. This title appears here courtesy of the author, who has retained all other copyrights. For more information, please contact thinkir@louisville.edu. 


\title{
MODULATION OF THE OVARIAN CANCER HUMORAL RESPONSE BY TUMOR-DERIVED EXOSOMES
}

\author{
By
}

Carolyn Denise Roberson

B.S., Stillman College, 1994

M.S., Mississippi State University, 1999

M.S., University of Louisville, 2011

\author{
A Dissertation \\ Submitted to the Faculty of the \\ School of Medicine of the University of Louisville \\ In Partial Fulfillment of the Requirements \\ for the Degree of
}

Doctor of Philosophy

Department of Microbiology and Immunology

University of Louisville

Louisville, Kentucky

December 2014 


\section{Copyright 2014 by Carolyn Denise Roberson}

All rights reserved 

MODULATION OF THE OVARIAN CANCER HUMORAL RESPONSE BY TUMOR-DERIVED EXOSOMES

By

Carolyn Denise Roberson

B.S., Stillman College, 1994

M.S., Mississippi State University, 1999

M.S., University of Louisville, 2011

A Dissertation Approved on

December 4, 2014

by the following Dissertation Committee:

Jill Suttles (Dissertation Co-Director)

Tom Mitchell

Jason Chesney

Haribabu Bodduluri 


\section{DEDICATION}

This dissertation is dedicated to my biggest supporters... my parents, Lewis and Alberta

Roberson. Thank you both for always loving me, believing in me, praying for me, and encouraging me to do my absolute best. 


\section{ACKNOWLEDGMENTS}

First and foremost, I must thank God for giving me this dream, for giving me the strength and endurance to see it through, and for maintaining my sanity throughout this journey. You truly are the reason that I live, breathe, and have my very being.

On a professional level, I want to thank my mentor from 2010-2013, Dr. Douglas D. Taylor. I truly appreciate you "taking a chance" on this teacher who had been out of the lab for over 10 years. Your patience, encouragement, financial support, and guidance through the early stages of this project were instrumental in reigniting my love for research, and for that I will always be grateful. I am also thankful for the friendship that I was fortunate to develop with you and your wife, Dr. Cicek Gercel-Taylor while you were here at the university. I will always be grateful to you both for the "non-science" talks, laughter, and lab outings that we shared over the years. You made my transition from teacher to student such a pleasant experience and I will never forget it.

A very special thanks to Dr. Jill Suttles for accepting me into your lab from 20132014 and taking on the responsibility as my co-mentor in lieu of your husband, Dr. Robert Stout. This past year has been one of the most trying times of my life, but you made it so much easier to deal with. You not only made a space for me in your lab, but you took an interest in me as a student and took on the responsibilities of guiding me and mentoring me, all while doing the same for your own student and managing your own loss. You did not have to do any of that, but you did... and I am eternally grateful. I not only respect you as a mentor, but as a person. From the very depths of my heart, I thank you. Special posthumous thanks to Dr. Robert Stout for his encouragement and 
positivity in reference to my project during those early stages when I was still trying to "figure things out." Thanks to the Suttles lab for accepting me into your lab home and into your lives.

Thanks to my committee members, Dr. Tom Mitchell, Dr. Hari Bodduluri, and Dr. Jason Chesney for your invaluable input and guidance over the years. Thanks for foreseeing that I needed "a little more time" to get things done. That extra time made all the difference in the world. Thank you.

Thanks to IPIBS for financially supporting me early in my academic pursuit and to the Microbiology and Immunology Department for the extended financial and emotional support over the last year. You made a somewhat stressful experience a lot more manageable by alleviating my financial concerns. Thank you.

On a personal level, a tremendous thanks to my amazing family. My parents, Lewis and Alberta Roberson... you are my biggest inspirations and the smartest people I know. Thank you for your love, your discipline, your prayers, and your encouragement over the years...and especially over the last 6 years. There were times when I didn't think that I could go on, but one call to you both would alleviate any doubts that I had in myself, my abilities, or my purpose. How truly blessed I am to have you in my life and how truly fortunate I am to have you as my parents. I love you more than words can express. Thanks to my siblings: Fannie, Jr., Pat, Barbara, Julie and Janice... you guys have been wonderful! Thanks for entertaining my email gripes and complaints, thanks for the encouraging emails, texts, phone calls, and the continued prayers...you guys are the best and I love you deeply. Thanks to my brother-in-laws and sister-in-law for your support and prayers. Thanks to my nieces and nephews for your well wishes over the years. Much love to my nephew, Darvin who unexpectedly passed away during my $3^{\text {rd }}$ year (may you rest in peace). 
Finally, thanks to all of my wonderful, supportive friends and extended family...the Oak Ridge, Tennessee crew and the Louisville, Kentucky crew. You guys have been the listening ears and the strong shoulders that l've needed on this $\mathrm{PhD}$ journey. Thanks for the prayers, the laughter, the texts, the emails, the calls, the hugs, the "straight talk" and the shared tears...you will never know what you mean to me. I love you all. Thanks for your friendship and support. 


\title{
ABSTRACT \\ MODULATION OF THE OVARIAN CANCER HUMORAL RESPONSE BY TUMOR-DERIVED EXOSOMES
}

\author{
Carolyn Denise Roberson
}

\section{December 4, 2014}

The pathogenesis of epithelial ovarian cancer is complicated by its diagnosis during the latter stages of the disease resulting from lack of symptoms or from presence of symptoms that mimic other conditions. Because of the often fatal prognosis by the time of actual detection, efforts are being made to better understand the host immune response to ovarian cancer. In this study, the contributions of the humoral immune response were investigated by focusing on the role of tumor-derived exosomes and their ability to modulate humoral immune responses. First, ovarian cancer patient-derived free circulating antibodies were investigated for immunoreactivity to patient antigen. The immunoreactivity allowed for the mass spectrometry identification of six proteins which have been shown to be correlated with cancer pathogenesis. The identity of these proteins were confirmed by immunoreactivity of patient-derived antibodies with recombinant proteins and their presence on in vivo and in vitro ovarian tumor-derived exosomes (TDE) was defined. Analysis of the TDE demonstrated bound tumor-reactive 
immunoglobulin (predominantly $\lg \mathrm{G} 1$ and $\lg \mathrm{G} 2$ ) that exhibited immunoreactivity with the identified antigens. Direct effects of the TDE on the B cell were investigated by coculture of B cells with patient TDE at different concentrations and time points. Surprisingly, B cells were induced to undergo apoptosis, with the greatest cell death seen at the latter time points and with the higher concentrations of exosomes. Apoptosis as the mechanism of cell death was confirmed by Western blot analysis with common apoptotic markers, PARP and caspase-3, and DNA fragmentation analysis using agarose gels. Further analysis of the supernatant from the $B$ cell/TDE cocultures revealed increases in three proteins (PAI-1, IL-16, and sICAM-1). Collectively, data from this study suggests that ovarian patient-TDE express immunogenic antigen that binds $\lg G$ as a mechanism to divert the humoral antitumor response away from the tumor, while utilizing different subclasses to mediate strength of the antitumor response. Furthermore, ovarian patient-TDE induce apoptosis of B cells to diminish production of antitumor antibodies and promote secretion of proteins to assist the ovarian tumor in immune escape and promote its survival. 
TABLE OF CONTENTS

PAGE

DEDICATION

iii

ACKNOWLEDGMENTS

iv-vi

ABSTRACT

vii-viii

LIST OF FIGURES

Xi

CHAPTER 1: INTRODUCTION (IMMUNOPHYSIOLOGY OF EPITHELIAL OVARIAN CANCER AND THE TUMOR MICROENVIRONMENT)

Epithelial Ovarian Cancer

The Tumor Microenvironment and Humoral Immune Responses .... 5

Tumor-Derived Exosomes and their Role in Modulation of the ....... 7 Tumor Microenvironment

Hypothesis and Goals

CHAPTER 2: IDENTIFICATION OF IMMUNOREACTIVE TUMOR ANTIGEN USING CIRCULATING FREE HUMORAL RESPONSES.

Introduction

Materials and Methods

Results

22

Recognition of Ovarian Tumor Antigens by Patient Sera Antibodies

22

Confirmation of Ovarian Tumor Antigens by Patient Antibodies

23

Validation of Sera Antibody Detection using Recombinant Proteins

23

Analysis of Ovarian Tumor-Reactive Antigens in in vivo and in vitroderived Ovarian TDE

Discussion 


\section{CHAPTER 3: ISOLATION OF TDE-ASSOCIATED IMMUNOGLOBULIN REVEALS PRESENCE OF SUBCLASSES AND IMMUNOREACTIVITY TO TUMOR ANTIGEN}

Introduction

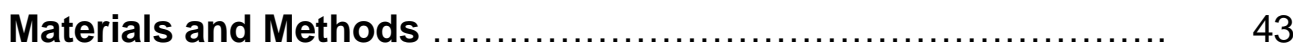

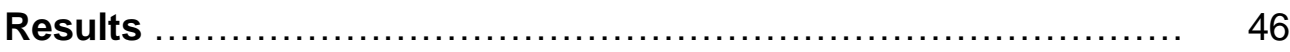

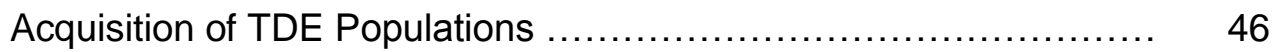

Verification of Exosome Acquisition ............................. 47

Association of $\lg G$ with TDE Populations $\ldots \ldots \ldots \ldots \ldots \ldots \ldots \ldots \ldots \ldots, 47$

Isolated IgG Displays Immunoreactivity to Cellular Antigen .......... 48

Subclass Characterization of Exosome-Isolated lgG ............... 48

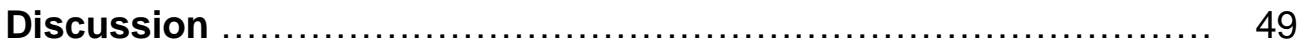

CHAPTER 4: OVARIAN TDE MEDIATION OF THE HUMORAL RESPONSE BY INDUCTION OF B CELL APOPTOSIS ...

B Cell Biology and their Responses in the Normal and Tumor

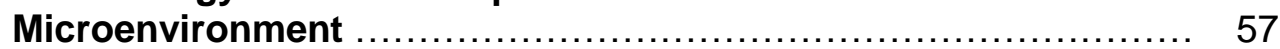

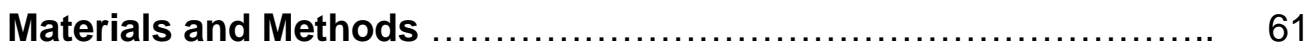

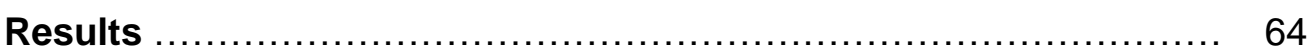

Coculture of UL-124 Patient-derived Exosomes with Ramos B cells ... 64

Coculture with TDE Enhances Particular Molecules $\ldots \ldots \ldots \ldots \ldots \ldots . . \ldots 6$

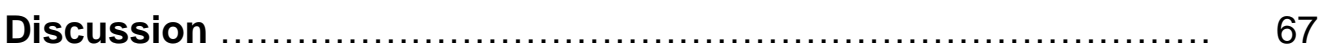

CHAPTER 5: CONCLUSION AND SIGNIFICANCE OF WORK $\ldots \ldots \ldots \ldots \ldots \ldots . \quad 80$

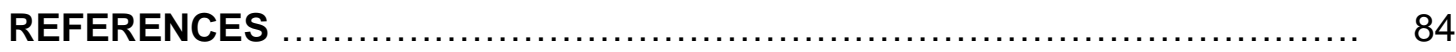

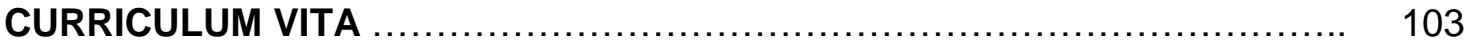




\section{LIST OF FIGURES}

\section{FIGURE}

PAGE

1. Shared immunoreactivity of rotofor-fractionated patient cellular lysate with antibodies from ovarian tumor patient sera

2. Validation of identified antigens of interest using commercial antibodies

3. Validation of ovarian cancer patient serum antibody recognition of of antigens of interest using recombinant proteins

4. Analysis of the association of antigens of interest with in vivo and in vitro-derived exosomes

5. Validation of tumor-reactive antigen presence in patient tumor-derived exosomes using different commercial antibodies

6. Separation of IgG-bound vs. unbound exosomes

7. Verification of exosome acquisition utilizing common exosome markers and nanoparticle tracking analysis (NTA)

8. Verification and isolation of patient-bound ascites exosome $\lg G$ and its immunoreactivity to identified antigen

9. Subclass characterization of isolated exosome-lgG

10. Percentage of cell death in Ramos cells cocultured with patient tumor-derived exosomes

11. Coculture of patient tumor-derived exosomes enhance presence of apoptotic marker, PARP

12. Coculture of patient tumor-derived exosomes enhance presence of apoptotic marker, caspase-3

13. DNA fragmentation analysis of $B$ cell apoptosis induced by coculture with TDE

14. Analysis of in vivo and in vitro-derived exosomes reveal presence of potential activators of $B$ cell apoptosis
54

57

35

37

38

39

40

55

56

74

75

76

77

78 
15. Molecule induction in Ramos B cells cocultured for $24 \mathrm{~h}$ with tumorderived exosomes

16. Proposed mechanism of TDE modulation in the ovarian cancer humoral response 


\section{CHAPTER 1}

\section{INTRODUCTION}

\section{IMMUNOPHYSIOLOGY OF EPITHELIAL OVARIAN CANCER AND THE TUMOR MICROENVIRONMENT}

\section{Epithelial Ovarian Cancer}

Recognized as one of the most common malignancies worldwide [1], epithelial ovarian cancer $(E O C)$ remains the $5^{\text {th }}$ leading cause of cancer death among women [2] and in the United States, stands as the leading cause of gynecologic cancer death [3]. Approximately, 21,980 U.S. cases are reported each year, with 14,270 estimated deaths [4]. From 2006-2010 reduction in mortality rates were documented in younger ( $<65$ years) and older (>65 years) women (2.8\%, $1.7 \%$ respectively) [5], which provides promise for improved future outcomes. Presently, the origins of ovarian cancer are undefined, but studies suggest that a number of factors contribute to increased or decreased risk for pathogenesis. Anatomically, the ovarian surface is surrounded by a squamous/cuboidal layer of pelvic mesothelium (called the ovarian surface epitheliumOSE) which aids in the import/export of materials in the peritoneal cavity and assists with rupture and repair of the ovary during cycles of ovulation [6]. The promotion of ovulatory repair mechanisms enhances ovarian cell susceptibility to mutations and subsequent malignancies [7, 8]. This hypothesis, known as incessant ovulation [7], has been validated by the relationship of the number of lifetime ovulations to risk of disease [9]. Studies indicate that decreases in factors such as: the number of full-term pregnancies, cycles of lactation, and usage of oral contraceptives are all related to decreases in ovarian cancer [10-12]. Other risk factors in ovarian oncogenesis 
include excessive hormonal secretion ( e.g. gonadotropins [13] and androgens/progestins [14]), inflammation [15], and heredity [9]. Increases in follicle stimulating hormone (FSH) and luteinizing hormone ( $\mathrm{LH})$ concentration during ovulation promotes follicle maturation and ovarian cell division and proliferation, which heightens the chances of mutations and malignant transformation [13]. Additionally, the concentration of androgens increase within the follicle [16] which upregulates ovarian androgen receptors and stimulates OSE proliferation [17]. Conditions displaying increased levels of circulating androgen (e.g. polycystic ovarian syndrome) have been shown to be associated with increased risk of EOC [18], although the evidence linking androgen exposure to malignant transformation is variable. Inflammation has been postulated to augment the risk of ovarian cancer through ovarian tumor cell release of pro-inflammatory cytokines [19], prostaglandins to promote ovarian tumor cell invasiveness [20,21], and OSE disruption resulting in the formation of inclusion cysts which favor differentiation towards a carcinogenic phenotype [22]. Of all the risk factors associated with ovarian carcinogenesis, heredity has the most compelling impact [23]. Women who have had multiple relatives diagnosed with ovarian cancer or who have had a relative diagnosed prior to 50 years of age display the greatest risk [24]. Inherited mutations in the autosomal dominant genes, BRCA1 and BRCA 2, have a strong association to familial breast and ovarian cancer [25]. Studies of high risk families revealed that the ovarian cancer risk for a woman who has both the familial history and the BRCA1 mutation ranges from 32-84\%, with lower probability for BRCA2 [26, 27].

The complexity of ovarian cancer is enhanced by its heterogeneity [28] demonstrated through the presentation of numerous histological subtypes [29] . The most common EOC subtypes are serous, endometrioid, clear cell, and mucinous [30] and are categorized by their primary pattern of differentiation [31]. Further discrimination between the EOC subtypes is established through their correlation with different 
molecular oncogenetic events $[32,33]$ and with the stage of disease in which early stages are predominantly nonserous [34] and advanced stages are commonly serous [35]. There are two staging systems used in classification of ovarian cancer: 1) Tumor/Lymph Node/Metastasis (TNM) method and the 2) International Federation of Gynecology and Obstetrics (FIGO) system [36]. The TNM system describes the extent of the primary tumor $(\mathrm{T})$, the presence or absence of metastasis to nearby lymph nodes $(\mathrm{N})$, and the presence or absence of metastasis to distant organs (M) [37]. TNM staging includes the letters $(T, N$, or $M)$ followed by a number $(0-4)$ which indicates increasing severity or an X which indicates that the information could not be assessed [38]. The FIGO system evaluates the pathological and/or clinical spread of the tumor and classifies the results into 4 stages [39], which are further subdivided $(A, B, C)$ to reflect specific biological, clinical, or pathological prognostic factors within each stage [40]. Both systems are used in classification of ovarian carcinomas and display great similarity, but FIGO does not contain a "0" classification (which indicates borderline or low potential for malignancy) and is most frequently used by gynecologic oncologists [41]. The staging procedure is performed through exploratory laparotomy in which the abdominopelvic organs are examined and the omentum, diaphragm, neighboring lymph nodes, and peritoneal fluid are sampled for evidence of cancer [42]. Stage classifications include: Stage I (tumor confined to ovaries), Stage II (tumor involves 1 or both ovaries with pelvic extension), Stage III (tumor involves 1 or both ovaries with cytologically/histologically confirmed spread to the peritoneum outside the pelvis, and/or metastasis to the retroperitoneal lymph nodes), and Stage IV (distant metastasis, not including metastasis in peritoneum) [43]. The metastatic nature of ovarian cancer can be attributed to the exfoliation of the ovarian surface, which releases tumor cells that can implant on the peritoneal surface [44] and adjacent organs [45], and/or integrate into the peritoneal fluid for transport throughout the peritoneal cavity [45]. Since no anatomical 
barrier exists between the ovary and other abdominopelvic organs [44], the entire peritoneal cavity is susceptible to metastatic lesions, designating the peritoneal cavity as the preferred site of metastasis [45]. Dissemination into the peritoneal cavity is generally followed by formation of ascites [45]. Under normal physiological conditions, capillary dynamics allow for the constant filtration of fluid into the peritoneum (to lubricate the serosal surfaces) and its partial reabsorption through the lymphatic channels of the diaphragm to eventually reunite with the blood circulation [46]. However, when peritoneal dissemination occurs, fluid accumulates (resulting from enhanced vascular permeability and lymphatic obstruction) $[46,47]$ and creates an imbalance in the rate of reabsorption, which leads to ascites formation. The presence of malignant ascites is one of the general symptoms detected upon initial diagnosis [48] and can be presented in early stages (stage IC and IIC), but is most often seen in advanced disease (stage III and IV) [43].

The pathogenesis of ovarian cancer is further complicated by the latent diagnosis [49], the unknown time requirement for the developmental period of invasive disease [50], and the decreased reliability of early detection methods [51]. Unfortunately, EOC is generally diagnosed at latter stages because of the lack of symptoms or presence of symptoms that could be indicative of other conditions (e.g. abdominal, gastrointestinal, urinary, pelvic) [52]. Current approaches for detection include a physical examination to detect the presence of a pelvic mass [53] , and serum screening for cancer antigen 125 (CA-125) in conjunction with transvaginal ultrasonography (TVUS) [50] to detect changes in ovarian size and structure. Although serum levels of CA-125 are found to be elevated in $90 \%$ of advanced epithelial cancer patients [54], $50 \%$ of stage I patients also present elevated levels [55-57]. The nonspecificity of CA-125 [55, 56] and the subsequent variation in interpretation, scoring, and sensitivity of TVUS [58] warrants the discovery of specific biomarkers and /or detection methods with enhanced efficacy. 


\section{The Tumor Microenvironment and Humoral Immune Responses}

The tumor microenvironment consists of the tumor and its surrounding extracellular matrix, extensive vasculature, various proteins, and a variety of cellular components. Because of its dynamic nature, the tumor microenvironment continuously evolves, resulting in alterations in the tissue, alterations in the metabolic capabilities of the tumor, and in the recruitment of cells to the microenvironment [59]. These components interact with surrounding cytokine signals [60] to generate the functional paradox of the tumor microenvironment manifested through the promotion of antitumorigenic vs. protumorigenic responses. This paradox forms the foundation of the cancer immunoediting hypothesis which emphasizes the tumor-destroying and tumorpromoting functions of the immune system [61]. Antitumor responses are important for resistance of tumor growth and the eventual elimination of the tumor. As a key component in cancer immunosurveillance, elimination works in conjunction with the tumor suppressor mechanisms that are intrinsic to the cell [62]. Utilizing both innate and adaptive responses, the mechanism of elimination collectively recognizes and presents tumor antigen, recruits innate immune cells into the tumor [63,64], and generates tumor antigen-specific T cells [65] which home to the tumor and contributes to tumor destruction [66]. In consideration of the adaptive immune responses, elimination of the tumor primarily occurs through cell-mediated immunity [67]. However, humoral antitumor responses have been documented to occur. In the humoral antitumor response, specific antibodies are produced against tumor antigen [68], and may kill the tumor by complement-dependent cytotoxicity (CDC; complement protein C1q binds Fc portion of antibody bound to antigen to trigger complement cascade) or antibody-dependent cellular cytotoxicity (ADCC; immune effector cells bind Fc portion of antibody bound to antigen via Fc receptors and mediate cytotoxicity) [69]. Immunogenic tumor antigen may be tumor-specific (unique to cancer cells) or tumor-associated (differential 
expression between cancer cells and normal cells) [70] and its expression may be initiated by increases in the immunogenicity of self antigen [71] resulting from DNA mutation (causing subsequent mutation in protein), protein overexpression, and/or protein post-translational modification [72]. Humoral immune responses against a variety of extracellular and cellular proteins have been documented in multiple cancers [73]. Free and immune-complexed natural antibodies to human MUC1 (a primary mucin in the ductal cell surface of normal glandular cells) have been identified in the circulation of breast cancer patients [74]. Autoantibodies against p53 have been documented in increased levels in gastric [75] and ovarian cancers [76]. In these aforementioned cases, the enhancement of antibodies correlated with a positive prognosis. However, other humoral response studies to tumor antigen such as: NY-ESO-1 (in prostate cancer [77]), p53 (in breast [78], colorectal [79, 80], vulvar [81] and ovarian [82, 83] cancers), and MUC5AC (in colorectal cancer [84]), indicated associations with poor prognoses. The variation in prognoses and recognition of tumor antigen contributes to the complexity in understanding the role of autoantibodies in the humoral antitumor response.

Those tumor cells that are not eradicated by the antitumor response may enter into equilibrium, the second phase of cancer immunoediting which involves the immunologic control of cellular outgrowth [61] and the "sculpting" of cells to produce new tumor variants [85] to result in dormancy of the tumor [61]. In the event that these tumor variants successfully evade innate and adaptive immunological defenses [85], they may transition into the escape phase (the third phase of immunoediting [86]), as a consequence of tolerance induction [87], host immune modifications in editing the tumor, or enhanced immunosuppression in the tumor microenvironment [61]. Modifications in the edited tumor target may range from decreased antigen recognition (e.g. loss of major histocompatibility complex (MHC I), loss of antigen processing) [61] to promotion of anti- apoptotic mechanisms (e.g. constitutive activation of STAT3 to 
promote high levels of Bcl-xL [88]), which collectively promote survival of the tumor variants. Generation of an immunosuppressive tumor microenvironment can be facilitated through tumor cell-immunosuppressive cytokine release (e.g. vascular endothelial growth factor (VEGF) [87], tumor growth factor- beta (TGF- $\beta$ ) [89], indoleamine 2,3-dioxygenase (IDO) [90]) to inhibit dendritic and T cell effector function, recruitment of suppressive cellular populations (regulatory T cell (Treg) and myeloidderived suppressor cell (MDSC)) [91] to inhibit host antitumor responses, and chronic inflammation (resulting in continuous generation of pro-inflammatory factors) $[92,93]$ to disrupt host immune cell responses and signal transduction pathways [94]. The heterogeneity of the tumor microenvironment provides a complex, yet ideal setting for intercommunication between the cellular, stromal, and environmental components of the host in order to regulate and promote tumor progression. Continuous intercommunication is necessary in order to ensure productive growth and dissemination of the tumor [95]. Emerging evidence suggests that tumor-derived exosomes (TDE) are key contributors to intercommunication and are involved in both evasion of antitumor responses and promotion of protumor responses.

\section{Tumor-Derived Exosomes and their Role in Modulation of the Tumor Microenvironment}

Exosomes are endosome-derived nanovesicles secreted from a number of different cell types including immune cells (mast cells, [96, 97], dendritic cells [98], macrophages [99], T cells [100, 101], B cells [98, 102]), epithelial [103] and neural [104]cells, and tumor cells. The release of exosomes is acknowledged to be important in intercellular communication [105], and TDE have been shown to interact with their targets through a number of mechanisms ranging from direct stimulation of the target

through exosome expression of surface ligands to acceptance of surface receptors from the tumor cell [106]. In addition to surface interactions with their target, TDE have also 
been documented to transfer genetic information resulting in genetic transformation in their target [107]. The efficacy of exosomes as vehicles of intercellular communication is related to the three-dimensional structure of their proteins which enhances the stability of the exosome and protects the biological activity of the exosome protein [108]. The protein composition of exosomes is correlated (but not identical) to the cell from which the exosome is derived. Therefore, TDE express tumor-related antigens, but are not molecular duplicates of the plasma membrane of their parental tumor cells. Instead, they represent a 'micromap' that displays increased expression of antigens associated with the tumor $[109,110]$. TDE are abundantly found in plasma and malignant effusions derived from cancer patients [111-113], and their accumulation in malignant fluids appears to be instrumental in the transformation process [114]. Studies indicate that increased release of exosomes facilitates communication between the tumor microenvironment and the tumor cell $[115,116]$, and has been documented to contribute to the anti- and protumorigenic effects on the tumor. TDE have been shown to induce specific antitumor responses after being exposed to stress which induced expression of molecules on (MHC, CD80, CD86) [117] or in (HSP70) [118] the exosome. Utilizing their expression of tumor antigen, TDE have been used to pulse dendritic cells which resulted in cross-presentation of tumor antigen to induce $\mathrm{CD} 8^{+} \mathrm{T}$ responses against the tumor [113]. From the humoral immune perspective, the antitumor response is demonstrated through the production of specific antibodies against tumor antigen [68], which is often correlated with poor survival [119].These antibodies may be deposited as IgG autoantibodies in the neoplastic parenchyma [120] or released into the circulation as free entities and/or associated with microvesicles/exosomes [112, 121]. Despite the presence of tumor-reactive $\lg G$ in the circulation of patients with various cancers including head and neck [122], melanoma [123], breast [124, 125], and ovarian [121, 126, 127], an effective humoral antitumor response fails to be mounted. Protumorigenic 
effects mediated by TDE range from regulation of tumor growth to invasion, angiogenesis, and metastasis [128-130] through expression of molecules such as matrix metalloproteinases (MMP-2, MMP-9)[131, 132] and horizontal transfer of growth factor receptors (EGFRvIII)[107]. Additionally, TDE have been shown to directly and indirectly modulate evasion of anti-tumor responses provided by effector T cells to assist in progression. Melanoma-derived exosomes have been shown to promote monocyte production of myeloid-derived suppressor cells [129] which can act to suppress T-cell responses [133, 134]. Ovarian TDE demonstrate induced apoptosis of T cells by enhanced expression of FasL on the exosomes and CD3-zeta suppression on the T cell [135], while nasopharyngeal TDE have been shown to express increased galectin- 9 to induce T cell apoptosis via Tim-3 [136].

\section{Hypothesis and Goals}

Since the interaction of TDE with other immune cells is pleiotropic, it stands to reason that the TDE may also exert effects on B cells that could manipulate both antiand protumorigenic constituents of the tumor microenvironment. Although it has previously been shown that B cells can produce exosomes that can activate T cells [102] and these exosomes have a number of targets including B cells [137], follicular dendritic cells [138], allergen-specific T cells [139], therapeutic CD20 antibodies [140], and cytokine-activated fibroblasts [141], little is known about the effects of TDE on B cells. A study conducted by Yang et al., 2012 revealed that mycoplasma-infected TDE preferentially activated B cells and induced robust pro- and anti-inflammatory cytokine production in splenic B cells [142]. However, that study focused more on the mycoplasma-inducing effects of the exosomes on immunomodulation. This study has primary interests in reasons behind the apparent, yet inefficient humoral response to ovarian cancer, and is proposing that TDE are exerting effects on B cells to mediate not only the humoral antitumor response, but also immunomodulation to support progression 
of the tumor. Using human ovarian cancer as a model system, the hypothesis is that ovarian TDE compromise the functional ability of $B$ cells to generate an adequate humoral antitumor response and exploit the B cell to modify the tumor microenvironment to support the tumor. The main goals of this study are to investigate the role of the TDE in the efficacy of the humoral antitumor response and explore their impact on humoral modulation through 1) Characterization of the immunoreactivity of ovarian cancer patient-derived free antibodies and utilizing that reactivity to define ovarian tumorassociated antigens; 2) Isolation and classification of ovarian cancer patient-derived exosome-associated antibodies; and 3) Analysis of the effects of ovarian cancer patientderived exosomes on $B$ cells. 


\section{CHAPTER 2}

\section{IDENTIFICATION OF IMMUNOREACTIVE TUMOR ANTIGEN USING CIRCULATING FREE HUMORAL RESPONSES}

\section{Introduction}

In the cancer microenvironment, antigens are functionally and/or structurally altered by overexpression, mutation, aberrant degradation, or post-translational modification that makes them immunogenic [143]. In an effective immune response, these immunogenic proteins are detected and an antitumor response is promoted to eliminate the transformed precursors before they establish malignancy. Effective elimination is characterized by the simultaneous collaboration of innate and adaptive cell-mediated and humoral responses [144]. In the adaptive antitumor response, T cells (with cognate TCR) recognize tumor-associated antigen processed/presented on the MHC of antigen-presenting cells (APC)[145], along with subsequent costimulation [146] and cytokine expression for facilitation and maintenance of the response [147]. Elimination of the tumor is accomplished through the activation of cytotoxic $T$ (CTL) cells to induce tumor cell apoptosis [148], activation of CD4 ${ }^{+} \mathrm{T}$ cells to promote cellular responses through stimulation of APC presentation of antigen [149], and promotion of humoral responses through activation of $\mathrm{B}$ cells to produce antigen-specific antibodies that enhance tumor cell uptake by APCs [150]. The primary antitumor response is facilitated by the cellular arm of the adaptive immune system [151], however, humoral responses to tumor antigen are clearly demonstrated through the production of antitumor antibodies [152-154]. This production of antibodies is presented as elevated IgG in the 
blood and sera [155-157]. As the most abundant plasma immunoglobulin [157], IgG is expressed through subclasses $\lg$ G1-IgG4, can exist in the circulation prior to detection of circulating antigen $[143,152,158]$ and is long-lived, which allows for efficient opsonization of the target and complement activation against the target [157]. In ovarian cancer sera, levels of tumor-reactive IgG are elevated [159], suggesting intact humoral immunity in ovarian cancer patients and an effective humoral antitumor response. However, in the midst of this IgG-laden environment, ovarian tumors continue to thrive. A key factor in the progression of transformed cells to malignancy is the tumor microenvironment [160]. The tumor microenvironment consists of a number of cellular participants including immune cells which are critical for suppression of tumor growth [160]. However, the functional activities of these immune cells are often counterregulated by tumor cell expression and release of a number of biologic components [128] which act to promote the growth and metastatic progression of the tumor [161]. One essential biologic component in growth and progression is the tumorderived exosome (TDE). Although the release of exosomes occurs in non-neoplastic cells, their accumulation in normal biological fluids is rare [162]. In contrast, TDE are abundant in malignant and pleural effusions [129, 163], but the effects of their presence on the survival of the tumor cell is somewhat ambiguous [164]. The majority of the available evidence suggests that TDE play a more active role in promoting progression of the tumor [164]. TDE have been documented to transfer and/or shed molecules in order to promote progression. TDE from mesothelioma and prostate cancer cell lines were found to transfer TGF $\beta-1$ to fibroblasts and trigger their differentiation into myofibroblasts [165], which generate chemical and mechanical conditions to encourage tumor progression [166]. Melanoma and liver carcinoma cells were found to release TDE that contain major histocompatibility chain (MHC-I) related chain ligands (MIC- A, MIC-B) as a means to subvert recognition by its receptor, natural killer group 2 member 
D ( NKG2D), on natural killer (NK) and cytotoxic T (CD8 $\left.{ }^{+} \mathrm{T}\right)$ cells [167], thereby subverting cytolysis. Another mechanism used by exosomes in tumor progression involves dampening the immune response against tumors. Melanoma exosomes in the blood promoted the conversion of peripheral blood monocytes to myeloid-derived suppressor cells (MDSC) [133]. As a different means of dampening the immune response, ovarian cancer exosomes were shown to enhance FasL expression on their surface and suppress CD3-zeta to stimulate tumor-reactive T cell apoptosis [135]. In addition, studies with melanoma TDE have demonstrated capabilities in programming the pre-metastatic niche and bone marrow progenitors toward a pro-metastatic, provasculogenic phenotype to support tumor growth and metastasis [168].

Since TDE can mediate the progression of the tumor and its evasion of cellular antitumor responses, perhaps they may also intervene in the humoral antitumor response, thereby permitting further development of the tumor. Utilizing these circulating antitumor antibodies to identify immunoreactive antigens may divulge proteins that are essential to carcinogenesis [51]. Likewise, analysis of antigens associated with TDE may unlock the mysteries of the existent, yet inadequate humoral response needed for efficient eradication of the tumor and the role of the TDE in tumor progression and the humoral response. We suggest that the circulating free and TDE-associated humoral immune response can be used to identify specific tumor-associated antigen, which in the context of TDE may be a mechanism for diverting the immune response from the tumor. Using human ovarian cancer as our model system, we investigate immunoreactivity of tumor-associated antigen of ovarian patient cancer cells, patient in vivo and in vitro-TDE antigen and patient-derived free antibodies. We establish that ovarian tumor-derived exosomes express tumor-associated antigen which is recognized by tumor-reactive antibodies, thereby indicating a role for TDE in the ovarian antitumor humoral response. 


\section{Materials and Methods}

\section{Patient sera, Ascites, and Cell Lines}

Biofluids (sera or ascites) used in this study were derived from patients diagnosed with Stage III (T3c) serous carcinoma (designated UL-124,-167,-190,-207,351,-398), mucinous adenocarcinoma (UL-324), carcinosarcoma (designated UL-224), teratoma (designated UL-184), and serous/endometrioid mixed carcinoma (designated UL-472). Samples were obtained from the Gynecologic Oncology Repository at the University of Louisville, under an approved IRB protocol. Additional information about ascites sample UL-309 was unavailable. Control sera were derived from age-matched women with no evidence of ovarian disease. Primary ovarian tumor cell cultures were established from UL-124 ascites. Primary cultures were grown in $75 \mathrm{~cm}^{2}$ tissue culture flasks initially in Hyclone RPMI 1640 medium (ThermoScientific) supplemented with 2mM L-glutamine, $10 \%$ fetal bovine serum (FBS, Biowest), $1 \mathrm{mM}$ sodium pyruvate (CellGro, Mediatech), $0.1 \mathrm{mM}$ nonessential amino acids (CellGro, Mediatech), and 100

units $/ \mathrm{mL}$ penicillin-streptomycin (Gibco, Invitrogen) in a humidified incubator at $37^{\circ} \mathrm{C}$ with $5 \% \mathrm{CO}_{2}$. After assurance of confluence, cells were transferred into Ultraculture General Purpose Serum-Free Media without L-glutamine, but supplemented with the same amount of sodium pyruvate, non-essential amino acids, and penicillin-streptomycin. Cell viability was evaluated by trypan blue exclusion and all cultures utilized were $>95 \%$ viable.

\section{Preparation of Tumor Cell Lysates}

Prior to harvesting of cells, culture supernatant was removed and saved for subsequent culture exosome isolation. Cells were rinsed twice with cold Hyclone DPBS/Modified (ThermoScientific) and were solubilized with RIPA Buffer (1X, Pierce) supplemented with protease inhibitor cocktail III (100X, RPI) and phosphatase inhibitor II 
(100X, Sigma). RIPA-solubilized cells were kept on ice for 5-10 minutes and then cells were collected using a cell scraper. Solubilized cell lysate was collected into $1.5 \mathrm{~mL}$ microcentrifuge tubes (Eppendorf) and centrifuged at $14,000 \times \mathrm{g}$ for 15 minutes at $4^{\circ} \mathrm{C}$ to pellet the cell debris. Resulting supernatant was collected and assayed for total protein by the Bradford assay (Bio-Rad) using bovine serum albumin (BSA) as a standard.

\section{Preparation of Tumor Cell Lysate for $1^{\text {st }}$ Dimension Focusing}

To ensure low conductivity and reduced charged agent presence in the UL-124 lysate, multiple samples of $100 \mu \mathrm{g}$ lysate were "cleaned up" using the Perfect-FOCUS kit (G-Biosciences) according to manufacturer's instructions in preparation for isoelectric focusing and 2DE. Post clean-up, the protein pellets were rehydrated (according to manufacturer's instructions) in 2D-Xtract Chaotropic Extraction Buffer (G-Biosciences) with the addition of $50 \mathrm{mM}$ dithiothreitol (DTT), and 0.2\% Bio-Lyte 3/10 Ampholyte (BioRad). Rehydrated protein was added to ReadyStrip Immobilized pH Gradient (IPG) Strips (11 cm, pH 3-10 NL, BioRad) placed into the Immobiline DryStrip Reswelling Tray (Pharmacia Biotech). Tray was sealed and strips were allowed to rehydrate overnight at room temperature. To facilitate the $1^{\text {st }}$ dimension run, the Multiphor II Electrophoresis Unit (Pharmacia Biotech) attached to an Isotemp 1016S Refrigerated Heated Recirculating Waterbath was set to $20^{\circ} \mathrm{C}$ and the protocol for $1^{\text {st }}$ dimension focusing was followed. In short, PlusOne DryStrip Cover Fluid (Pharmacia Biotech) was added to the surfaces of the Multiphor II and Immobiline Strip Tray (Pharmacia Biotech). A drystrip aligner (GE Healthcare) was placed into the strip tray and the rehydrated IPG strips were placed into the aligner with the acidic end properly aligned. Two $11 \mathrm{~cm}$ IEF electrode strips (Pharmacia Biotech) were moistened with $\mathrm{ddH}_{2} \mathrm{O}$ and placed on top of the strips at the cathode and anode ends and covered by the electrodes. Strips were focused $16 \mathrm{~h}$ 
(300 V, 1h; 1400 V, 15h) using an EPS 3501XL Electrophoresis Power Supply

(Pharmacia Biotech).

\section{IPG SDS-PAGE and Analysis of Immunoreactivity}

In preparation for $2^{\text {nd }}$ dimension SDS-PAGE, IPG strips were equilibrated in $2 \mathrm{~mL}$ of IPG-Strip Equilibration Buffer (G-Biosciences) with 2\% DTT (Research Products International, RPI) and incubated for 15 minutes at room temperature on a Mistral MultiMixer (LabLine), low setting. Incubation was repeated with IPG-Strip Equilibration Buffer with $2.5 \%$ iodoacetamide (Sigma). Criterion Tris-HCI IPG +1 well gradient $(8-16 \%)$ polyacrylamide gels (BioRad) were equilibrated for 10 minutes using $1 \mathrm{X}$

Tris/Glycine/SDS (TGS) buffer (10X, BioRad) on a Criterion Cell electrophoresis cell (Bio Rad). Post equilibration, strips were rinsed in 1X TGS buffer. An agarose sealing solution (G-Biosciences) was placed into the IPG well on the aforementioned Criterion Tris- $\mathrm{HCl}$ gel and the IPG strip placed into the well. Once the agarose had solidified, the single well was loaded with Precision Plus Protein Dual Color Standard (BioRad) and SDS-PAGE was carried out using the Criterion Cell and Power Pac 300 (BioRad). Gels were silver stained (BioRad) or subjected to Western blotting. Western blotting was performed using the Criterion Blotter (BioRad) and immunoreactivity patterns defined by probing membranes overnight at $4^{\circ} \mathrm{C}$ with patient sera, diluted $1: 250$, followed by peroxidase-conjugated anti-human IgGAM (1:4000, Sigma). Dilution of sera was determined by serial dilution to identify the optimal dilution to distinguish seropositive patients and seronegative controls. Bound immune complexes were visualized by Immune Star HRP chemiluminescence (BioRad) and the resulting film was analyzed for similarity in reactivity between different sera. Bands/spots corresponding to similar reactivity were cut out of the silver stained gel and analyzed by mass spectrometry (Vanderbilt University, Nashville, TN). 


\section{Isolation of Tumor Cell Protein by Rotofor Fractionation}

Tumor cell lysate was desalted by column chromatography using P6 Desalting Gel (BioRad) and resulting protein was assayed by the Bradford method. Desalted protein concentration was used to determine amount of ampholyte to combine with the protein sample. Desalted protein was combined with 0.5\% Bio-Lyte 3/10 Ampholyte (BioRad) and $\mathrm{ddH}_{2} \mathrm{O}$ and loaded onto the Rotofor Cell (BioRad). Protein was focused for $4 \mathrm{~h}$ using the PowerPacHV (BioRad) under recirculated refrigeration. Focused proteins were collected into 20 fractions and the $\mathrm{pH}$ and protein concentration acquired for each. 50 $\mu \mathrm{g}$ protein of each fraction were loaded onto a Criterion Tris HCl 4-15\% (BioRad) gel, electrophoretically separated, and silver stained or analyzed by Western blotting. Membranes were probed at $4^{\circ} \mathrm{C}$ overnight with patient sera $(1: 250)$ followed by peroxidase-conjugated anti-human IgGAM (1:4000, Sigma). Bound immune complexes were visualized by Immune Star HRP chemiluminescence (BioRad) and the resulting film was analyzed for similarity in reactivity between different sera. Thirteen bands corresponding to shared immunoreactivity were cut out of the rotofor fractionated-silver stained gel and analyzed by mass spectrometry (Vanderbilt University, Nashville, TN).

\section{Mass Spectrometry (MS) Sample Preparation: In-Gel Digestion Procedure}

Silver-stained protein gel bands were rinsed with water thoroughly to remove residual acetic acid. Fresh reducing reagents (30 mM of potassium ferricyanide, $100 \mathrm{mM}$ of sodium thiosulfate) in a 1:1 ratio were mixed and immediately added in sufficient volume to cover the gel piece. Once the silver-brown color in each gel piece disappeared, the reducers were removed. The gel slice was washed with $\mathrm{HPLC} \mathrm{H}_{2} \mathrm{O}$ and $100 \mathrm{mM}$ of $\mathrm{NH}_{4} \mathrm{HCO}_{3}$, alternatively, until the gel piece was clear. Each gel slice was diced into small pieces $\left(1 \mathrm{~mm}^{2}\right)$ and placed into a clean tube, then washed twice with $100 \mu \mathrm{L}$ (or enough to cover the gel pieces) of $25 \mathrm{mM} \mathrm{NH}_{4} \mathrm{HCO}_{3} / 50 \% \mathrm{ACN}$ with vortexing 
for 10 minutes. The gel pieces were completely dried by Speedvac. Dried gel pieces were partially rehydrated with $5 \mu \mathrm{L}$ of $100 \mathrm{mM} \mathrm{NH}_{4} \mathrm{HCO}_{3}$ and the proteins reduced in 25 $\mu \mathrm{L}$ of $10 \mathrm{mM}$ DTT in $25 \mathrm{mM} \mathrm{NH}_{4} \mathrm{HCO}_{3}$ for $1 \mathrm{hr}$ at $56^{\circ} \mathrm{C}$. Supernatant was removed and discarded and proteins were alkylated with $25 \mu \mathrm{L}$ of $55 \mathrm{mM}$ iodoacetamide in $25 \mathrm{mM}$ $\mathrm{NH}_{4} \mathrm{HCO}_{3}$ in the dark for 45 minutes at room temperature. Gel pieces were washed twice in $100 \mu \mathrm{L}$ of $100 \mathrm{mM} \mathrm{NH}_{4} \mathrm{HCO}_{3}$ (with vortexing for 10 minutes), dehydrated with $100 \mu \mathrm{L}$ of $25 \mathrm{mM} \mathrm{NH}_{4} \mathrm{HCO}_{3}$ in $50 \% \mathrm{ACN}$ (with vortexing for 5 minutes, repeated once), and were completely dried by Speedvac for 20 minutes. Dried gel pieces were rehydrated with $5 \mu \mathrm{L}$ of trypsin solution $\left(0.1 \mu \mathrm{g} / \mathrm{mL}\right.$ trypsin in $\left.100 \mathrm{mM} \mathrm{NH}_{4} \mathrm{HCO}_{3}\right)$, and 50-70 $\mu \mathrm{L}$ of $100 \mathrm{mM} \mathrm{NH}_{4} \mathrm{HCO}_{3}$ was added until the gel pieces returned to their original size. Digestion was carried out overnight at $37^{\circ} \mathrm{C}$ and then stopped by the addition of 1.5 $\mu \mathrm{L}$ of trifluoroacetic acid. The resulting peptides were recovered by two- 25 minute extractions using $30 \mu \mathrm{L}$ of $50 \% \mathrm{ACN} / 5 \%$ formic acid at room temperature with 20 minute vortex/5 minute sonication cycles. The extracts were combined and dried in a Speedvac. The tryptic peptides were reconstituted in $25 \mu \mathrm{L}$ of HPLC water with $0.1 \%$ formic acid.

\section{Peptide separation and MS/MS analysis}

Digested peptides were separated and mass analyzed using an Eksigent NanoLC system connected to a LTQ Velos (Thermo Fisher Scientific) ion trap mass spectrometer. Briefly, tryptic peptides were loaded onto a $150 \mu \mathrm{m}$ ID microcapillary fused silica pre-column, which was in-house packed with $4 \mathrm{~cm} \times 5 \mu \mathrm{m} \mathrm{C18} \mathrm{resin} \mathrm{(Jupiter}$ C18, $5 \mu \mathrm{m}$ particle size, $300 \AA$ pore size). The C18 trap column was coupled to a nanoflow analytical column packed with $10 \mathrm{~cm}$ of $3 \mu \mathrm{m}$ C18 reverse-phase resin (Jupiter C18, $3 \mu \mathrm{m}$ particle size, $300 \AA$ pore size) constructed with an integrated electrospray emitter tip. Peptides were eluted with a 90 minute gradient (from $2 \%$ ACN with $0.1 \%$ FA 
to $35 \% \mathrm{ACN}$ with $0.1 \% \mathrm{FA}$ ) over 35 minutes, followed by $35 \% \mathrm{ACN}$ to $90 \% \mathrm{ACN}$ over 15 minutes at a flow rate of $0.5 \mu \mathrm{L}$ per minute. The $\mathrm{LTQ}$ Velos mass spectrometer was operated in data-dependent mode in which an initial MS scan was recorded, the massto-charge range $300-2000 u$, and the 5 most abundant ions were selected for subsequent collision-induced dissociation. Dynamic exclusion (repeat count 1, exclusion list size 150 , and exclusion duration 60s) was enabled to allow detection of less abundant ions.

\section{MS Data Analysis}

LC-MS/MS raw files were converted into .dta files by a custom ScanSifter algorithm. Spectra that contained fewer than 25 peaks or that had less than $2 \mathrm{e} 1$ measured total ion current were removed. DTA files for singly charged precursor ions were created if $90 \%$ of the total ion current occurred below the precursor ion $\mathrm{m} / \mathrm{z}$ ratio and all other spectra were processed for doubly and triply charged ions. DTA files were searched against the human protein database Uniprot-human 155_200907_rev with 20,914 total protein entries using the SEQUEST algorithm. The search parameters used allowed for the following differential modifications: +57 on cysteine and +16 on methionine. SEQUEST-searched files (pepXML) were imported into ID Picker software for protein assembly. Results were filtered using the following criteria: a minimum peptide length of five amino acids, a minimum of one unique peptide per protein (modifications to cysteines or methionines were not considered distinct from the unmodified peptides), overall maximum false positive rate (FDR) of $5 \%$, a minimum of two additional peptides to establish a unique protein group, one protein reported per protein group, and single protein groups indicated by proteins that share the same set of peptides (indiscernible from each other based on available data).

\section{Verification of Mass Spectrometry-Identified Ovarian Cancer Antigen}

To verify the presence of the ovarian cancer antigen identified by mass spectrometry, immunoprecipitation of immune complexes was performed using Protein 
G HP SpinTrap columns (GE Healthcare) and True Blot anti-rabbit or anti-mouse Ig IP Beads (eBioscience). In short, UL-124 serum-containing and serum-free lysate was precleared by combining $520 \mu \mathrm{g}$ lysate protein to a SpinTrap column or to $50 \mu \mathrm{L}$ of the anti-rabbit /anti-mouse Ig IP beads. Lysate and beads were incubated at $4^{\circ} \mathrm{C}$ on a Labquake rotisserie shaker (Barnstead Thermolyne) for 1 hour, centrifuged to acquire the precleared lysate, and protein concentration of precleared lysate obtained by the Bradford method. For SpinTrap IP: Commercial antibodies corresponding to the mass spec-identified antigens were conjugated to the Protein G SpinTrap matrix (20 $\mu \mathrm{g}$ protein/column) for 3-4 hours at room temperature (with rotisserie rocking) and the Protein G SpinTrap cross-link protocol was followed. Antibodies used include: GRP-78 [rabbit polyclonal, Santa Cruz Biotechnology [SCBT], annexin 2, cathepsin D, alphaenolase, HSC 70, and PDI--all mouse monoclonal (SCBT). Tris-buffered saline (TBS) was used as an IP control. Unconjugated antibody was removed and precleared lysate mixed with TBS was added to the conjugated Protein G SpinTrap beads for incubation overnight at $4^{\circ} \mathrm{C}$. Supernatant was collected by centrifugation and the cross-link protocol was continued. Bound antigen was eluted using $0.1 \mathrm{M}$ glycine/urea as an elution buffer and Bradford protein assay performed. For dot blot analysis, $5 \mu \mathrm{L}(0.5 \mu \mathrm{g})$ of each antigen sample (in duplicate) were spotted onto individual nitrocellulose membranes (BioRad) and allowed to air dry. BSA (1 mg/mL) and HeLa or A431 (epidermoid carcinoma cell line) lysate were used as negative and positive controls respectively. Membranes were blocked in 5\% nonfat milk/TBST, washed with 1X TBST (TBS $+0.1 \%$ Tween-20) and incubated at $4^{\circ} \mathrm{C}$ overnight with corresponding commercial antibodies (diluted 1:1000) and control or ovarian patient sera (diluted 1:250). Secondary HRP goat anti-mouse/anti-rabbit (1:5000, BioRad) or peroxidase-conjugated anti-human IgGAM (1:4000, Sigma) was added and immunoreactivity analyzed by Immune Star HRP 
chemiluminescence (BioRad). For TrueBlot IP: $5 \mu \mathrm{g}$ of the aforementioned antibodies were added to the precleared lysate, incubated with rotisserie mixing for $3 \mathrm{~h}$ at $4^{\circ} \mathrm{C}$, and the incubated GRP-78/lysate sample added to the True Blot anti-rabbit beads with the remaining Ab/lysate samples added to the anti-mouse beads for an overnight incubation at $4^{\circ} \mathrm{C}$. Post incubation, supernatant was collected by centrifugation at $10,000 \times \mathrm{g}$, beads were washed $3 x$ in cold NP-40 Lysis Buffer $(50 \mathrm{mM}$ Tris HCl, pH 8, $150 \mathrm{mM} \mathrm{NaCl}$, $1 \% \mathrm{NP}-40$ ), supernatant aspirated, and beads combined with $50 \mu \mathrm{L}$ of $1 \mathrm{X}$ Laemmli. Beads were boiled and centrifuged to collect supernatant containing the immunoprecipitated antigen. Immunoprecipitated antigen samples were loaded onto Mini-Protean TGX Precast Gels (4-15\%, BioRad), electrophoretically separated, and analyzed by Western blotting. Membranes were blocked and probed overnight at $4^{\circ} \mathrm{C}$ with corresponding commercial antibodies as previously mentioned. Secondary rabbit and mouse TrueBlot anti-rabbit/anti-mouse lgG HRP (eBioscience) was added followed by analysis of immunoreactivity using Immune Star HRP chemiluminescence (BioRad).

\section{Recognition of Recombinant Proteins by Ovarian Cancer Sera Antibodies}

To verify recognition of the mass spectrometry-identified proteins by ovarian cancer sera, $0.2 \mu \mathrm{g}$ human recombinant protein for GRP-78, Annexin 2, Cathepsin D, PDI (all from ProSpec Bio), Alpha-enolase (American Research Products), and HSC70 (Enzo Life Sciences) were combined with 4X LDS Nonreducing Buffer (ThermoScientific), loaded onto a 10\% SDS-PAGE gel, and analyzed by Western blot using sera from a non-cancer control (Ctrl, 1:250) and ovarian cancer patients [serous carcinoma (sample 167, 351, 398), serous adenocarcinoma (sample 190, 207), and mucinous adenocarcinoma (sample 324)]. All ovarian sera were used at 1:250 with the exception of the mucinous sample (1:100), due to lack of detection at the greater dilution. In addition, the recombinant proteins were probed with a mixture of commercial 
antibodies against the identified proteins (1:1000) to further ensure detection of the recombinant antigen.

\section{Isolation of Ovarian TDE and Analysis of TDE Immunoreactivity}

Exosomes were isolated from ovarian tumor-patient (UL-124) ascites, serumcontaining and serum-free conditioned ovarian tumor culture media, patient ascites (UL472, UL-309, UL-316, UL-224) and a non-cancer serum control (NCC) by a two-step

procedure developed in our laboratory [126]. In short, ascites and media (100 mL) were concentrated by ultrafiltration and applied to a $2 \%$ agarose (ABT) chromatography column $(1.5 \times 20 \mathrm{~cm})$ equilibrated with $\mathrm{dd}_{2} \mathrm{O}$. Fractions $(1 \mathrm{~mL})$ were collected and the absorbance $(280 \mathrm{~nm})$ of the elution was monitored. Fractions containing material greater than 50 million Daltons were obtained and ultrafiltrated, and the quantity of protein was assayed by the Bradford method. $15 \mu \mathrm{g}$ (UL-124 ascites and culture-derived) and/or 10 $\mu \mathrm{g}$ (remaining ascites) of exosome protein was mixed with $1 \mathrm{X}$ Laemmli sample buffer, loaded on a $10 \%$ SDS-PAGE gel, and analyzed by Western blot. Immunoreactivity of tumor-exosome derived protein was assayed by commercial antibodies (Santa Cruz and Cell Signaling Technology) corresponding to mass spectrometry-identified proteins as mentioned previously.

\section{$\underline{\text { Results }}$}

\section{Recognition of Ovarian Tumor Antigens by Patient Sera Antibodies}

In the initial two-dimensional gel electrophoretic (2-DE) analysis, traditional isoelectric focusing of ovarian tumor antigenic protein was evaluated by silver staining of IPG SDS-PAGE gels containing focused protein followed by Western blot with serum antibodies from an ovarian carcinosarcoma patient (UL-224) and an ovarian teratoma patient (UL-184). Bands corresponding to shared recognition between sera were subjected to mass spectrometry. As a comparative focusing tool to traditional IEF, 
rotofor fractionation was used in a separate analysis, although it is typically used as a means of pre-fractionation to reduce complexity of crude protein. Ovarian tumor antigenic protein was rotofor fractionated and the protein content of each fraction evaluated by silver-stain of gradient gels and subsequent Western blot with serum antibodies from patient UL-224 (Fig. 1A) and UL-184 (Fig. 1B). Thirteen bands (as indicated in figure 1) were randomly chosen for mass spectrometry analysis. Similar reactivity between patient-derived antibodies to antigenic protein was noted with some variation in intensity (stronger recognition with UL-224: fraction 12; stronger recognition with UL-184: fraction 9, lower band).

\section{Confirmation of Ovarian Tumor Antigens by Patient Antibodies}

Mass spectrometry analysis identified multiple proteins. From the analysis, six proteins [GRP 78 (glucose-related protein 78), annexin 2, cathepsin D, alpha-enolase, HSC70, and PDI (protein disulfide isomerase)] were selected for focus due to their high or low protein scores, their association with tumor survival, and/or their present status as a potential biomarker. In order to verify the presence of these antigenic proteins in the ovarian cancer lysate sample, True Blot bead and Protein G SpinTrap Column immunoprecipitation was performed by complexing UL-124 serum-containing or serumfree culture lysate with commercial antibodies corresponding to the proteins of interest, subjecting the eluted antigen to Western and dot blot, and probing with the commercial antibodies corresponding to the antigens of interest. For the dot blot assays, captured antigens were applied to the membrane in duplicate. Immunoreactivity of precipitated antigen for all antigens of interest were detected by dot blot (Fig. 2A) and confirmed by Western (Fig. 2B).

\section{Validation of Sera Antibody Detection Using Recombinant Proteins}

Humoral responses in detection of GRP 78, annexin 2, cathepsin D, alphaenolase, HSC70 and PDI were evaluated by Western blot with sera from patients with 
grade 3 serous adenocarcinoma/carcinoma and grade 1 mucinous adenocarcinoma. Using serous adenocarcinoma/carcinoma patient antibodies (Fig. 3A-E), Western blot identified the presence of annexin 2, alpha-enolase, and HSC70 with variations in intensities and isoforms between samples. Preliminary assays for antigen detection by serum revealed minimal detection of cathepsin D by the serous samples tested, with the exception of sample 351. Out of the serous carcinoma samples assayed, sample 351 displayed lone recognition of the intermediate cathepsin $D$ isoform ( 46 kDa).

Additionally, reactivity to isoforms of HSC70 ( 30 kDa) and annexin 2 ( 75-90 kDa) were detected in varying degrees by the serous samples. Mucinous adenocarcinoma patient antibodies (Fig. 3F) detected GRP78 and alpha-enolase, and faintly detected the intermediate form of cathepsin D ( 46 kDa). Additionally, the higher molecular weight isoform was detected with annexin 2 , as seen in some of the serous samples. A mixture of commercial antibodies (Fig. 3G) corresponding to recombinant proteins of interest) was utilized to detect viability of the antibodies and their ability to recognize the antigens at their standard molecular weights. Of the 6 antigens assayed, the commercial antibodies recognized GRP78, annexin 2 (both isoforms), alpha-enolase, and PDI. Identification of recombinant antigens using serum antibodies from normal, non-cancer presenting controls (Fig. $3 \mathrm{H}$ ) similarly recognized alpha-enolase and $\mathrm{HSC} 70$ at its standard molecular weight and the lower molecular weight form.

\section{Analysis of Ovarian Tumor-Reactive Antigens in in vivo and in vitro-derived Ovarian TDE}

To determine whether ovarian tumor-derived exosomes are enriched with the same antigens identified by mass spectrometry of ovarian tumor cells, exosomes from UL-124 ascites or cell culture (with and without serum) were probed with commercial antibodies against the antigens of interest from the mass spectrometry analysis. Western blot analysis of ascites-derived and culture-derived exosomes demonstrated 
the presence of GRP 78, alpha-enolase, PDI, and varying isoforms of cathepsin D (Fig. 4). The presence of the cathepsin D active intermediate enzyme ( $46 \mathrm{kDa})$ was detected in all samples, while the immature proenzyme $(52-60 \mathrm{kDa})$ was detected in ascites and the serum-containing culture. The active mature form ( $33 \mathrm{kDa})$ was detected in ascites only. Variation in recognition was seen between the culture-derived samples, particularly in the serum-containing identification of annexin 2 and HSC70, whose expression was shared in the ascites sample (Fig. 4). It is known that cells grown in serum-free media are more sensitive to factors such as $\mathrm{pH}$, temperature, mechanical stresses etc., which can affect growth and may alter molecular expression.

Concern was raised over the multiplicity of bands detected in the in vivo-derived tumor exosomes from patient UL-124, which could suggest lack of specificity of the commercial antibodies used. In order to clarify presence of the tumor-reactive antigens in in vivo-derived exosomes, several patient-exosome samples were used and were probed with a different set of commercial antibodies. Western blot analyses revealed the presence of annexin 2 (A2) as double bands $\sim 38 \mathrm{kDa}$ in patient samples UL-472, $309,-124,-316$ with faint recognition in patient sample UL-224 and no recognition in the corresponding non-cancer control (Fig. 5A). Utilizing the new anti-Enolase-1 (alphaenolase) antibody, however, presented an interesting result. While the positive cellular control exhibited recognition at $\sim 47 \mathrm{kDa}$ (corresponding to Enolase-1), three of the exosome samples recognized bands at a lower molecular weight, around $30 \mathrm{kDa}$. We surmise that this lower molecular weight band is the isoform of enolase-1, c-myc binding protein-1 (MBP-1, $37 \mathrm{kDa}$ ) (Fig. 5B) or potentially an alternative splice variant of enolase-1.

\section{Discussion}

Cellular proteins present in the tumor microenvironment can be functionally and/or structurally altered, resulting in their ability to become immunogenic and provoke 
an autoantibody response. These autoantibodies reflect responses to tumor-associated (differentially expressed on normal and cancer cells) [70] antigens and can be detected in the circulation regardless of the magnitude of tumor associated-antigen expression or tumor size [169]. As a result of the long-lived humoral response, the antigen presence is "amplified," which facilitates ease in detection [170]. Since autoantibodies act as sentinels of aberrant cellular activity [171] and their presence reflects the execution of a humoral immune response to the tumor, detailed analysis of their immunoreactivity can provide a clearer understanding of the tumor associated-antigens that they recognize and their role in tumorigenesis.

Progress in the characterization of human cancers has been attained through proteomic analyses of cancer-associated serum proteins [172]. Proteomic analysis involves extensive characterization of proteins, including identification of any modifications and interactions, and structural determination of isoforms and related functional components [173]. Traditional approaches to quantitative analysis of proteomes involve high resolution separation of the proteins (by size and charge) using 2DE accompanied by identification of the resolved proteins using mass spectrometry (MS) $[174,175]$. Protein profiles from such analyses can reveal differential protein expression between samples which may denote key molecules that are critical to protein function.

In the investigation of the ovarian cancer patient humoral antitumor response, this study approaches the use of patient serum autoantibodies in the detection of ovarian cancer specific-antigenic protein. Proteomic analysis allowed for the identification of numerous proteins with six of particular interest (GRP78, annexin 2, cathepsin D, alphaenolase, HSC70, and PDI) due to their roles in tumor survival and present status as potential biomarkers in different cancers. Here, the identities of these antigenic proteins were confirmed by Western and dot blot analyses. One concern in this study was the 
effects of denaturation on the ability of the antigenic protein to be recognized by our commercial antibodies. Hence, we utilized both Western and dot blot analysis to reduce the likelihood of "overlooking" the detection of the antigens. As expected, there was variability in detection between Western and dot blot analysis of some of the antigenic proteins, namely annexin 2, HSC70, and PDI. Dot blot analysis revealed detection of all antigens, while Western blot resulted in definitive detection of GRP 78, cathepsin D, and alpha-enolase.

GRP78 (also known as BiP--binding immunoglobulin protein), a member of the heat shock protein 70 family, is a molecular chaperone commonly housed in the lumen of the endoplasmic reticulum (ER), and its increased expression in the ER is instrumental in allowing neoplastic cells to endure the tumor microenvironment [176]. It is also expressed on the cell surface in various cancers [177], and its location on the surface has been documented to form complexes with ligands important in signal transduction [178, 179]. Cell-surface expression of GRP78 in cancer cells has been shown to activate pathways that induce cellular survival and proliferation [180,181], and to correlate with the expression of circulating autoantibodies in prostate [182] and ovarian [183-185] cancers. Previous studies of circulating ovarian cancer sera autoantibodies by the Taylor lab demonstrated recognition of GRP78 and cathepsin D (immature proenzyme form and mature form) in ovarian cancer patients [183]. In this study, immunoprecipitated antigen probed with commercial antibodies revealed bands $\sim 75 \mathrm{kDa}$ (corresponding to GRP78), $\sim 48 \mathrm{kDa}$ (corresponding to the intermediate form of cathepsin D), and $\sim 47 \mathrm{kDa}$ (corresponding to alpha-enolase). Cathepsin $\mathrm{D}$ is an aspartic lysosomal peptidase with a variety of functions including: degradation of proteins (intracellular [186], cytoskeletal [187],) activation/degradation of growth factors and chemokines [188, 189], and activation of enzymatic precursors [190]. Synthesis of cathepsin D occurs by the rough ER as a "pre-pro" protein which loses its leader 
sequence ("pre" portion) upon entering the ER lumen. Processing of the single polypeptide immature (pro) form $(52 \mathrm{kDa})$ of cathepsin D occurs through the transport of the protein through endosomal compartments and involves removal of the pro-peptide to form the active intermediate isoform $(48 \mathrm{kDa})$. Eventual formation of the doublechained mature isoform (34 kDa heavy chain, $14 \mathrm{kDa}$ light chain) takes place in the lysosome [191]. The proteolytic activity is seen at the level of the endosome and lysosome compartments as a result of the acidic $\mathrm{pH}$ of the compartment environment [192]. Although present in normal cells, its overexpression has been reported in a number of cancers [193]. Functionally, cathepsin D is believed to act on tumor growth and metastasis by assisting with stromal remodeling, and affect angiogenesis of tumors through the stimulation of endothelial and cancer cells [194]. In the induction of apoptosis of human T cells, cathepsin D appears to be the result of translocation from the lysosomes to the cytosol, which triggers Bax (apoptotic-inducing protein) activation to induce expression of apoptosis-inducing factor (AIF) [192]. Alpha-enolase is a glycolytic enzyme important in the catalysis of 2-phospho-D-glycerate (PGA) to phosphoenolpyruvate [195], and is upregulated under stressful conditions, like hypoxia, in order to mediate enhanced anaerobic metabolism [196]. Increased autoantibodies against alpha-enolase have been recorded in some cases of organ-specific autoimmunity [197], and in a number of metastatic cell lines [195]. This study indicates strong recognition of immunoprecipitated ovarian cancer antigen by commercial anticathepsin D and alpha-enolase antibodies. Consistent recognition of human recombinant alpha-enolase was seen by serous adenocarcinoma/carcinoma and mucinous adenocarcinoma serum antibodies with variation in cathepsin D and GRP78 recognition between sera types. Additionally, recombinant alpha-enolase was also recognized by non-cancer controls. GRP78 and alpha-enolase were also detected in all 3 exosome samples, with detection of all 3 isotypes of cathepsin D among the exosome 
samples. Exosome-associated antibodies also recognized alpha-enolase with faint detection of GRP78. Our data suggests that GRP78, cathepsin D, and alpha-enolase are tumor-associated antigens that are transported to the released exosome, and elicit a humoral response, indicated by the presence of antibodies to these molecules.

During cellular quiescent phases, the translation of alpha-enolase is virtually undetectable but is upregulated in cellular growth phases [198, 199]. In the translation process, alpha-enolase can use an alternative start codon which yields the production of a $37 \mathrm{kDa}$ isosform, c-myc promoter binding protein (MBP-1), which binds to c-myc P2 promoter to negatively regulate transcription of c-myc [200], and lacks the enzyme activity of enolase $[200,201]$. c-myc is an oncogene, commonly overexpressed in the majority of human cancers [202], and is responsible for a number of pleiotropic effects at the cellular (increases proliferation, metabolic transformation, metastasis) and molecular (increases glycolysis, protein biosynthesis, mitochondrial function) levels [203]. Exogenous expression of MBP-1 has been shown to arrest growth in chronic myeloid leukemia cells [204], to suppress proliferation in non-small cell lung cancer [205], and to induce death of neuroblastoma cells [206]. The expression of MBP-1 in TDE may play a role in the anti- and protumorigenic functions of the TDE. From the antitumorigenic perspective, the transport of MBP-1 in the TDE may be a mechanism for delivery to other tumor cells in order to induce c-myc suppression, thereby affecting tumorigenesis. In a study conducted by Ghosh et al.(2002), the transduction of MBP-1 in MCF-7 (breast carcinoma) cells acted to induce cytochrome c release from the mitochondria, which subsequently activated procaspases and cleavage of poly ADP-ribose polymerase (PARP) to initiate apoptosis [207]. From the protumorigenic perspective, tumor cells may shed MBP-1 in their exosomes as a mechanism to lose the suppressive constraints on c-myc so that the tumor cell can continue to proliferate. 
Annexins are calcium-binding proteins with functions ranging from trafficking of vesicles, to apoptosis and regulation of cellular growth [208]. Annexin 2 is a key mediator in the plasminogen activator system, in which plasminogen binds to annexin 2 and is converted to plasmin by tissue plasminogen activator (t-PA) and urokinase plasminogen activator (u-PA) to promote production of products important in clot dissolution and wound healing [209]. Located on the surface of endothelial cells and various tumor cells [210, 211], annexin 2 can exist as a monomer ( $36 \mathrm{kDa})$ or a heterotetramer ( 90 kDa) where it complexes with S100A10 (p11), a cell surface receptor that regulates the generation of plasmin. Correspondingly, annexin 2 can bind to other proteins (e.g. tenascin C, procathepsin B) to facilitate proteolysis leading to extracellular matrix degradation instrumental in tumor progression, invasion, and metastasis [211]. Because of its functional importance in fibrin production, dysregulation of annexin 2 compromises fibrinolysis and may interfere with the proteolytic processes needed to ensure tumor dissemination. In disorders characterized by thrombosis (i.e. lupus and antiphospholipid syndrome), autoantibodies to annexin 2 were identified, and their presence is speculated to be key contributors to pathogenesis [212]. In the context of cancer, a study of sera from lung cancer patients displayed $\lg \mathrm{G} 1$ and $\lg \mathrm{M}$ autoantibodies to annexin 2, which were not seen in the non-cancer controls [213]. In our studies, the cellular presence of annexin 2 was validated by dot blot, while both isoforms were detected in the patient ascites TDE. In the group of patient TDE samples, the presence of annexin 2 was presented as double bands; however, it is not clear as to why. It is known that proteins can undergo post-translational modifications which can alter the protein, and previous studies indicate modifications of annexin 2 by phosphorylation of tyrosine [214], splice variant formation [215], and partial proteolysis [216] . Investigation of the immunoreactivity of ovarian cancer patient serum antibodies confirmed recognition primarily of the heterotetramer form of the antigen. Annexin 2 is 
also integral to cancer progression [217] by influencing migration, proliferation, and metastasis. Expression of annexin 2 is varied in different types of cancers [218] with increased expression in pancreatic [219] and breast [220] cancers, but variable expression in prostate cancer [221, 222]. In prostate cancer, annexin 2 has been shown to regulate adhesion and migration to endothelial cells and osteoblasts [223]. Ovexpression of annexin 2 in multiple myeloma [224] and gastric cancer [225] has been shown to enhance proliferation and metastasis, respectively. Conversely, the knockdown of annexin 2 by siRNA demonstrated the reduction in glioma migration [226] and multiple myeloma invasion [224].

Chaperone proteins, HSC70 and PDI were detected by dot blot assay and were found to be associated with patient ascites and serum-containing TDE, with additional detection of PDI in serum-free TDE. HSC70 is a constitutively expressed cytoplasmic protein which binds to new peptides exiting the ribosomes to protect the hydrophobic residues from inefficient interactions [227]. Additionally, it can catalyze the disassembly of clathrin cages [227] and has been implicated in the regulation of tumorigenesis and apoptosis [228]. With the assistance of co-chaperones, HSC70 can be recruited to the intracellular membrane [227], but can be released from cells as a result of active secretion [229]. Humoral autoimmune reactions against HSC70 have been documented in patients with cancer-associated retinopathy (characterized by visual loss and impairment) an ocular manifestation of underlying cancer, generally small-cell lung carcinoma [230]. These autoantibodies are believed to contribute to the pathogenesis of the retinopathy and may not necessarily target the cancer, although other studies indicate that sera from cancer-associated retinopathy patients are immunoreactive to HSC70 protein from the tumor cell [231, 232]. In establishing malignancy, an interrelationship between cathepsin D and HSC70 has been documented. Studies of a cell line transfected with cathepsin D showed that overexpression of cathepsin D 
resulted in an increase in the malignant phenotype of the transformed cells [233]. Subsequent studies of these cells revealed that this overexpression prevented the release of HSC70, which led to the malignant phenotype [229]. In our study, the expression of cathepsin D was seen in the ovarian cancer cells and all cathepsin D isoforms on the exosomes. However, the ovarian patient serum antibodies failed to detect cathepsin D in all cases. The antigen expression of cathepsin D, the lack of antibodies to cathepsin D, and the reduced HSC70 expression on the cells may indicate a "protective" mechanism used by the tumor in order to maintain high cathepsin D expression so that HSC70 release can be minimized, and the tumor growth can be maintained. Furthermore, the exosome expression of all 3 isoforms may act to "block" recognition of antigen on the tumor cell, thereby protecting the tumor from immunosurveillance. PDI is a key endoplasmic reticulum chaperone that catalyzes the breakage of disulfide bonds within a protein and rearranges them to form the native protein [234]. Because accumulation of misfolded proteins in the cell can lead to enhanced cellular stress and death [234], upregulation of PDI can act to reduce stressassociated apoptosis [235]. In the manifestation of an antitumor response to spontaneous hepatic carcinoma, PDI autoantibodies have been identified in Long Evans Cinnamon rats [236]. At the present, there appears to be minimal information on autoantibody production against PDI in humans. However, human immune responses to PDI have been documented. Studies of $\lg A$ in human tears revealed immunoreactivity to PDI in Toxoplasma gondii [237, 238]. Human PDI-family member, ERp5, has been shown to promote shedding of MICA from epithelial tumors [239]. MICA is the ligand for NK group member 2D (NKG2D) receptor on $\mathrm{NK}^{\mathrm{C}} \mathrm{CD}^{+} \mathrm{T}, \mathrm{NKT}$, and $\gamma \delta \mathrm{T}$ cells [240] and upon ligation, activates cytolysis of the target cell. Tumor-derived exosomes have been shown to express MICA/B, which downregulates NKG2D expression to reduce NKG2Dmediated killing [241, 242]. In our studies, PDI was strongly expressed in ascites TDE, 
with less expression in the culture-derived exosomes. Expression of PDI in TDE may participate in the facilitation of MICA expression, resulting in interference of innate and adaptive immune effector cell function against the tumor, thereby contributing to tumor survival.

TDE do express tumor antigen, and antibodies to those antigens may be expressed in the biologic fluids of the tumor patient, as indicated in this study. However, those antibodies do not effectively mediate an antitumor response that sufficiently eliminates the tumor. We propose that the tumor cell expresses certain antigens in their exosomes in order to divert the humoral immune response away from the tumor, thereby preventing its effective detection and elimination and allowing for progression. Because of the defined presence of autoantibodies in the circulation, and the known association of antibodies with exosomes, we further wanted to investigate the antibodies associated with these ovarian TDE to potentially gain greater insight on the ineffective antitumor response. 
TABLE 1: Characteristics of the 6 mass-spectrometry identified antigens

\begin{tabular}{|c|c|c|c|}
\hline MOLECULE NAME & BIOLOGICAL FUNCTION & CELLULAR LOCATION & SIGNIFICANCE IN CANCER \\
\hline GRP78 (BiP, HSPA5) & $\begin{array}{l}\text { Assists in unfolded protein response } \\
\text { Binds } \mathrm{Ca}^{2+} ; \text { assists in } \mathrm{Ca}^{2+} \text { homeostasis } \\
\text { (Induced by glucose deprivation) }\end{array}$ & $\begin{array}{l}\text { ER } \\
\text { Cell surface } \\
\text { Colocalizes with COP9 signalosome }\end{array}$ & $\begin{array}{l}\text { Promotes invasion/metastasis } \\
\text { Inhibits activation of apoptosis }\end{array}$ \\
\hline ANNEXIN 2 (A2) & $\begin{array}{l}\text { Binds phospholipids }\left(\mathrm{Ca}^{+2-} \text { dependent }\right) \\
\text { Converts plasminogen } \rightarrow \text { plasmin }\end{array}$ & $\begin{array}{l}\text { Early endosome } \\
\text { Cytosol } \\
\text { Plasma membrane (post cell } \\
\text { stimulation) }\end{array}$ & Promotes progression/metastasis \\
\hline CATHEPSIN D & $\begin{array}{l}\text { Degrades proteins } \\
\text { Regulates apoptosis }\end{array}$ & $\begin{array}{l}\text { Rough ER } \\
\text { Translocates to } \\
\text { endo/lyso/phagosomes }\end{array}$ & Promotes invasion/metastasis \\
\hline $\begin{array}{l}\text { ALPHA ENOLASE } \\
\text { (Enolase-1) }\end{array}$ & $\begin{array}{l}\text { Key enzyme in glycolysis } \\
\text { Gluconeogenesis }\end{array}$ & $\begin{array}{l}\text { Cytoplasm/cytosol } \\
\text { Plasma membrane }\end{array}$ & Enhances glycolysis \\
\hline HSC70 (HSPA8) & Folds proteins & $\begin{array}{l}\text { Cytosol } \\
\text { Plasma membrane }\end{array}$ & $\begin{array}{l}\text { Assists with autophagy of } \\
\text { cytoplasmic proteins }\end{array}$ \\
\hline $\begin{array}{l}\text { PDI (protein disulfide } \\
\text { isomerase, P4HB) }\end{array}$ & $\begin{array}{l}\text { Folds proteins } \\
\text { Catalyzes formation of disulfide bonds } \\
\text { Reduces/isomerizes disulfide bonds }\end{array}$ & $\begin{array}{l}\text { ER } \\
\text { Plasma membrane }\end{array}$ & Promotes survival/proliferation \\
\hline
\end{tabular}


A. UL-224 SERUM

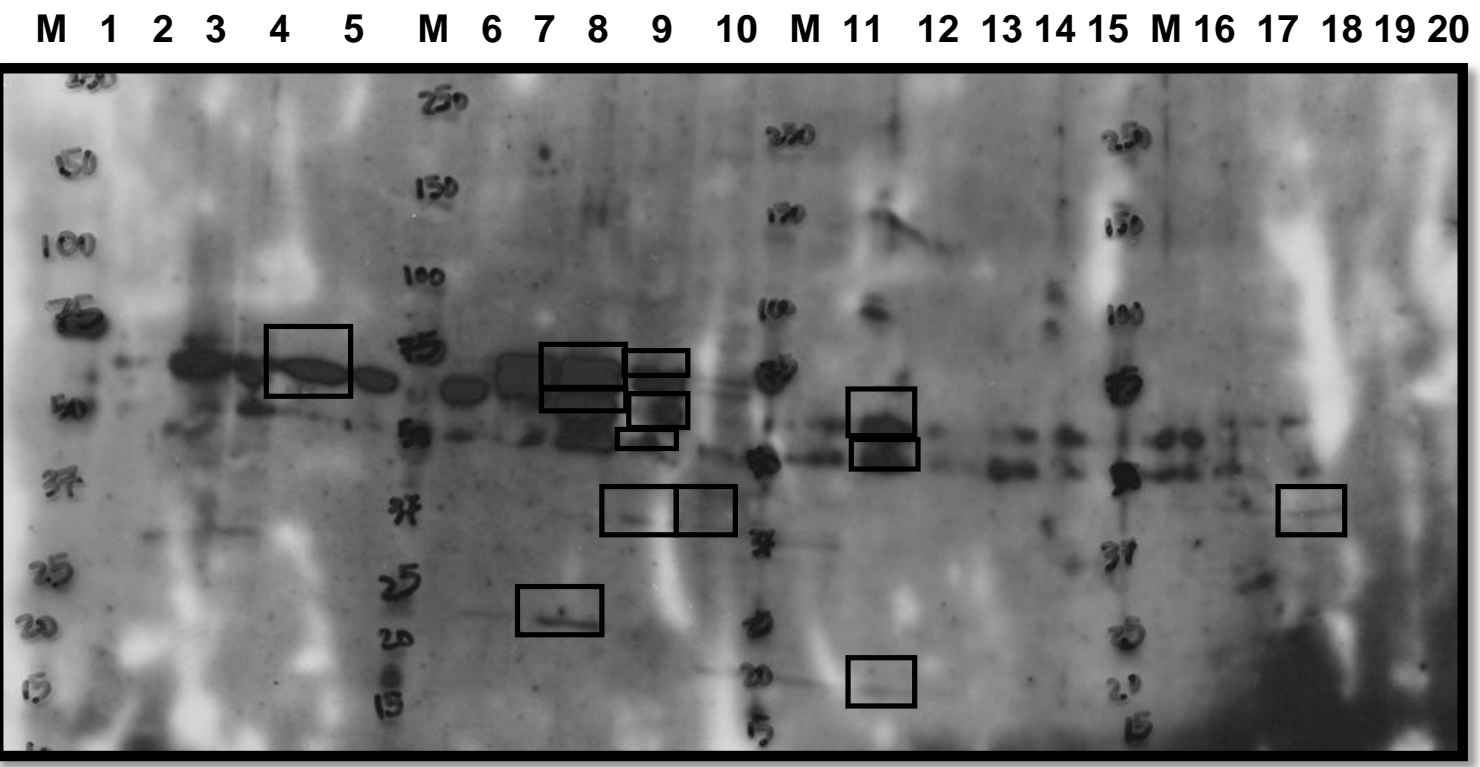

Increasing pl

B. UL-184 SERUM

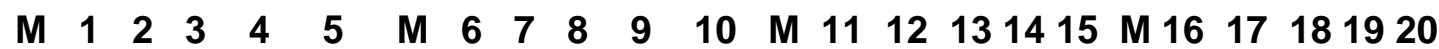

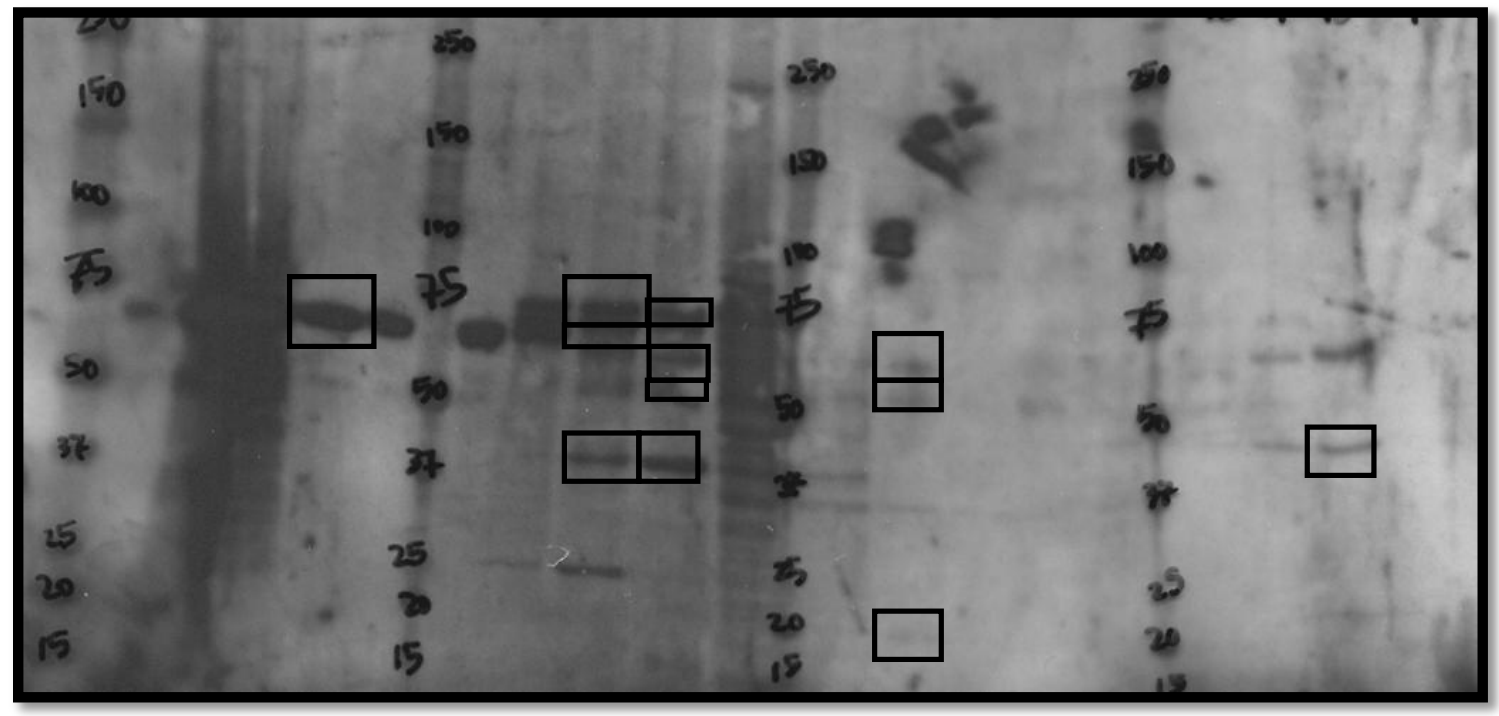

Increasing pl

Figure 1: Shared immunoreactivity of rotofor-fractionated cellular lysate with

antibodies from ovarian tumor patient sera. Serum antibodies of patient A) UL-224

$(1: 250)$ and B) UL-184 (1:250) were used to detect immunoreactivity with cellular lysate protein from patient UL-124. Boxes indicate the shared immunoreactivity between 
randomly chosen bands. Molecular marker (M) and rotofor fractions (1-20) are indicated above each image. Increasing isoelectric point $(\mathrm{pl})$ is indicated by the arrow beneath each image. 
A.
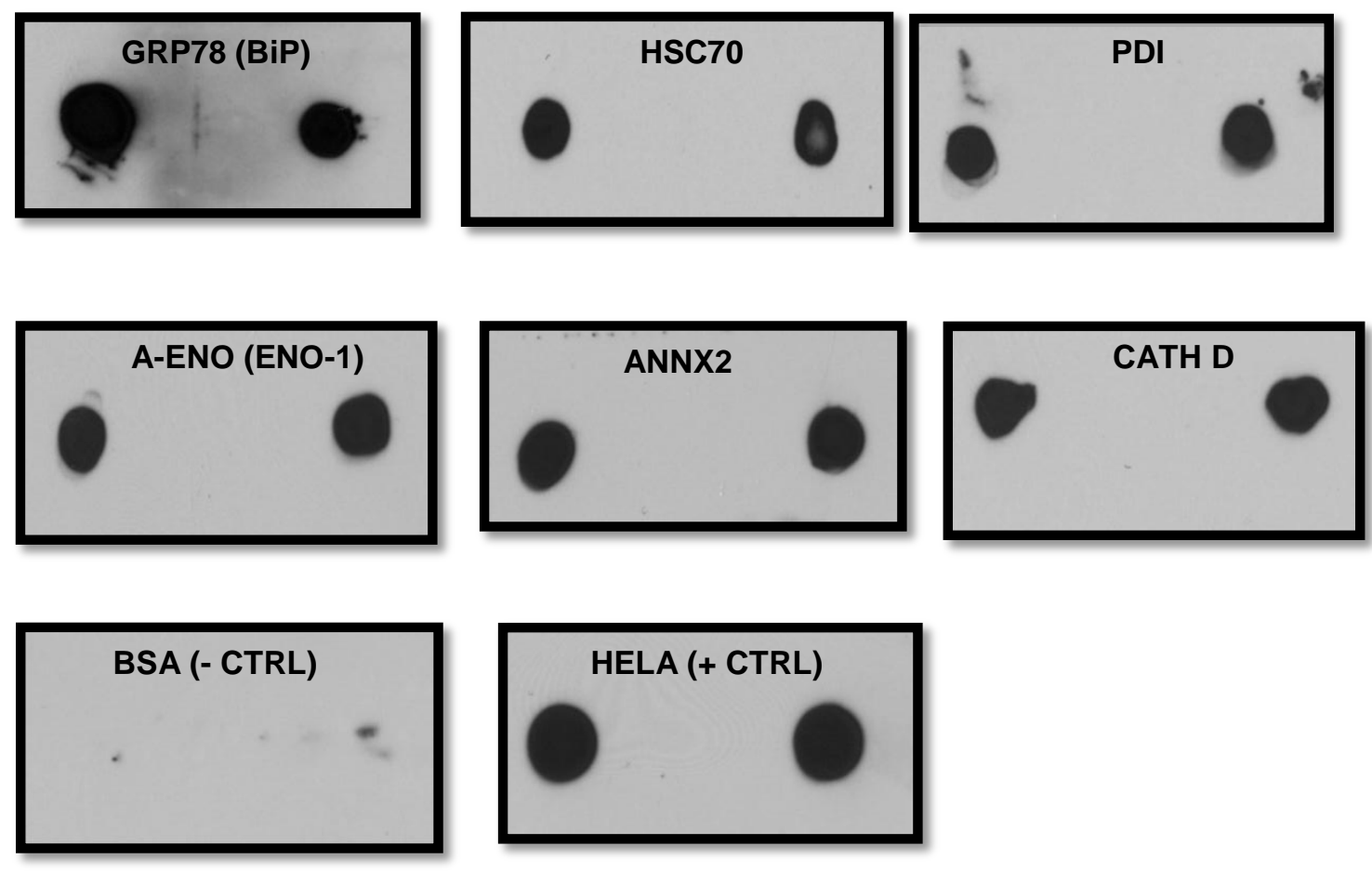

B.

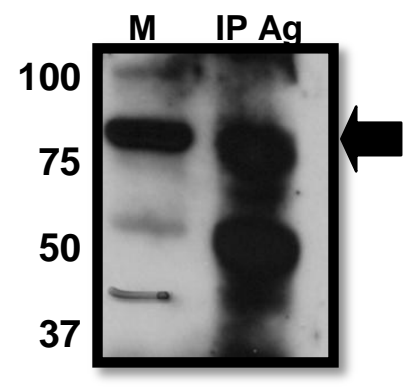

GRP78 (BiP)

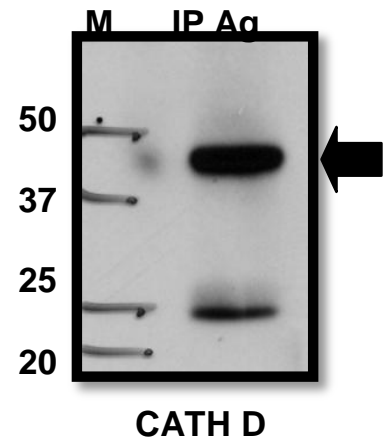

CATH D

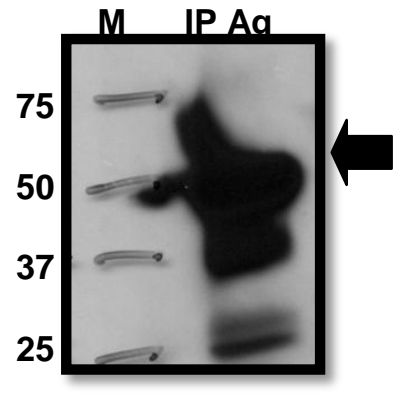

A-ENO (ENO-1)

Figure 2: Validation of identified antigens of interest using commercial antibodies.

UL-124 cellular antigen was immunoprecipitated by A) Protein G HP SpinTrap columns (applied in duplicate) and subjected to dot blot); and B) TrueBlot IP beads and subjected to Western blot (representative immunoreactivity shown). Arrows indicate identified antigen. Molecular marker (M), immunoprecipitated antigen (IP Ag). Molecules identified in Table 1. 


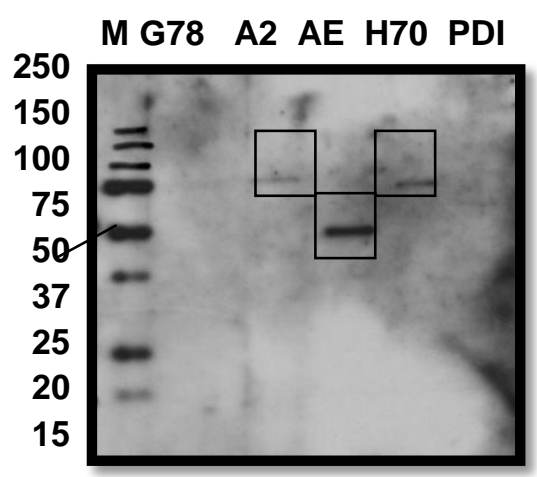

A. 190-sa

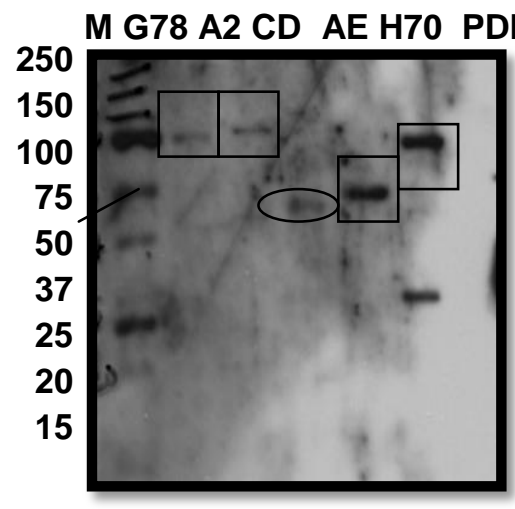

E. 351-sc

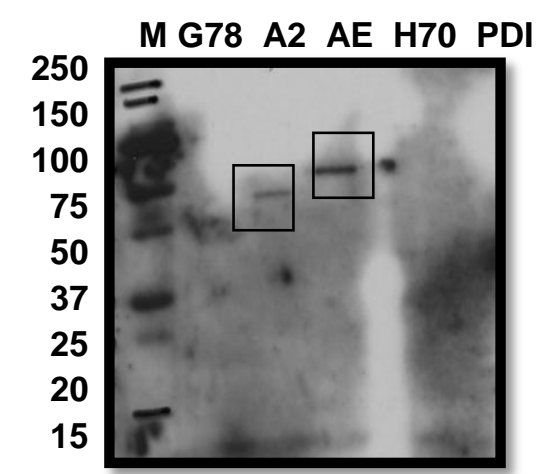

B. 207-sa

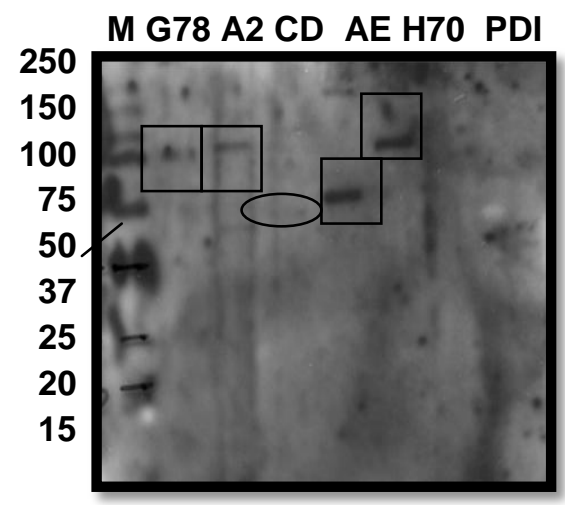

F. 324-ma

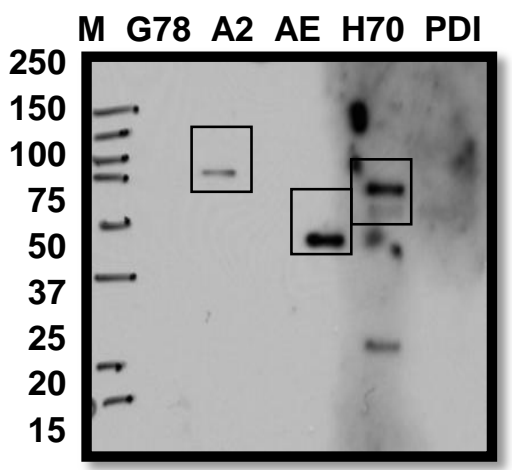

C. $398-\mathrm{sc}$

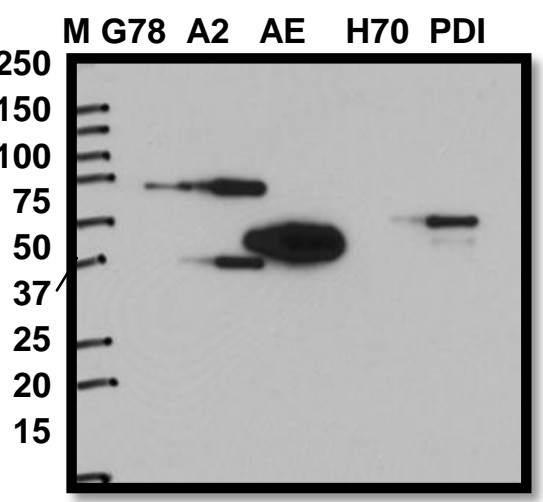

G. comm mix

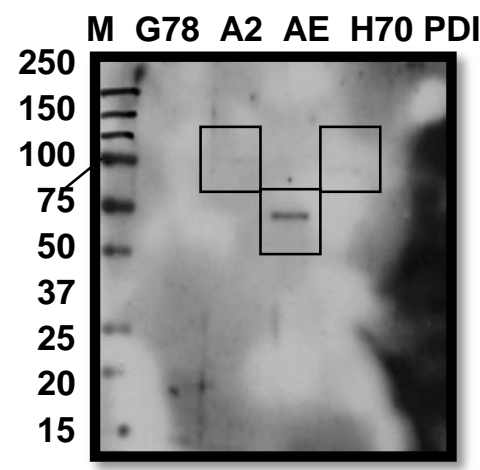

D. 167-sc

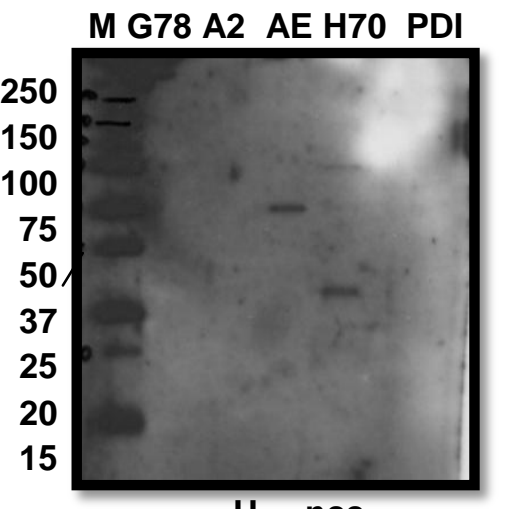

H. ncc

Figure 3: Validation of ovarian cancer patient serum antibody recognition of antigens of interest using recombinant proteins. Boxes indicate immunoreactivity of recombinant proteins with ovarian cancer patient sera (A-F). Recombinant proteins indicated as: G78 (GRP78), A2 (Annexin 2), CD (Cathepsin D), AE (Alpha-enolase), H70 (HSC 70), PDI (Protein disulfide isomerase). Ovals indicate recognition of CD. Molecular marker indicated by M. Ovarian cancer cell types (A-F) indicated as: sa (serous adenocarcinoma), sc (serous carcinoma), ma (mucinous adenocarcinoma). G indicates a mixture of commercial antibodies and $\mathrm{H}$, the ncc (non-cancer control). Initial assays showed no reactivity of $\mathrm{CD}$ with other sera samples. 

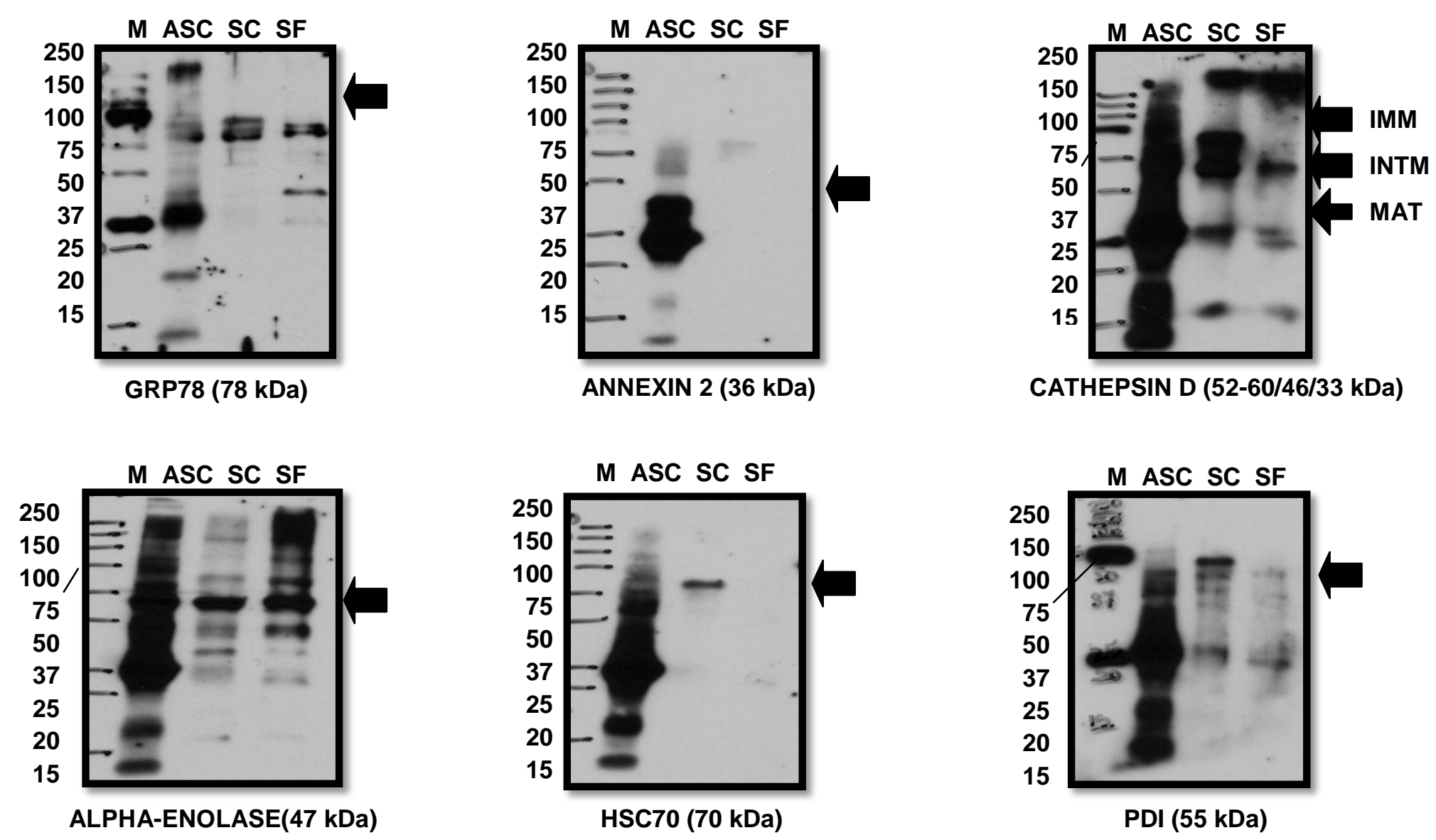

Figure 4: Analysis of the association of antigens of interest with in vivo and in vitro-derived exosomes. Western blots of UL-124 ascites-derived (ASC), serum-containing (SC), and serum-free (SF) culture-derived exosomes demonstrating immunoreactivity to commercial antibodies corresponding to the antigens of interest (indicated by arrow). Cathepsin $D$ isoforms: immature (IMM), intermediate (INTM), mature (MAT). 


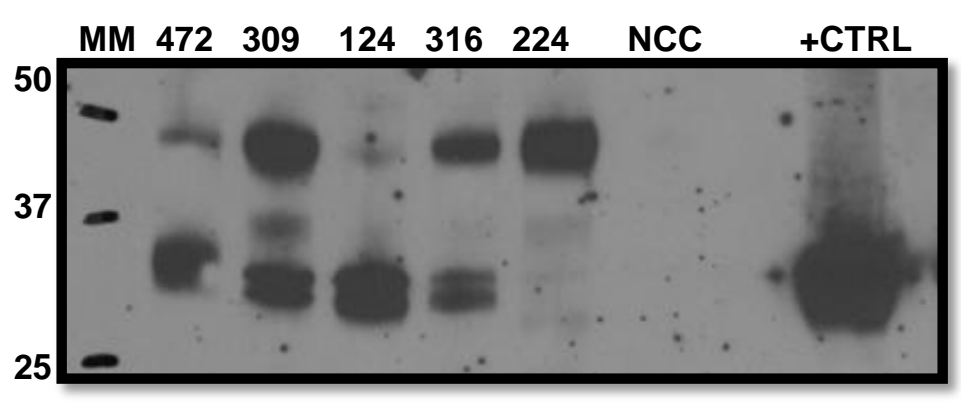

A. ANNEXIN 2

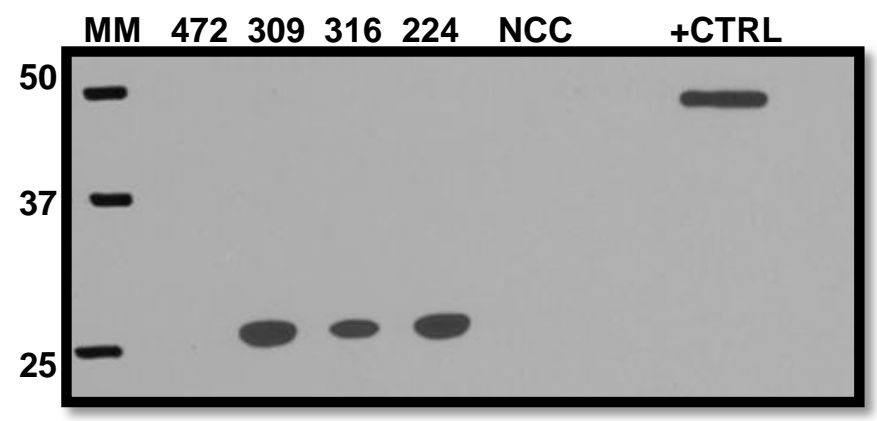

B. ENOLASE-1 (alpha-enolase)

Figure 5: Validation of tumor-reactive antigen presence in tumor-derived exosomes using different commercial antibodies. Western blots of TDE patient samples (UL-472, -309, -124, -316,- 224) and a serum non-cancer control (NCC) demonstrating immunoreactivity to A) Annexin 2 and B) Enolase-1 antibodies from Cell Signaling Technology. Positive control (+CTRL) cellular lysate, H929 (B cells), indicates molecular weights of Annexin 2 ( $\sim 38 \mathrm{kDa}$ ) and Enolase-1 $(47 \mathrm{kDa})$. Additional bands detected in the TDE by Annexin 2 ( $\sim 50 \mathrm{kDa})$ and Enolase-1 ( 30KDa) suggest the presence of isoforms of these molecules. 


\section{CHAPTER 3}

\section{ISOLATION OF TDE-ASSOCIATED IMMUNOGLOBULIN REVEALS PRESENCE OF SUBCLASSES AND IMMUNOREACTIVITY TO TUMOR ANTIGEN}

\section{Introduction}

Malignant cells are often a consequence of aberrant gene expression which influences production of abnormal cellular proteins presented as new or altered antigen [243]. Often, these antigens are shed from the malignant cells [244, 245], leading to their enhanced expression in the body fluids. Although shedding has been identified as an immunosuppressive mechanism used by tumors to escape antitumor immunity [246], studies indicate that shed antigen can be detected by the immune system and elicit cellular and humoral antitumor responses in different cancers [86, 247-249]. These antitumor responses are manifested by increased frequency of antigen-specific CD8 ${ }^{+}$ and $\mathrm{CD}^{+} \mathrm{T}$ cells [247] and tumor-reactive antibodies $[143,152,158]$ in the peripheral circulation. In experimental animal models the appearance of tumor-reactive antibodies is evident promptly after induction of the tumor and prior to the detection of palpable tumors or tumor antigen $[143,152,158]$. In a number of malignancies, the distinct presence of circulating autoantibodies has been documented [250], and unlike other circulating components, they have long half-lives and are stable [159]. Collectively, the early emergence, availability, and stable presence of tumor-reactive antibodies establish a promising platform for investigation of the humoral antitumor response.

Expression of this humoral antitumor response is reflected through increased levels of IgG in the blood and sera $[155,156]$, which is characteristically indicative of maturation of the antibody response. IgG is the predominant immunoglobulin in the 
serum of healthy adults [251], and is distributed as four subtypes (IgG1, $\lg G 2, \lg G 3$, and IgG4) named in accordance with their normal abundance in the serum [252]. The relative serum concentration of $\lg G$ is dependent upon the number of plasma cells producing that particular subtype and their metabolic rates in the intravascular/extravascular space [251]. However, during the humoral immune response, the distribution of the subclasses is adjusted, resulting in an altered IgG profile and consequently, modification in effector activity. Immunoglobulin levels in the serum can provide critical information on the status of humoral immunity [253], and may be instrumental in defining humoral immunodeficiencies [254] or other disorders or malignancies [255]. In patients with primary Sjorgen's syndrome (chronic autoimmune disorder targeting moisture-producing glands), analysis of the sera revealed increases in $\lg G 1$ and $\lg G 3$, substantiating the pathogenicity of the disease [256]. Studies of the isotype patterns of multiple myeloma sera indicated variation among subclasses and heterogeneity in hypogammaglobulinemia patterns [257]. The correlation of immunoglobulin effector activity with IgG subclass expression suggests the importance of investigating subclass distribution because of its potential for insight into the ineffective immune responses seen in other conditions or disorders.

Tumor-reactive $\lg G$ is elevated in the sera of ovarian cancer patients [159], and in experimental animal models, is expressed in the circulation before palpable tumors or circulating tumor antigens [258]. IgG may exist as free immunoglobulin or may be associated with tumor-derived membrane fragments [126] which include vesicular structures ranging from high molecular weight complexes to microvesicles and exosomes. Originally demonstrated in the peripheral circulation of patients with ovarian cancer [121, 259, 260], tumor-derived exosomes (TDE) express a membrane molecular representation of the tumor cell and enhanced expression of tumor antigen [115, 261]. Early studies conducted by this lab demonstrated that these tumor-derived exosomes 
displayed high levels of IgG bound to their surface [115, 121, 126], suggesting a humoral immune response to surface antigenic protein. The antibody response to antigen expressed on the exosome indicates that these antibodies are specific and display high affinity for the tumor antigen. Isolation of these antibodies could provide information on the immunoreactivity, structure, subclass, and effector function of the tumor-reactive $\lg$. Furthermore, exploiting the use of TDE as the antibody source for detection of tumor antigen may be more informative than free antibody in sera because the antibody is bound to the antigen, and the antigen has been "selected" in the formation of the exosome. Therefore, we hypothesize that the ovarian tumor humoral response associated with TDE can recognize and identify ovarian tumor antigen, which may be a mechanism used by the tumor cell to discourage recognition and stimulation of an antitumor response.

\section{Materials and Methods}

\section{Patient Ascites}

Ascites used in this study was derived from ovarian tumor patients diagnosed with Stage III (T3c) serous carcinoma (UL-124, TB-0836, ML-457), serous/endometrioid mixed carcinoma (UL-472), and presentation of a pelvic mass (UL-309). Control serum was derived from age-matched women with no evidence of ovarian disease.

\section{Isolation of Circulating Ovarian Tumor-derived Exosomes (TDE)}

Exosomes were isolated from ovarian tumor-patient ascites and control serum by a two-step procedure developed in our laboratory [126]. Initially, the biological fluids were centrifuged at $400 \times \mathrm{g}$ for 10 minutes (to remove whole cells). $10-20 \mathrm{~mL}$ of cell-free ascites was concentrated by ultrafiltration using an Amicon Stirred Cell (Model 8200) and a membrane with a molecular weight cut off of 500,000 Daltons (Millipore) to concentrate high molecular weight molecules. $1 \mathrm{~mL}$-aliquots of the concentrated sample 
was applied to a $2 \%$ agarose (ABT) chromatography column $(1.5 \times 20 \mathrm{~cm})$ equilibrated with $\mathrm{ddH}_{2} \mathrm{O}$ or $1 \mathrm{X}$ TBS. $1 \mathrm{~mL}$-fractions were collected and the absorbance $(280 \mathrm{~nm})$ of the elution was monitored. Fractions containing material greater than 50 million Daltons were obtained, ultrafiltrated, and the quantity of protein assayed by the Bradford method (Bio Rad).

\section{Nanoparticle Tracking Analysis (NTA)}

Exosome samples were diluted 1:10 with $1 \mathrm{X}$ PBS and NTA measurements (at room temperature) were performed using a NanoSight LM10 (Nanosight Ltd). NTA 2.3.5 software was used for capturing and analyzing the data.

\section{Isolation of Bound and Unbound Exosome Populations}

Exosomes were isolated from UL-124, UL-472, UL-309, TB-0836, ML-457 patient ascites and normal control serum using the aforementioned two-step procedure. Exosome fractions were pooled and ultrafiltrated 10-fold, and the concentrated sample prepped for use with the HiTrap Protein G HP column (GE Healthcare). In short, $1 \mathrm{~mL}$ of binding buffer (20 mM sodium phosphate, $\mathrm{pH}$ 7.0) was combined with the exosome sample prior to application onto the column. The column was washed with 10 column volumes of binding buffer at $1 \mathrm{~mL} / \mathrm{min}$, and the sample was applied to the column under closed recirculation for $1 \mathrm{hr}$. Post recirculation, the system was opened and the unbound material $(U)$, fraction containing exosomes without associated IgG, was collected. The column was washed with 10 column volumes of 1 X PBS, and the exosome-bound IgG fraction (B) was eluted isocratically using IgG Elution buffer, $\mathrm{pH} 2.8$ (Pierce). Eluted fractions were neutralized with $1 \mathrm{M}$ Tris $-\mathrm{HCl}(\mathrm{pH}$ 9) and unbound and bound fractions were concentrated by ultrafiltration. Protein concentration of bound and unbound protein fractions were quantitated by the Bradford method. 


\section{Western Blot Analyses of Exosome Protein Expression}

Western blotting was performed to analyze the presence of common exosome markers (CD63, CD81). $40 \mu \mathrm{g}$ of ascites bound and unbound exosome protein (TB0836, ML-457) was loaded onto a 10\% SDS-PAGE gel, transferred to nitrocellulose membrane (Bio Rad) on ice for $1 \mathrm{~h}$ at $98 \mathrm{~V}$, blocked with $5 \%$ blotting grade blocking grade nonfat dry milk (Bio Rad) and probed with commercial antibodies (1:1000, Santa Cruz Biotechnology) corresponding to common exosome markers.

\section{Isolation and Verification of Exosome-Associated IgG}

In preliminary experiments, $1 \mathrm{~mL}$ of patient UL-124, UL-472, and UL-309 ascitesderived exosomes were subjected to different methods in order to ascertain the optimal method for isolation of $\lg G$. Based upon the results, we proceeded with the vivaspin method of isolation. Here, the $1-\mathrm{mL}$ exosome sample was combined with $50 \mu \mathrm{L}$ increments of IgG elution buffer until a pH of $\sim 3.0$ was obtained. Samples were incubated with end-over-end rotation on the Labquake rotisserie shaker (Barnstead Thermolyne) for 30 minutes at room temperature and then added to a pre-rinsed (1X PBS) Vivaspin 2 centrifugal concentrator with a membrane MWCO of $1 \times 10^{6}$ (Sartorius Stedim Biotech). IgG was eluted from the exosomes by centrifugation (4000 x g, 20 min.), collected from the filtrate tube, and neutralized using $1 \mathrm{M} \mathrm{Tris-}-\mathrm{HCl}, \mathrm{pH}$ 9.0. IgG protein was quantitated by the Bradford method. To verify IgG isolation from TDE, 0.5-1 $\mu \mathrm{g}$ isolated $\lg G$ was loaded onto a NuPAGE $4-12 \%$ Bis-Tris gel (Novex) along with 0.1 $\mu g$ human IgG subclass control serum (1:20, The Binding Site), electrophoretically separated using MOPS SDS Running Buffer (1X, Novex) under reducing conditions, and transferred/blocked according to aforementioned methods. Efficient IgG isolation was analyzed by immunoreactivity of peroxidase-conjugated anti-human polyvalent immunoglobulin IgGAM (1:10,000,Sigma). 


\section{Analysis of Immunoreactivity and Subclasses of Isolated Exosome-associated IgG}

Post verification of $\operatorname{lgG}$ isolation, $0.5 \mu \mathrm{g}$ of GRP78, annexin 2, cathepsin D, protein disulfide isomerase (PDI; all from ProSpec Bio), alpha-enolase (American Research Products), and HSC70 (Enzo Life Sciences) human recombinant proteins were combined with 4X LDS Nonreducing Buffer (ThermoScientific), loaded onto a Mini PROTEAN TGX 4-15\% gel and electrophoretically separated. Immunoreactivity of the isolated exosome-associated IgG was analyzed by Western blot using the isolated IgG at 1:50. For the subclass analysis: $3 \mu \mathrm{g}$ of isolated IgG protein was loaded on to a Criterion TGX 4-20\% gel, electrophoretically separated, transferred using Trans Blot Turbo Transfer System (Bio Rad) with TransBlot Transfer Pack Midi Format Nitrocellulose (Bio Rad), blocked with 5\% nonfat milk, and probed with monoclonal mouse anti-human lgG1, IgG3, IgG4 (1:10,000, Sigma) and IgG2 (1:20,000, Sigma).

\section{$\underline{\text { Results }}$}

\section{Acquisition of TDE Populations}

In the isolation of exosomes from patient biological fluids it is expected that a subset of the exosome population is derived from the tumor and the remaining may be derived from normal cells. To investigate the differences between these exosome populations, exosomes were first isolated from ovarian tumor-patient ascites and normal serum. Using the two step isolation procedure, samples were concentrated by ultrafiltration and applied to $2 \%$ agarose columns, monitoring elution at $280 \mathrm{~nm}$. The fractions containing the exosome populations were acquired, combined with sodium phosphate (to enhance the affinity of any $\lg G$ associated with the exosomes to the protein G) and further separated using a HiTrap Protein G HP column. HiTrap Protein G HP columns specifically recognize all subclasses of lgG. In the application of the exosome samples to the column, those exosomes that have $\lg$ G bound to them (those 
that express tumor antigen) bind to the column, while exosomes that lack bound IgG (those that express normal antigen) "flow through". The "flow through" represents the unbound fraction of exosomes. Using low $\mathrm{pH}$ buffers to reduce affinity between protein $\mathrm{G}$ and IgG, bound exosomes were eluted, collected, and neutralized with Tris buffer ( $\mathrm{pH} 9)$ to maintain the stability of the eluted lgG after being exposed to acidic conditions (Fig. $6)$.

\section{Verification of Exosome Acquisition}

Protein concentrations of eluted bound and unbound exosome fractions were obtained, analyzed by SDS-PAGE, and subjected to Western blot. Since CD63 and CD81 have been demonstrated as markers of exosomes, their presence on bound and unbound populations were analyzed. CD63 and CD81 were present in both bound and unbound populations with slight variation in intensity between patient samples (Fig. 7A). Additionally, the sizes of the isolated nanoparticles were verified using Nanoparticle Tracking Analysis (NTA) (Fig. 7B), with bound fractions in the 30-100 nm range and unbound fractions in the higher ranges (primarily $>100 \mathrm{~nm}$ ), thereby confirming the isolation of exosomes.

\section{Association of IgG with TDE Populations}

To establish the association of immunoglobulin with TDE, fractions collected by our two-step method were prepared as aforementioned, applied to a HiTrap Prot G HP column, and eluted. Since exosomes from non-malignant cells can be present in malignant effusions, the association of IgG with bound and unbound populations was investigated to distinguish between exosomes of malignant and non-malignant origin. Patient bound exosome fractions revealed bands corresponding to the $\lg G$ heavy (50 $\mathrm{kDa}$ ) and light chains (25 kDa), while little to no immunoreactivity was seen in the patient unbound fractions and serum control (Fig. 8A). 


\section{Isolated IgG displays Immunoreactivity to Cellular Antigen}

Because IgG association to TDE suggests the occurrence of an immune response, further analysis of the exosome-associated IgG should provide insight on the specificity and affinity of the TDE for tumor antigen. To isolate the exosome-associated $\lg \mathrm{G}$, exosomes were subjected to chemical treatment to separate the $\lg \mathrm{G}$ from the exosome surface and concentrated using nanomembrane centrifugation to separate the extracted IgG from the exosome. The protein concentration of the isolated IgG was acquired and its presence verified by Western blot which identified IgG heavy and light chains (Fig. 8b). The affinity and specificity of the isolated IgG was evaluated by analyzing its immunoreactivity to the six immunogenic proteins identified via mass spectrometry. Immunoreactivity was seen with annexin 2 (higher and lower molecular weight forms), alpha-enolase, and HSC70, with faint recognition of GRP78 (Fig. 8C).

\section{Subclass Characterization of Exosome-Isolated IgG}

Since human IgG is comprised of different subclasses, it was of interest to analyze the isolated IgG to see if particular subclasses are associated with TDE (Fig.9). Analysis of total lgG revealed heavy and light chains in the commercial control and patient samples, with no lgG seen in the non-cancer control. Although multiple bands were seen in the cancer patient samples in all subclasses, there were variations of intensity between the subclasses. Banding patterns with anti-lgG1 and lgG2 were more intense and similar to anti-total IgG for patient sample 472, 124 (double bands), and 309, suggesting that $\lg \mathrm{G} 1$ and $\lg G 2$ may be the predominant subclasses associated with the ovarian TDE. 


\section{Discussion}

Tumor progression and metastasis is influenced by the tumor microenvironment [161] which facilitates the expression and release of a number of biological constituents [128], including enhanced release of microvesicles/exosomes into the circulation [115, 116]. The enhancement of circulating TDE has been implicated not only as a communicative mechanism with the microenvironment in order to expedite effector functions in the target cell [106] and mediate tumor progression [113, 163, 262-264], but also as a diagnostic mechanism to be utilized as an approach in cancer detection [265, 266]. Proteomic analysis of effusion-derived exosomes has demonstrated the presence of both common and unique proteins, which has expanded the present knowledge of exosome composition. In addition to the expression of common surface antigen, TDE display immunogenic antigen specific to the tumor from which it is derived such as MelanA/Mart 1 in melanoma [113] and carcinoembryonic antigen (CEA) in colon carcinoma [111]. In the context of ovarian cancer, several tumor cellular antigens (e.g. Her2/neu, MUC-1) [267-270], ovarian antigen-3 (OA-3) [271], and cancer testis antigen (NY-ESO-1) [272]) have been identified . However, the association of these antigens with ovarian cancer exosomes is somewhat ambiguous. In this study, proteomic analyses of circulating antibody immunoreactivity to ovarian cancer lysates led to the identification of six proteins (GRP78, annexin 2, cathepsin D, alpha-enolase, HSC70, PDI) and further investigation revealed the association of these same proteins with ovarian tumor exosomes.

The association of immunogenic antigen to ovarian cancer exosomes elicits an immune response resulting in the production of immunoreactive antibodies which bind to exosome-associated antigen. The antibody-associated exosomes are what we are defining as "bound exosomes." To isolate bound exosomes, exosome fractions were applied to HiTrap Protein G columns which contain Protein G, a Group G Streptococci 
cell surface FcRIII which binds the Fc portion of IgG. The bound exosomes are eluted from the column using low $\mathrm{pH}$ buffers. As the exosome sample flows over the column, those exosomes that are associated with IgG are trapped onto the column, allowing exosomes without lgG to flow through. The flow-through fraction is what we define as "unbound exosomes." In previous studies (not shown here), analysis of the association of the proteomics-identified proteins with bound and unbound exosome fractions confirmed the presence of each of the six proteins, with suggested enrichment in the bound fractions. Since bound exosomes are likely derived from the tumor cells, it is expected that the identified proteins from the tumor would be enriched in its exosome derivative.

In order to gain a deeper understanding of the humoral response to ovarian tumor antigen, the antibodies associated with the bound exosomes were isolated using centrifugal concentration of bound exosome fractions in low pH buffers. Eluted antibody was verified and then used to investigate immunoreactivity to recombinant antigens corresponding to the proteomics-identified proteins. Although recognition of only 4 (annexin 2, alpha-enolase, HSC70 and faint recognition of GRP78) of the six proteins was seen, it is important to remember that immunogenic proteins typically display modifications which are instrumental in their immunogenicity. Moreover, these modifications may or may not be present in the recombinant protein, which would affect recognition of the epitope by its corresponding antibody.

To acquire further insight into the exosome humoral response, we verified the presence of exosome-associated $\lg G$ and analyzed the subclass distribution of the isolated exosome-associated $\lg \mathrm{G}$. IgG is a large (150 kDa), bilaterally symmetric glycoprotein made of two heavy (50 kDa) and two light (25 kDa) polypeptide chains associated by inter- and intra-chain disulfide bonds [273]. It is composed of 3 functionally distinct regions-2 Fab ("fragment antigen-binding") regions which bind the 
antigen, and a single Fc ("fragment crystallizable") region which interacts with effector cells and molecules [157]. In humans, $\lg G$ is further categorized into 4 subclasses: $\lg G 1, \lg G 2, \lg G 3$, and $\lg G 4$. Although the general structure of the subclasses is the same, there is some variation seen in the flexibility of the hinge region and the positional attachment of the light chain to the heavy chain [251]). These structural variations in the hinge region and in the Fc region are important in establishing the biological functions of the subclasses [274]. The key biologic functions of the $\lg G$ subclasses are complement fixation and opsonization. In the fixing of complement, the Fc portion of $\lg G$ (bound to pathogenic surfaces) is bound by complement protein 1 (C1). This triggers a cascade of reactions, eventually leading to the formation of a membrane-attack complex (MAC) which lyses the target $[275,276]$. Of the $\lg G$ subclasses, $\lg G 1$ and $\lg G 3$ are the most efficient at fixing complement, followed by weak fixation by $\lg G 2$ and the absent fixation of IgG4 [273]. The process of opsonization involves the coating of antibodies onto the surface of a pathogen or foreign substance in order to promote Fc receptor-mediated phagocytosis [157]. The Fc regions of IgG (particularly IgG1 and IgG3 and to a lesser degree, $\lg$ G2) are recognized by the Fc-gamma receptor of phagocytes, triggering phagocytosis and eventual killing of the target [277].

Here, isolated TDE IgG was subjected to SDS-PAGE and Western blotted with IgG subclass antibodies. Immunoreactivity to all antibodies was evident with the revelation of IgG heavy $(50 \mathrm{kDa})$ and light $(25 \mathrm{kDa})$ chains in all of the cancer patient samples. However, with the $\lg G 1$ and $\lg G 2$ antibodies, the heavy chain bands were more distinct, suggesting that $\lg G 1$ and $\lg G 2$ are the predominant subclasses associated with TDE. Additionally, doublet bands appeared in the heavy chain migration of patient sample UL-124, suggesting heterogeneity of that protein [278] or a potential post-translational modification. Expression of $\lg G 1$ and $\lg G 2$ as predominant subtypes on the TDE may be an important mechanism used by to tumor to mediate the antitumor 
response and promote immunomodulation. The expression of tumor antigen on the TDE and ovarian tumor cell stimulates a humoral antitumor response in which all subclasses would bind to the tumor antigens, but all may potentially be unable to actively participate in the antitumor response. Research indicates that some IgG subclasses are functionally more protective. IgG1 and IgG3 are known as cytophilic antibodies (have a strong affinity for $\mathrm{FcR}$ ) and are able to mediate cell destruction by complement-dependent cytotoxicity (CDC) and antibody-dependent cell mediated-cytotoxicity (ADCC). In clinical studies of $\lg G$ isotype distribution in the sera of individuals protected from and affected by Plasmodium falciparum (causative agent of malaria), higher levels of $\lg \mathrm{G} 1$ and $\lg \mathrm{G} 3$ were found in protected adults, while lgG2 and lgG4 levels predominated in nonprotected individuals [279]. Because of their ability to bind and recognize the same epitopes, it is hypothesized that the $\lg G 2$ and $\lg G 4$ are binding in order to block the protective activity of the other isotypes [280]. In vitro analyses of Plasmodium falciparum in the presence of blood monocytes inhibited phagocytosis and opsonization as a result of IgG2 and IgG4 presence, and allowed continued growth of the microorganism [281, 282]. In our analysis, we speculate that the predominant presence of lgG1 (to invoke an immune response against the tumor) and IgG2 (to block the strength of the immune response against the tumor) on the TDE surface may be humoral contributors to the provs. anti-tumor dichotomy. Additionally, we surmise that the ovarian tumor utilizes its release of TDE as a "decoy" to capture opsonizing antibodies in the attempt to promote its own survival.

In summary, analyses of the ovarian TDE humoral response revealed the presence of all $\operatorname{lgG}$ isotypes and their ability to recognize ovarian tumor antigen, thereby suggesting the mobilization of an anti-tumor response. However, the prevalence of noncytophilic antibodies (i.e. IgG2) indicates a potential defense mechanism exploited by the tumor to minimize efficacy of the antitumor response, which is further enhanced by 
TDE "absorption" of cytophilic antibodies. Collectively, these mechanisms may be instrumental in promoting survival of the ovarian tumor and protecting it from the humoral antitumor response. 


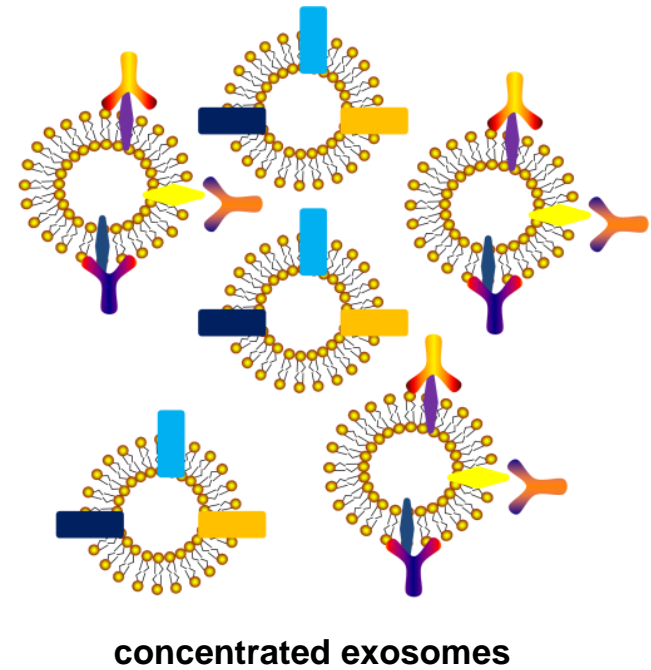

+ IgG elution buffer ( $\mathrm{pH} \sim 2.9$ )

$$
+1 \mathrm{M} \text { Tris (pH 9) }
$$

eluted IgG-bearing exosomes (bound fraction)

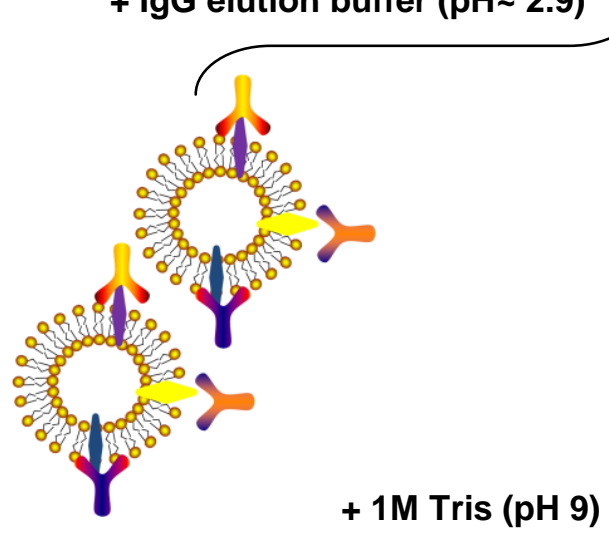

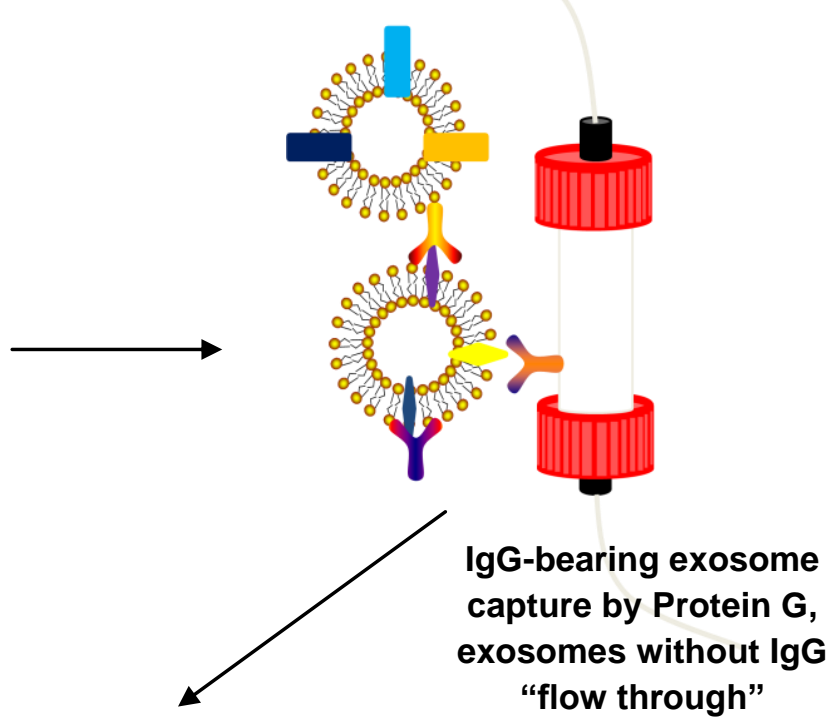

"flow through" 
A.
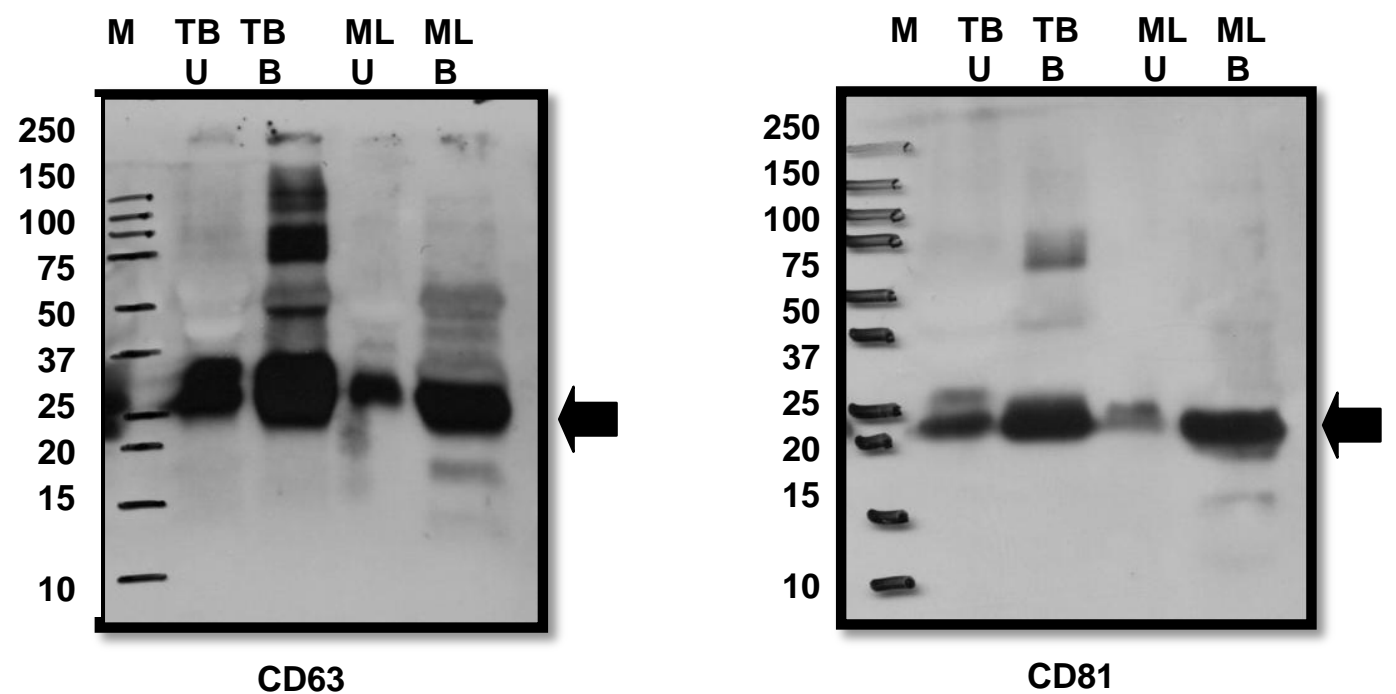

B.

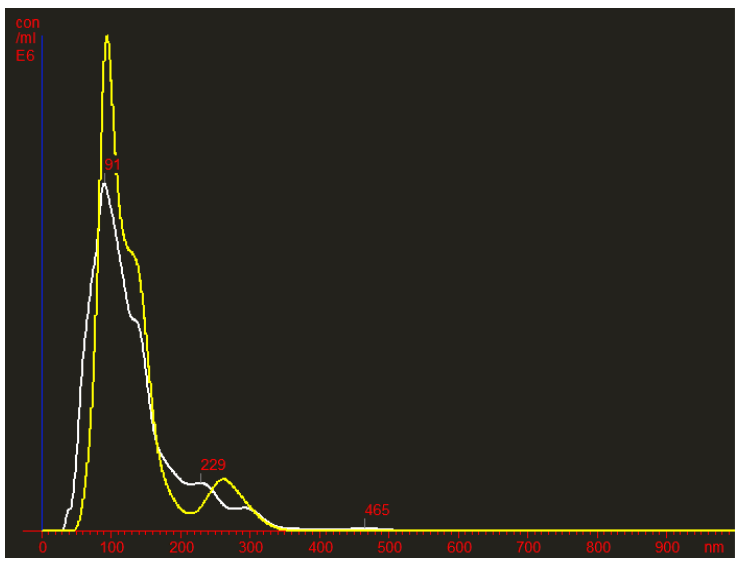

TB- B SIZE DISTRIBUTION (mean $\sim 91 \mathrm{~nm}$ )

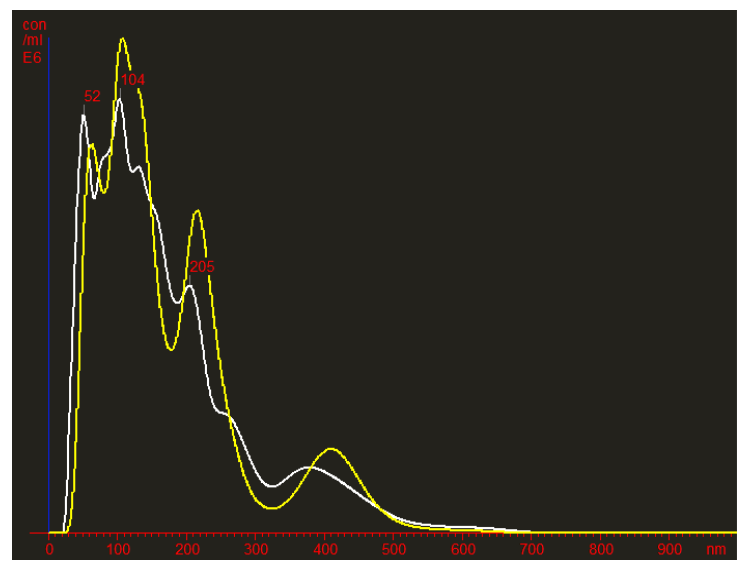

TB- U SIZE DISTRIBUTION (mean $\sim 67-206 \mathrm{~nm}$ )

Figure 7: Verification of exosome acquisition utilizing common exosome markers and nanoparticle tracking analysis (NTA). Bound and unbound exosome fractions of patient TB-0836 and ML-457 ascites exosomes were acquired and verified by Western blot for A) CD63 and CD81, and the nanoparticle size distribution in the fractions determined by $B$ ) nanoparticle tracking analysis. TB-B (bound exosomes from patient TB-0836), TB-U (unbound exosomes from patient TB0836), ML-B (bound exosomes from patient ML-457), ML-U (unbound exosomes from patient ML-457. 


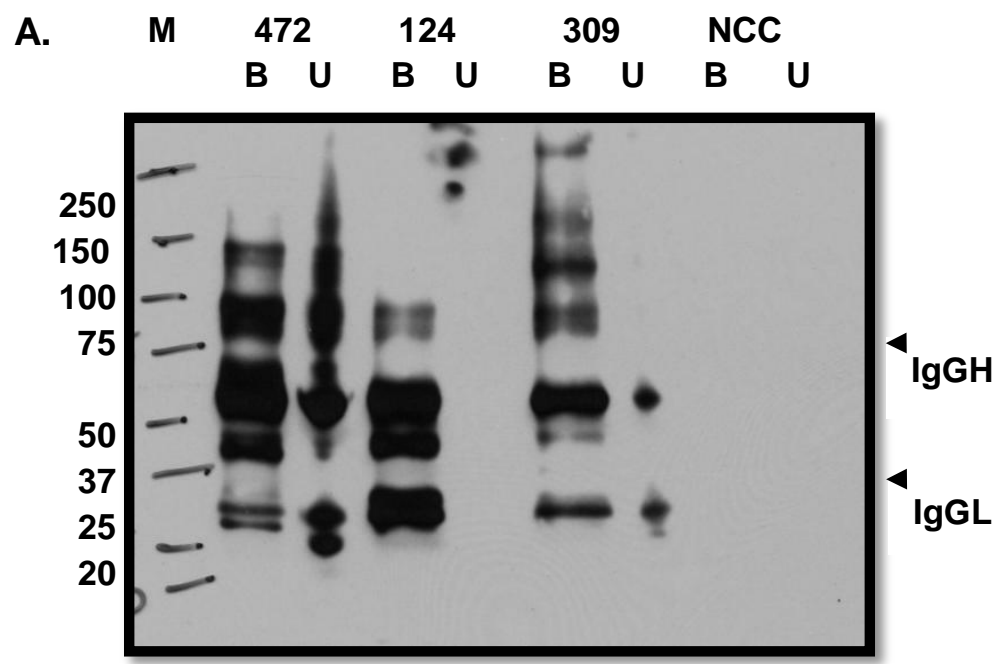

B.
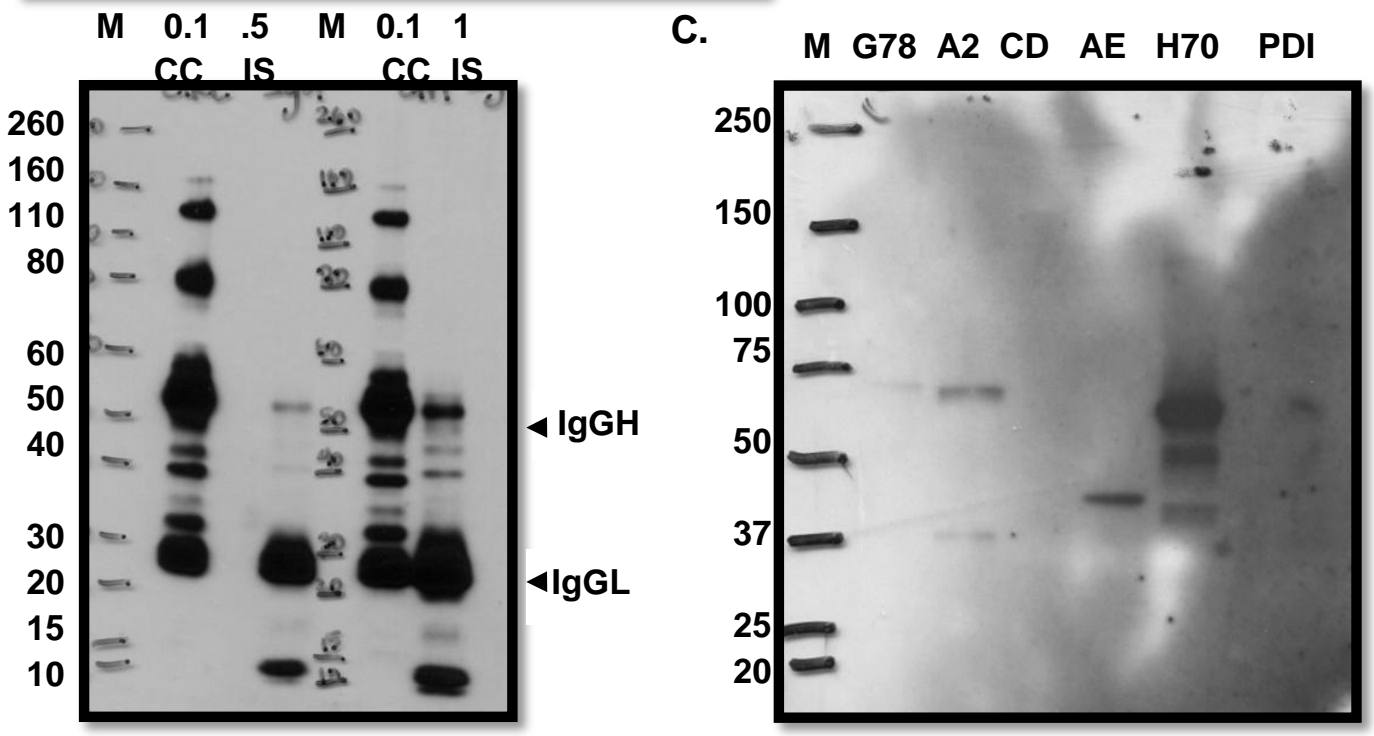

Figure 8: Verification and isolation of patient-bound ascites exosome IgG and its immunoreactivity to mass-spectrometry identified antigen. A) Western blot of patient UL-472, UL-124, UL-309, and non-cancer control (NCC) bound (B) and unbound $(\mathrm{U})$ exosome fractions reveal association of $\lg G$ with exosomes. B) Western blot of isolated IgG (IS) from patient UL-124 ascites bound exosomes $(0.5 \mu \mathrm{g}, 1 \mu \mathrm{g})$ along with commercial IgG control (CC; $0.1 \mu \mathrm{g})$. C) Western blot of immunoreactive isolated patient IgG to recombinant proteins corresponding to mass spectrometry antigens of interest. Recombinant protein abbreviations indicated in Figure 3. Heavy chain (lgGH), light chain (lgGL). 


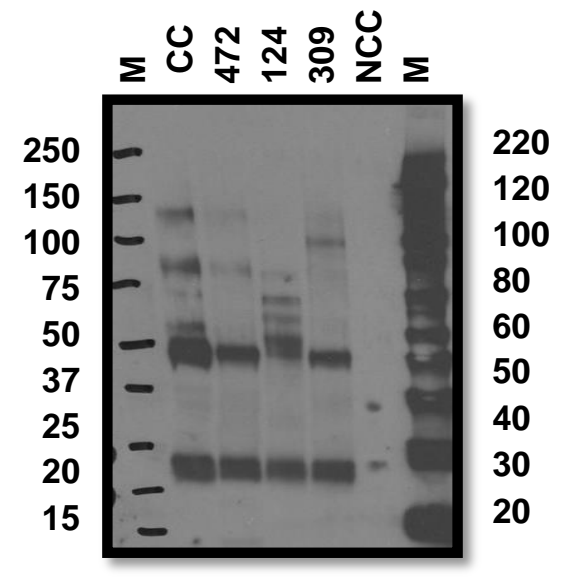

A. Total IgG

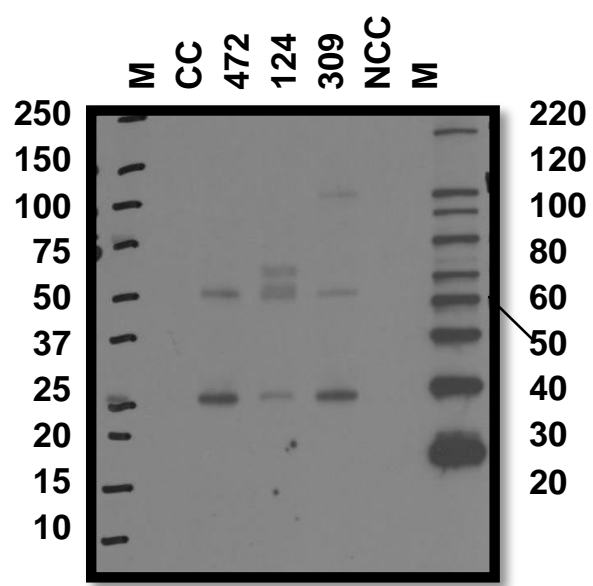

B. $\lg G 1$

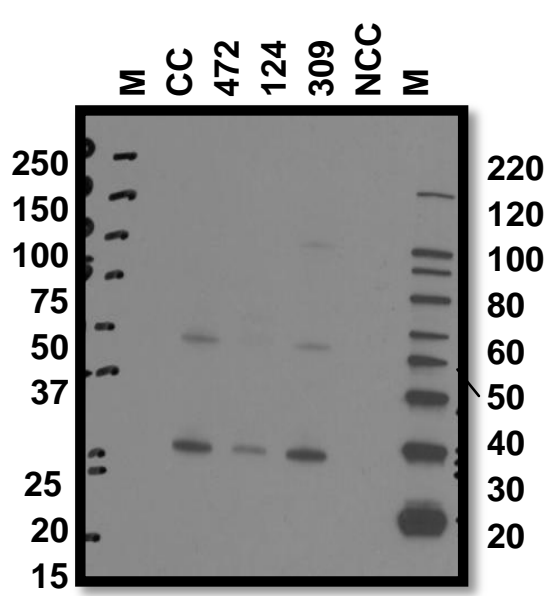

D. IgG3

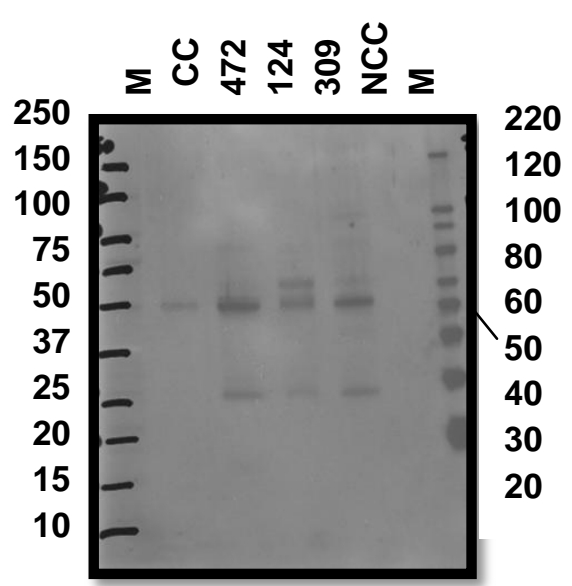

C. IgG2

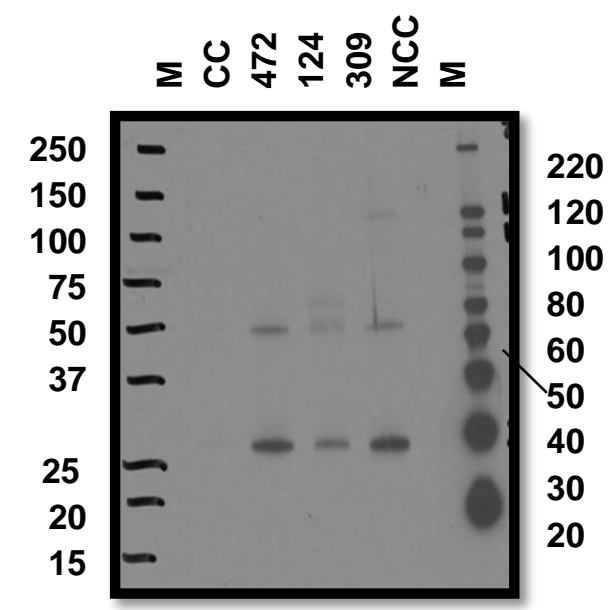

E. $\lg$ G4

Figure 9: Subclass characterization of isolated tumor-derived exosome-lgG. Western blot of isolated patient ascites exosome- IgG probed with a) anti-human IgGAM (1:5000), B) anti-human IgG1, C) anti-human IgG2, D) anti-human IgG3, E) anti-human IgG4. Anti-human IgG2 (1:15,000), all other antibodies (1:10,000). Molecular marker (M), commercial lgG control (CC). patient ascites exosome- IaG (UL-472. UL-124. UL-309). batient non-cancer control ( NCC). 


\section{CHAPTER 4}

\section{OVARIAN TDE MEDIATION OF THE HUMORAL RESPONSE BY INDUCTION OF B CELL APOPTOSIS}

\section{B Cell Biology and Responses in the Normal and Tumor Microenvironment}

As one of the lymphocyte derivatives of the common lymphoid precursor, B cells begin their earliest development in the fetal liver and subsequent post-birth development in the hematopoietic bone marrow via adhesive and chemical interactions with bone marrow stromal cells. Within the bone marrow, early B cells differentiate and functionally rearrange their immunoglobulin gene segments with the assistance of recombination activating genes (RAG-1/RAG-2), to produce a $\mu$ heavy chain and $\kappa$ or $\lambda$ light chains, resulting in production of immature $B$ cells that express the surface $B$ cell receptor (BCR), IgM [157]. The immature B cells leave the bone marrow and migrate into the periphery, continuing their development through transitional stages where they undergo negative selection processes in order to generate B cells that are capable of survival and progression towards maturity [157]. As a consequence of transitional differentiation and BCR signaling strength [283], immature B cells form mature subpopulations, namely marginal zone B cells which assist in ensuring a rapid antibody response during the lapse between innate and T cell dependent adaptive antibody responses [284] and follicular B cells which may recirculate and enter/exit the follicular microenvironment of secondary lymphoid organs in search of antigen [285]. In response to chemokine cues, mature B cells enter the follicles of secondary lymph organs and undergo rapid 
proliferation to create germinal centers (specific microenvironments of dividing cells [286] in which antibody affinity maturation takes place [287]). In response to the rapid proliferation, anatomically and functionally distinct polar regions are created i.e. the dark zone (contains the rapidly dividing B cells called centroblasts) and the light zone (contains fewer B cells called centrocytes, but a number of follicular dendritic cells) [288]. The interactions of these B cells with helper T cells (within the dark zone) and follicular dendritic cells (within the light zone) are critical in initiating class switch recombination (CSR) and somatic hypermutation (SHM), two processes that target the rearrangement and mutation of immunoglobulin genes in order to produce the highaffinity immunoglobulin needed to facilitate an adequate humoral response [289].

In the context of pathogenesis, the behavior and function of B cells is not as well documented or characterized as that of other immune cells. In autoimmune or organspecific disorders, the formation of germinal centers is common [290], resulting from the pro- inflammatory conditions/cytokines which promote germinal center organization [291, 292]. As a result, B cell production is generally abundant. However, in some autoimmune conditions, the presence of these B cells suggests more harm than benefit due to their potent antigen-presenting function to their cognate helper T cells [293] and their production of autoantibodies [294]. In the tumor microenvironment, B cells have been proposed contribute to immunomodulation by: 1) altering cytokine and/or chemokine levels in the circulation [120] and 2) producing antibodies to human tumorassociated antigen which in a study of bladder cancer, correlated with decreased patient prognosis and survival [295]. Additionally, the elevated levels of antitumor antibodies typically result in the formation of immune complexes which accumulate [296] and further contribute to an unfavorable prognosis [297-299]. Alternative contributions to immunomodulation in the tumor microenvironment are demonstrated through the release of exosomes by the cancer cells. Enhanced exosome release has been documented in 
cancer cell cultures [300] and malignant effusions [113] including mesothelioma patient pleural fluid [112] and peritoneal ascites [301]. Evidence suggests that in a number of cancers, tumor-derived exosomes (TDE) act as an "immunological accomplice" to promote the progression of their parent cells. One of the mechanisms used by exosomes is the induction of apoptosis in effector immune cells, particularly T cells. A study of melanoma-derived exosomes revealed the induction of T-cell apoptosis via expression of FasL [302], while human colorectal microvesicles were found to induce apoptosis of CD8 ${ }^{+} \mathrm{T}$ cells through expression of both FasL and tumor necrosis factorrelated apoptosis inducing ligand (TRAIL) [111]. In ovarian cancer patients, T cells have been shown to display enhanced apoptosis and diminished expression of CD3-zeta $[303,304]$. To address these findings, previous studies by the Taylor lab indicated that ovarian cancer exosomes suppress both CD3-zeta and JAK-3 and suggested that the exosomes could be the link between the reduced expression of CD3-zeta and apoptosis of T cells [305]. Taking these immunomodulatory characteristics into account, this current investigation explores the relationship between ovarian tumor-derived exosomes (TDE) and the ovarian cancer humoral antitumor response by evaluating the effects of these exosomes on B cells. Our findings indicate that ovarian cancer TDE induce apoptosis in B cells in a dose-dependent manner and enhance the expression of immunomodulatory molecules which have been documented to mediate apoptosis and assist in immune escape. Based upon these findings, we propose that ovarian cancer TDE can induce apoptosis in B cells as a mechanism to divert the ovarian cancer antitumor humoral response away from the tumor in order to support progression. 


\section{Materials and Methods}

\section{Cell Cultures}

Ramos B cell line (human Burkitt's lymphoma, ATCC) was maintained in Hyclone RPMI 1640 medium (ThermoScientific) supplemented with 10\% fetal bovine serum (FBS, Biowest), and 100 units/mL gentamicin 10 (Atlanta Biologicals) in a humidified incubator at $37^{\circ} \mathrm{C}$ with $5 \% \mathrm{CO}_{2}$. For cocultures, cells were transferred into culture medium with $10 \%$ exosome-depleted FBS (Exo-FBS, SBI). As previously mentioned (chapter 3), primary ovarian tumor cell cultures were established from UL-124 ascites and grown in Hyclone RPMI 1640 medium (ThermoScientific) supplemented with 2mM L-glutamine, $10 \%$ fetal bovine serum (FBS, Biowest), $1 \mathrm{mM}$ sodium pyruvate (CellGro, Mediatech), $0.1 \mathrm{mM}$ nonessential amino acids (CellGro, Mediatech), and 100 units $/ \mathrm{mL}$ penicillin-streptomycin (Gibco, Invitrogen) in a humidified incubator at $37^{\circ} \mathrm{C}$ with $5 \% \mathrm{CO}_{2}$. After assurance of confluence, cells were transferred into Ultraculture General Purpose Serum-Free Media without L-glutamine, but supplemented with the same amount of sodium pyruvate, non-essential amino acids, and penicillin-streptomycin in order to ensure that the exosomes later collected would be derived from the tumor cells and not the FBS. Later, exosome-free FBS (Exo-FBS, SBI) was purchased and 10\% was added to this media.

\section{Isolation and Preparation of Culture Supernatant Exosomes}

Supernatant from the UL-124 ovarian cancer cell culture was collected and centrifuged at $400 \times \mathrm{g}$ for 10 minutes to pellet any cells present in the supernatant. The cell-free culture supernatant was ultrafiltrated (under sterile conditions) using an Amicon Stirred Cell (Model 8200) and a membrane with a molecular weight cut off of 500,000 Daltons (Millipore) to concentrate high molecular weight molecules. $1 \mathrm{~mL}$-aliquots of the concentrated sample was applied to a $2 \%$ agarose (ABT) chromatography column $(1.5 \mathrm{x}$ 
$20 \mathrm{~cm}$ ) equilibrated with sterile $\mathrm{ddH}_{2} \mathrm{O} .1 \mathrm{~mL}$-fractions were collected and the absorbance $(280 \mathrm{~nm})$ of the elution was monitored. Fractions containing material greater than 50 million Daltons (exosome fractions) were obtained, ultrafiltrated, and the quantity of exosome protein assayed by the Bradford method (Bio Rad). A chromogenic LAL assay (GenScript) was performed to assess endotoxin levels in the exosome preparations. Preparations with detectable levels above the acceptable range were subjected to endotoxin removal (MoBio) and endotoxin content reassessed. All endotoxin content levels were $<0.2 \mathrm{EU} / \mathrm{mL}$. Exosome protein concentration was reacquired by BCA protein assay (ThermoScientific Pierce) and exosome preparations were dispensed into $100 \mu \mathrm{g} / \mathrm{mL}$ aliquots in preparation for cocultures.

\section{Coculture of B cells with Ovarian TDE}

Ramos cells $\left(1 \times 10^{6}\right)$ were cocultured alone or with UL-124 culture supernatant exosomes at varying concentrations $(10,20,50$, and $100 \mu \mathrm{g} / \mathrm{mL})$ for $3,6,18$, and $24 \mathrm{~h}$. Cells were pelleted (2000 rpm, $5 \mathrm{~min}$ ) and supernatant collected for human cytokine array analysis. Cells were washed with sterile 1X DPBS (CellGro, Mediatech) and lysed on ice using lysis buffer (125 mM Tris (pH 6.8), 2\% SDS, 20\% glycerol, $100 \mu \mathrm{M}$ PMSF, protease inhibitor cocktail and phosphatase inhibitor (100X)). Lysed cells were centrifuged at $13,000 \mathrm{rpm}$ for 10 minutes to pellet debris. Lysate was stored at $-20^{\circ} \mathrm{C}$ until use.

\section{Trypan Blue Assay}

Post culture, $20 \mu \mathrm{L}$ of the culture suspension was mixed with an equal amount of $0.4 \%$ trypan blue (Sigma) and live and dead cells counted using the Neubauer hemocytometer (Reichert). Each sample was assayed three times in triplicate. Percentage of dead cells (\% dead) were calculated and expressed as mean \pm standard deviation (SD). T-test statistical analyses were performed using GraphPad Prism 4 
(version 4.03) graphing and statistical software. A p-value $<0.05$ was considered statistically significant.

\section{Analysis of B Cell Apoptosis}

Apoptosis was analyzed by agarose gel electrophoresis and Western blot using antibodies to common apoptotic markers. Agarose gel analysis was performed as indicated by Kasibhatla et al. [306], with some modifications. In short, $2.5 \times 10^{5}$ cells were cocultured with UL-124 exosomes as previously mentioned. Cells were collected, supernatant removed, and cells lysed using TES (Tris, EDTA, SDS) buffer with added RNase cocktail (Ambion) and incubated at $37^{\circ} \mathrm{C}$ for $1 \mathrm{~h}$. Proteinase $\mathrm{K}$ (Qiagen) was added and cells incubated at $50^{\circ} \mathrm{C}$ for $1 \mathrm{~h}$, followed by a 5 minute incubation at $65^{\circ} \mathrm{C}$. Samples were mixed with 5X Loading Dye (Qiagen) and loaded onto a 1.2\% agarose FlashGel DNA Cassette (12 +1, Lonza) with the Flash Gel DNA marker (100-4000 bp, Lonza). Marker and samples were electrophoresed on the FlashGel system (Lonza) at 237 V. Images were captured using the FlashGel camera and capture software. For Western blot analysis: $10 \mu \mathrm{g}$ coculture cell protein was loaded onto a 4-20\% Criterion TGX Precast Gel (Bio Rad), electrophoresed and transferred using Trans Blot Turbo Transfer System and transfer pack (0.2 $\mu \mathrm{m}$ nitrocellulose, Bio Rad). Membranes were blocked with $5 \%$ nonfat dry milk and probed with PARP, caspase-3 (Cell Signaling,1:1000), and $\beta$-actin (Jackson ImmunoResearch, 1:5000) commercial antibodies. To analyze potential mechanisms of apoptosis by TDE, in vivo-derived (UL472, 309, 316, 224) and in vitro-derived (UL-124, UL-OY) exosomes were isolated (as mentioned previously) and solubilized in reducing buffer $(62.5 \mathrm{mM}$ Tris- $\mathrm{HCl} \mathrm{pH} 6.8,25 \%$ glycerol, $2 \%$ SDS, $0.01 \%$ bromophenol blue, $5 \% \beta$-mercaptoethanol) and boiled for 5 minutes. $20 \mu \mathrm{g}$ of in vivo exosome protein and $45-60 \mu \mathrm{g}$ of in vitro exosome protein was loaded onto a 12.5\% and 4-15\% (Mini-PROTEAN TGX Precast, Bio Rad) gel, 
respectively, and transferred at $98 \mathrm{~V}$ (on ice) for $1 \mathrm{~h}$. Membranes were blocked and probed with anti-CD40L (for in vivo sample) and anti-FasL ( for in vitro sample), both 1:1000 (Santa Cruz Biotechnology).

\section{Analysis of Coculture Supernatant using an Antibody Array}

To investigate the effects of TDE on B cell cytokine and chemokine profiles, the relative levels of coculture proteins including cytokines and chemokines in the supernatant was analyzed by ProteomeProfiler ${ }^{\mathrm{TM}}$ Human Cytokine Array Panel A (R\&D Systems) according to the manufacturer's instructions. In short, coculture supernatant was incubated with array assay buffer and detection antibody, then added to blocked array membranes to incubate overnight at $4^{\circ} \mathrm{C}$. Membranes were washed with assay wash buffer $(1 \mathrm{X})$ and incubated at room temperature for 30 minutes with horseradish peroxidase conjugated-streptavidin (1:2000). Membranes were washed and revealed using the array chemiluminescent peroxidase substrate reagent 1 and $2(1: 1)$. Results were scanned and quantitated using UN-Scan-IT gel and graph digitizing software version 6.1 (Silk Scientific). Positive controls at three spots were used to normalize the results and to orient the membranes. For each spot, the net pixel value was determined by subtracting the background pixel value from the raw pixel values. The average of the reference spots (positive controls) was obtained and multiplied by the net pixel value to normalize the values. To calculate the fold change in cytokine levels between samples, the normalized treated value was divided by the normalized control value corresponding to that particular spot. Differences in cytokine levels \pm 2 fold (compared to corresponding controls) were considered significant.

\section{$\underline{\text { Results }}$}

\section{Coculture of UL-124 Patient-Derived Exosomes with Ramos B cells}

Since this study investigates the role that TDE play in mediating the humoral response, it was essential to analyze any direct effects that TDE have on B cells and to 
see if exosome dosage and length of exposure modified the outcomes. To do so, Ramos cells were cocultured with exosomes at different doses $(10,20,50$, and $100 \mu \mathrm{g} / \mathrm{mL})$ for 3, 6, 18, and 24h. Post coculture, cells were collected and a fraction saved for hemocytometer counts using trypan blue to ascertain viability. Counts revealed decreases in cell viability with increasing dosages of exosomes and longer lengths of exposure (Fig. 10). To distinguish whether these exosome-mediated mechanisms of cell death were a result of apoptosis or necrosis, Western blot with several apoptotic markers was utilized along with analysis of DNA fragmentation using agarose gels. Presence of uncleaved PARP was seen at all time points with enhanced presence at $6 \mathrm{~h}$ followed by subsequent increases at the latter time points (Fig. 11). Cleaved PARP (indicative of apoptosis) is evident at $6 \mathrm{~h}$ with enhanced presence in the latter time points, particularly in the samples cocultured with the highest dosage of exosomes (T6, T18, T24--Fig. 11A). Additionally, the greatest amount of cleaved PARP is seen at 18h, which suggests that this time point may be critical in the apoptotic response for the $B$ cell. Furthermore, the seemingly absent $\beta$-actin at 18 and $24 \mathrm{~h}$ at the highest dosage suggests death of these cells, with death resulting from apoptosis since cleaved PARP presence is strong at these points. Uncleaved caspase-3, also known as procaspase-3, follows a similar pattern as uncleaved PARP-- present in all samples and enhanced at the latter time points (Fig. 12). Reduction in uncleaved caspase-3 is seen at 18 and $24 \mathrm{~h}$ with the highest dosage of exosomes. Cleavage of caspase-3 (which indicates apoptosis) is not evident for either subunit in 3 and $6 \mathrm{~h}$, but is seen at the $18,24 \mathrm{~h}$ time points, with both subunits present in several of the titrations $(10,20,50 \mu \mathrm{g} / \mathrm{mL})$. Neither cleaved subunit is evident in the $100 \mu \mathrm{g} / \mathrm{mL}$ dose at these time points. To further differentiate apoptosis from necrosis, DNA was extracted from cocultured cells, combined with RNase and proteinase $\mathrm{K}$ (to eliminate RNA/protein to ensure presence of 
genomic DNA) and electrophoresed on an agarose gel to detect fragmentation, which indicates apoptosis (Fig. 13). Ramos cells cultured for 3, 6,18, 24h without exosomes do not exhibit DNA fragmentation. In the case of Ramos cells cocultured with exosomes for 3 and $6 \mathrm{~h}$, apoptosis is seen with the highest concentration of exosomes, with diminishing effects as the exosome titration decreases. However, in the 18 and $24 \mathrm{~h}$ exosome cocultures, apoptosis is strongly detected at both 100 and $50 \mu \mathrm{g} / \mathrm{mL}$, with diminishing effects in the lower doses.

To address potential mechanisms of apoptotic induction in B cells by TDE, culture (UL124, UL-OY) and ascites-derived exosomes were isolated, solubilized, and subjected to electrophoresis and subsequent Western blot, utilizing FasL (for culturederived) and CD40L (for ascites-derived) detection antibodies (Fig. 14). Of the two culture-derived samples, UL-124 indicated presence of both membrane and soluble FasL in all amounts, with greater expression of the membrane isoform in the higher quantities of protein. Expression of CD40L was seen in all ascites-derived exosomes analyzed. The presence of these molecules suggest potential mechanisms for exosome communication with B cells, and subsequent induction of apoptosis

\section{Coculture with TDE Enhances Particular Molecules}

To further evaluate the direct effects of TDE on B cells, 24h coculture supernatant (T24) and the corresponding control (C24) was analyzed for comparative expression of various molecules using a human cytokine array (Fig. 15). The expression of several molecules appeared to be enhanced in the exosome-treated sample, with three (soluble intercellular adhesion molecule (sICAM-1), IL-16, and plasminogen activator inhibitor-1 (PAI-1)) exhibiting a greater than 2 -fold difference in comparison to the corresponding control. 


\section{Discussion}

As a collaborator in the effector immune response, mature B cells employ a number of tactics in recognizing and destroying microorganisms. They can produce antibodies, express various molecules (e.g. costimulatory molecules [307], toll-like receptors (TLRs) [308, 309]) to enhance the promotion of antibody function [310], act as antigen presenting cells [311], produce inflammatory cytokines and reactive oxygen intermediates [312], and release exosomes which display exosomal proteins and B cell surface antigens [313] which are believed to enhance cognate interaction with $\mathrm{CD} 4^{+} \mathrm{T}$ and subsequent B cell activation and exosome production [314]. Although the specific function of B cell exosomes has yet to be fully elucidated, the roles of tumor-derived exosomes/microvesicles in intercellular communication are rapidly emerging. One such role is the induction of apoptosis of effector cells to facilitate immune escape and mediate tumor progression. Human colorectal cells were reported to release microvesicles containing FasL and TRAIL which induced apoptosis in activated CD8 ${ }^{+} T$ [111]. In a study investigating the role of immunosuppression in glioblastoma patients, glioblastoma-derived exosomes were found to induce apoptosis in T cells via the Fas signaling pathway [315]. Correspondingly, tumor-derived microvesicles isolated from the sera of melanoma and head and neck squamous cell carcinoma patients promoted the expansion of regulatory $T$ cells by inducing apoptosis of $C D 8^{+} T$ cells [316]. This investigation seeks to gain a clearer understanding of the role of TDE in the ovarian cancer humoral response, by analyzing the effects of TDE on the B cell. Because our TDE express CD40L, our initial hypothesis was that TDE could activate the B cell (possibly via CD40 ligation) thereby initiating the production of antibodies and potentially the induction of antibody class switch. A series of preliminary experiments post coculture of TDE with Ramos B cells revealed that activation of the B cells to produce antibodies 
may not be likely due to the undetected phosphorylation of molecules in the CD40L signaling pathway. However, upon extension of culture times $(3,6,18,24 \mathrm{~h})$ it became apparent through cell counts for viability and culture appearance post incubation that an effect was taking place. Cells cocultured with UL-124 TDE $(100 \mu \mathrm{g} / \mathrm{mL})$ displayed a shrunken morphology. Furthermore, RTPCR analysis (data not shown) revealed a reduction in gene expression in the TDE-treated cells in all housekeeping genes tested ( $\beta$-actin, glyceraldehyde 3-phosphate dehydrogenase (GAPDH), $\beta 2$-microglobulin, hypoxanthine-guanine phosphoribosyltransferase (HPRT)), which suggested a potential issue with toxicity. In order to distinguish whether these cellular alterations were the result of apoptosis or necrosis, several mechanisms were employed. First, cellular lysates from the cocultures were obtained, subjected to Western blot and probed with known apoptotic markers, caspase-3 and PARP. Apoptosis (programmed cell death) is the active, controlled intracellular disassembly by which the cell coordinates selfdestruction [317] without inducing inflammation or damage to neighboring cells [318]. In apoptosis, activation of initiator caspases (caspase-8 and 9) result in the activation of executioner caspases (e.g. caspase-3) which can result in cleavage of downstream substrates including poly-ADP Ribose polymerase (PARP) [317]. PARP, a DNA-binding enzyme, transfers poly ADP-ribose polymers to DNA strand breaks [319] to assist in DNA stability and repair [320]. In facilitation of apoptosis, cleaved caspase-3 can cleave the $116 \mathrm{kDa}$ PARP into 89 and 24 kDa fragments, thereby inhibiting the catalytic activity of PARP [321]. This inhibition results in lack of repair to DNA strand breaks and activation of endogenous $\mathrm{Ca}^{2+}$ and $\mathrm{Mg}^{2+}$ endonucleases that promote DNA degradation, producing DNA fragments $180-200$ base pairs in length [322]. In our study, treating B cells with ovarian cancer exosomes (in a dose-dependent manner) not only induced cleavage of PARP into the requisite fragments that renders it inactive, but also resulted 
in fragmentation of DNA, particularly with the higher concentrations of exosomes $(100 \mu \mathrm{g} / \mathrm{mL}$ at all time points and $50 \mu \mathrm{g} / \mathrm{mL}$ at the latter time points, 18 and $24 \mathrm{~h}$ ). Collectively, these data implicate ovarian TDE as an inducer of apoptosis in B cells. The induction of apoptosis in human immune effector cells by tumor-derived exosomes/microvesicles has been documented in several different cancers, each mediating the process in various ways. One of the common mechanisms of mediation is through the release of exosomes that contain apoptosis-induction signal molecules, such as FasL or TRAIL. Studies have implicated exosome/microvesicle associated FasL as the signal for apoptotic induction in activated T cells [323], in peripheral blood mononuclear cells [324], and CD8 ${ }^{+}$T cells [315, 325]. FasL is a tumor necrosis factor receptor (TNF-R) family cytokine [326] which can be synthesized in soluble or membrane-bound form, the latter shown to be more active than the soluble form in apoptotic induction of primary T cells [327, 328] and hepatocytes [329]. Mechanistically, FasL engages and induces trimerization of its cognate receptor, Fas [330], resulting in Fas activation and recruitment of adaptor proteins (i.e. Fas-associated death domainFADD) to its cytoplasmic death domain to form a death receptor-induced signaling complex (DISC) [331, 332]. Procaspase-8 is recruited into the DISC [333] and is proteolytically activated to caspase-8 which activates downstream effector caspases, like caspase-3 [334], resulting in cleavage of substrates including PARP and the inhibitor of caspase-activated DNase (ICAD) [335]. Cleavage of ICAD releases caspaseactivated DNase (CAD) which cleaves the chromosomal DNA which is responsible for the DNA fragmentation detected during apoptosis [336]. In analysis of our UL-124 culture-derived exosomes used throughout this study, the expression of both soluble and membrane-bound FasL suggests that these exosomes may be activating the Fas/FasL pathway in the induction of B cell apoptosis. A plausible yet equally important contributor to this exosome-mediated apoptotic induction of B cells is the CD40/CD40L 
pathway. CD40 is a TNF-R family member transmembrane receptor [337] that is trimerized and activated upon engagement by its cognate ligand, CD40L [338]. Under normal conditions in conjunction with signals from the engaged B cell receptor (BCR), CD40 ligation triggers B cell activation, characterized by increases in tyrosine kinase activity [339] and DNA synthesis [340], expression of costimulatory molecules [341] and transcription factors [342], and immunoglobulin class switch [343]. Correspondingly, the engagement of these receptors have been shown to induce Fas expression on the B cell surface, with greater amounts of Fas when both receptors were ligated [344]. In spite of the expression of fewer Fas molecules, murine B cells with ligated CD40 without BCR engagement are more sensitive to apoptosis [345, 346]. Likewise, apoptotic induction via upregulation of Fas by CD40 ligation has been corroborated in normal and malignant human B cells [347]. With this in mind, we propose that the exosome-associated FasL and CD40L ligate their respective receptors on the B cell to mediate apoptosis of the $\mathrm{B}$ cell as a mechanism of modulating the humoral immune response. Further analysis is needed to verify the contributions of CD40L and FasL in the mediation of B cell apoptosis. Additional investigation could include coincubation of blocking antibodies to CD40L and FasL with TDE or to their respective receptors with the B cells prior to coculture. Post coculture, analysis of apoptotic induction would implicate exosomeassociated CD40L as the activator of the B cell to upregulate Fas expression and exosome-associated FasL as the extrinsic mechanism that induces apoptosis.

To further investigate potential contributors to the TDE-mediated apoptosis of B cells, the supernatants from the $24 \mathrm{~h}$ control (C24) and treated (T24, highest concentration) cultures were analyzed for the presence of soluble mediators. Analyses revealed a greater than 2 -fold expression of three molecules (PAI-1, IL-16, sICAM-1) in the exosome- treated sample in comparison to the non-treated control. A closer investigation of the literature suggests that these molecules may contribute to immune 
escape of malignant cells, either through mechanisms that assist with evasion or promotion of apoptosis, or progression of the tumor. PAI-1 is a key inhibitor of plasminogen activators (serine proteases responsible for plasmin production which leads to fibrinolysis [348] and activation of matrix metalloproteinases and growth factors [349]). PAI-1 subsequently inhibits plasmin production, thereby preventing these responses and affecting cell migration [349]. The expression of PAl-1 has been shown to be elevated in different cancers [350,351], and its enhanced presence is linked to tumor cell survival [351-353]. In the promotion of apoptosis, PAI-1 binds to vitronectin (extracellular glycoprotein), which interferes with cellular adhesion by blocking cell receptors and integrins [354]. B cells display the vitronectin receptor $(\alpha \vee \beta 3)[355,356]$ which plays a role in mediating phagocytosis of cells that are undergoing apoptosis [357]. In consideration of the apoptotic induction of B cells by TDE, we propose that in the tumor microenvironment, $\mathrm{PAl}-1$ may allow the exosomes to interact with vitronectin in an attempt to block B cell interaction, which would induce apoptosis of the B cell because of its inability to adhere. Because the vitronectin receptor on the B cell surface would remain unbound, it would act as a signal to phagocytes to remove the B cells from the microenvironment. We believe that PAI-1 is also associated with the exosomes, which the tumor cell would release as a means of interacting with B cells and other effector cells. IL-16 is an immunomodulatory cytokine typically released at the site of inflammation [358] as a chemoattractant for eosinophils, monocytes, and T cells [359]. Synthesized in its precursor form (pro IL-16), this precursor is cleaved by caspase-3 to release the active form, IL-16 [358] which is secreted by epithelial, mesenchymal, and a number of immune cell types [360], including B cells [361]. In the context of cancer, documented levels of IL-16 are elevated in the serum of cancer patients [362] and correlate with the progression of disease [363]. Furthermore, enhancements in IL-16 expression have been associated with apoptotic activity. A study of human monocytes 
indicated that spontaneous activation of caspase-3, resulted in apoptosis and extracellular increases in IL-16 [360] In this study, greater than 2-fold expression of IL16 was seen in the TDE-treated sample in comparison to the control. We propose that as the TDE interact with the B cells through CD40L and FasL to activate apoptotic pathways, they activate caspase- 3 which is able to cleave pro IL-16 in the B cell, thereby allowing the release of IL-16 into the extracellular environment. This released IL-16 could be instrumental in recruiting a number of immune cells to facilitate apoptotic B cell clearance. ICAM-1 is a membrane glycoprotein expressed on a number of cells, including endothelial cells and B cells, that mediates cell-matrix and cell-cell interactions by binding with its ligand, leukocyte function-associated antigen-1 (LFA-1) [364]. ICAM1 also exists in soluble form, sICAM-1, a product of proteolytic cleavage of the membrane-bound version $[365,366]$. Correlation between heightened serum levels of sICAM-1 and tumor progression and/or poor prognosis is evidenced in various cancers. Increases in sICAM-1 in colorectal cancer [367] and melanoma [368] were found to be linked to tumor progression. In studies of human melanoma cell lines, sICAM-1 was found to obstruct the interactions between T cells and the tumor cells [369] and to block the tumor from the cytotoxic effects of NK cells [370]. Breast cancer patients were documented to have increased levels of SICAM-1 in their sera correlating with tumor progression and poor prognosis [371, 372]. In cancer patients, SICAM-1 is thought to derive from the cancer cells themselves or from some component of the tumor microenvironment [371, 373, 374]. Investigation of the efficacy of prostate cancer exosome-associated ICAM-1 revealed the presence of both membrane-bound and soluble forms, but the sICAM-1 was shown to be less effective in interacting with LFA-1 and in modulating the immune response [375]. In our studies, we propose that the increases in sICAM-1 in our TDE-treated samples indicate its association with the exosomes. Shedding of ICAM-1 by tumor cells has been proposed as an 
immunosuppressive mechanism that prevents interaction between the tumor cell target and the cytotoxic effector [376]. The ovarian tumor may preferentially release exosomes with sICAM-1 associated with them in an attempt to subvert interaction with cytotoxic effectors, thereby contributing to their survival and progression. 


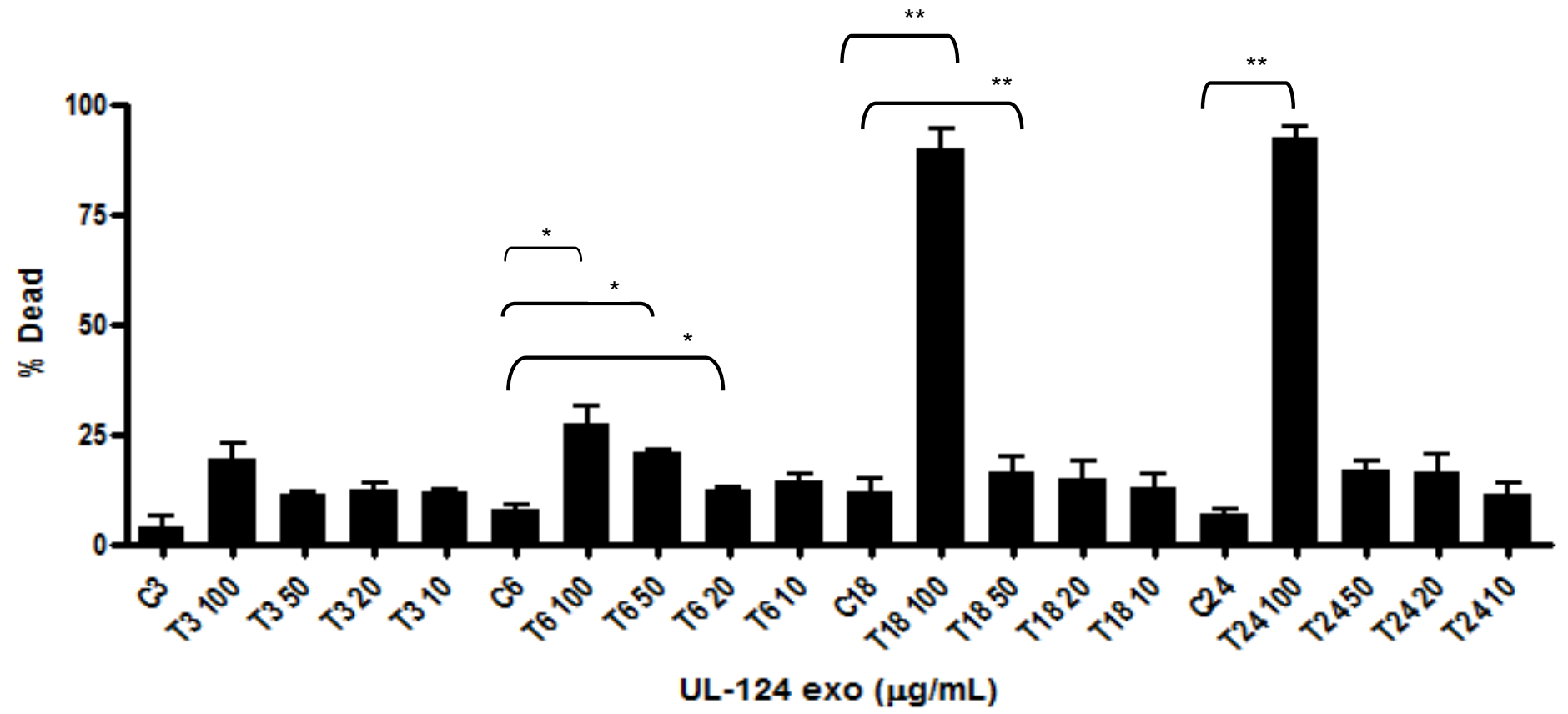

Figure 10: Percentage of cell death in Ramos cells cocultured with patient tumor-derived exosomes. The percentage of dead cells in culture as determined by trypan blue staining. Ramos B cells were cocultured with patient UL-124 exosomes for different lengths of time $(3,6,18,24 \mathrm{~h})$ and at different exosome doses $(10,20,50,100 \mu \mathrm{g} / \mathrm{mL}) . \mathrm{C}$ (control, untreated), $\mathrm{T}$ (treated with exosomes). The number following the letter indicates the time point $(\mathrm{h})$. The number following the time point indicates the exosome concentration $(\mu \mathrm{g} / \mathrm{mL})$. Asterisks indicate significance levels of t-test control comparisons with treated at the corresponding time point, ${ }^{*} p<0.05,{ }^{* *} p<0.01$. 

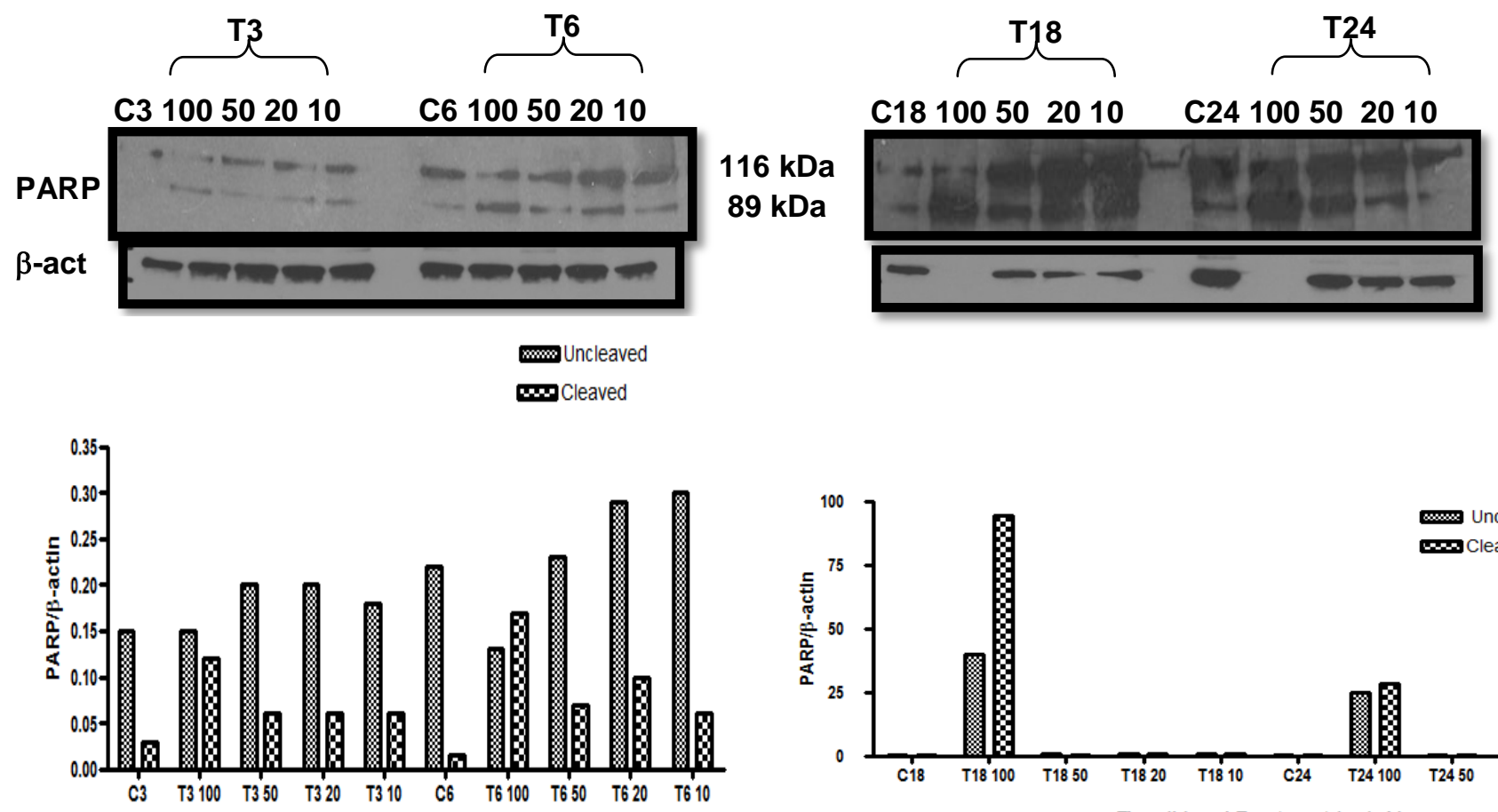

Time (h) and Treatment $(\mu \mathrm{g} / \mathrm{mL})$

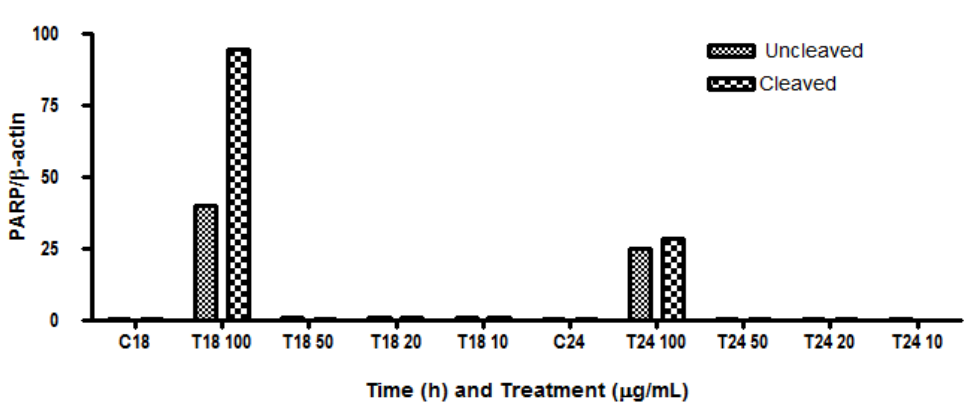

Figure 11: Coculture of patient tumor-derived exosomes enhance presence of apoptotic

marker, PARP. Western blot analysis of PARP and PARP cleavage in total cell lysates from 3, 6 , 18 and $24 \mathrm{~h}$ cocultures of Ramos cells with UL-124 OC exosomes (10-100 $\mu \mathrm{g} / \mathrm{mL})$. Densitometric quantification of the ratio of PARP (cleaved and uncleaved) to $\beta$-actin is shown. Data represents 3 indenendent experiments with similar results. 


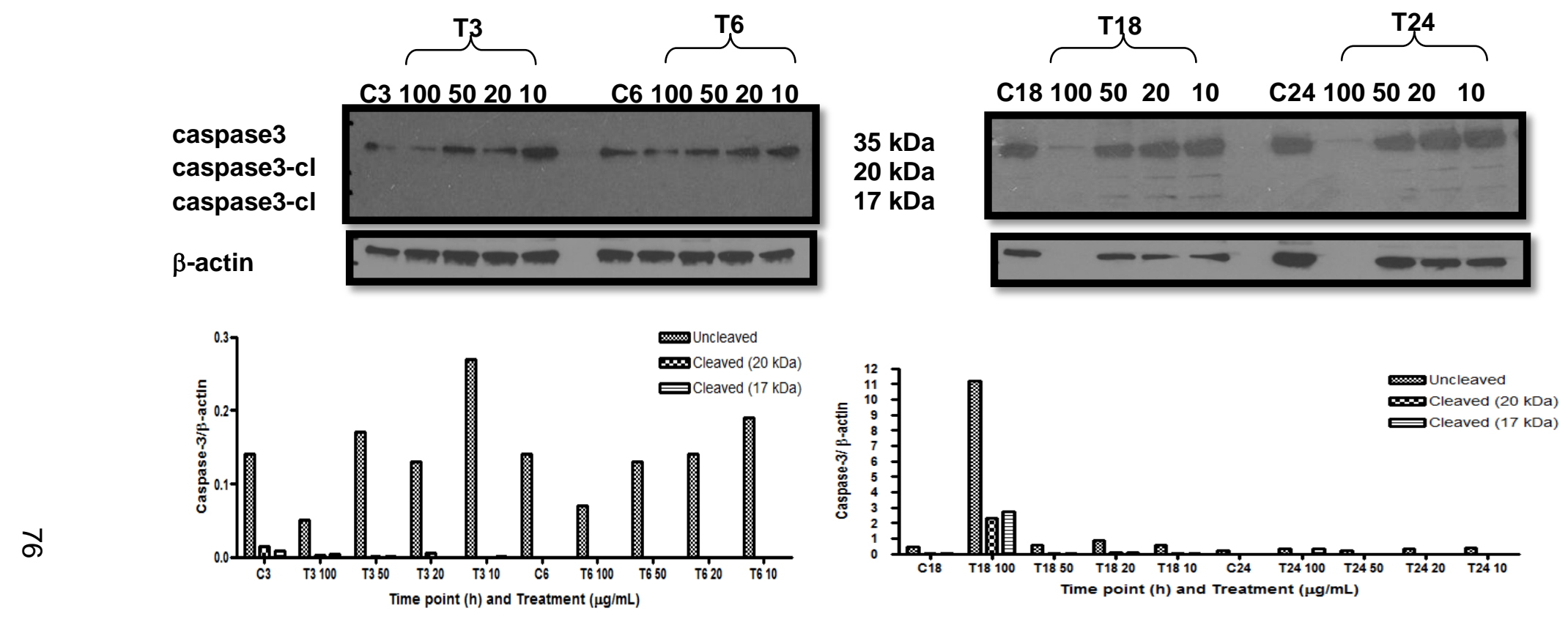

Figure 12: Coculture of patient tumor-derived exosomes enhance presence of apoptotic marker,

caspase-3. Western blot analysis of caspase-3 and caspase-3 cleavage in total cell lysates from 3, 6 , 18 and $24 \mathrm{~h}$ cocultures of Ramos cells with UL-124 OC exosomes (10-100 $\mu \mathrm{g} / \mathrm{mL})$. Densitometric quantification of the ratio of caspase-3 (cleaved isoforms and uncleaved) to $\beta$-actin is shown. Data represents 3 independent experiments with similar results. 

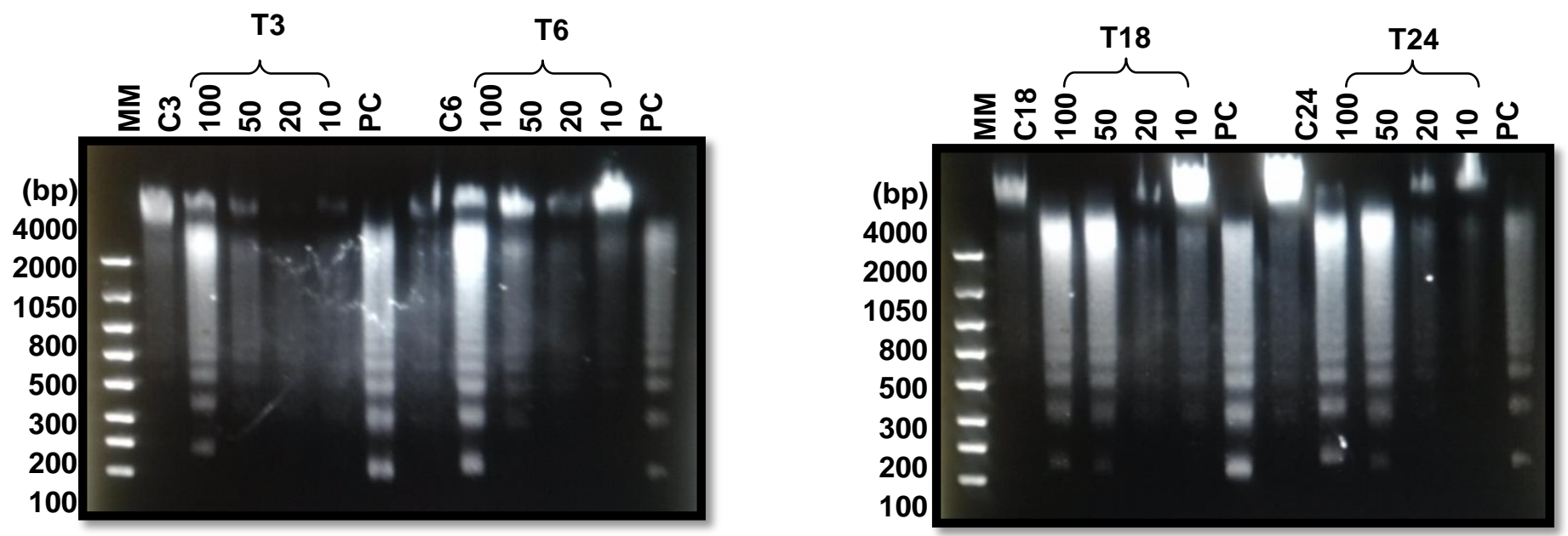

Figure 13: DNA fragmentation analysis of B cell apoptosis induced by coculture with TDE. Ramos B cells were

cocultured for $3,6,18$, and $24 \mathrm{~h}$ with tumor-derived exosomes at concentrations ranging from $10-100 \mu \mathrm{g} / \mathrm{mL}$. Apoptosis is not detected in control samples (C3, C6, C18, C24) while exosome-treated samples (T) undergo apoptosis to varying degrees.

The greatest fragmentation is seen with the higher concentrations of exosomes ( $T$ 100) with gradual decreases as exosome concentration decreases. $\mathrm{C}$ (control), $\mathrm{T}$ ( treated with exosomes). Number following $\mathrm{C}$ or $\mathrm{T}$ represents length of time for coculture $(3,6,18$, or $24 \mathrm{~h})$. Numbers $(10,20,50,100)$ represent concentration of exosomes added in $\mu \mathrm{g} / \mathrm{mL}$. PC represents the positive control (Ramos + cycloheximide $(5 \mathrm{ng} / \mathrm{mL}))$ cocultured for $24 \mathrm{~h}$. 
A.

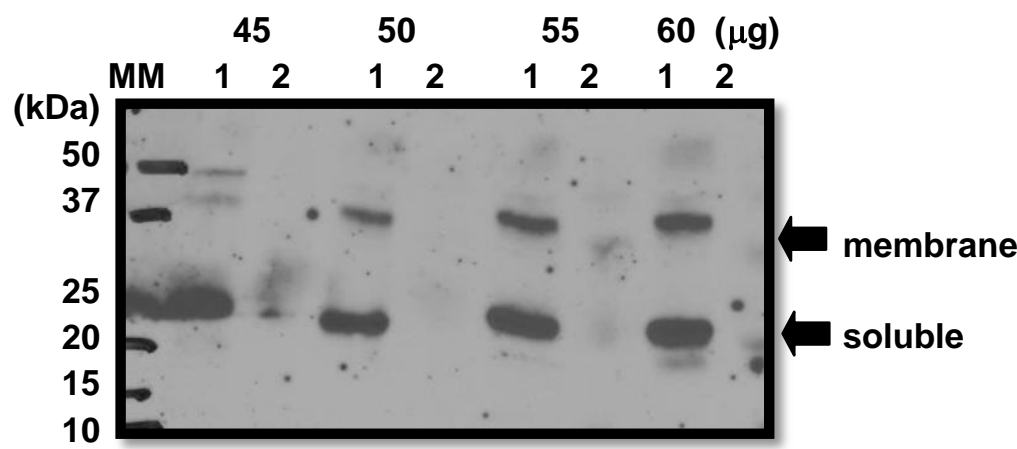

FasL
B.

In vivo-derived exosomes

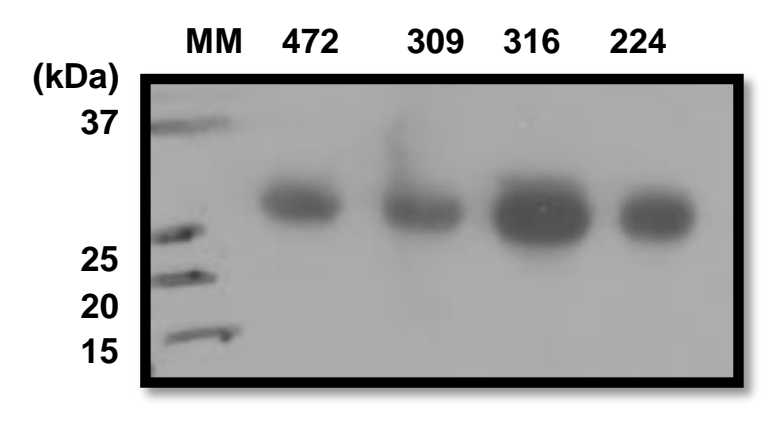

CD40L

Figure 14: Analysis of in vitro and in vivo derived-exosomes reveal presence of potential activators of B cell apoptosis.

A) Western blot of UL-124 (1) and UL-OY (2) culture-derived patient exosomes ( UL-124:1; UL-OY: 2) using varying amounts of exosomal protein $(45,50,55,60 \mu \mathrm{g} / \mathrm{lane})$ reveal presence of both soluble (26 kDa) and membrane-bound (40 kDa) forms of FasL in the UL-124 sample. B) Western blot of OC patient-derived ascites exosomes (UL-472, 309, 316, 224) reveal presence of CD40L. Both Fas L and CD40 L have been implicated in inducing B cell apoptosis. 


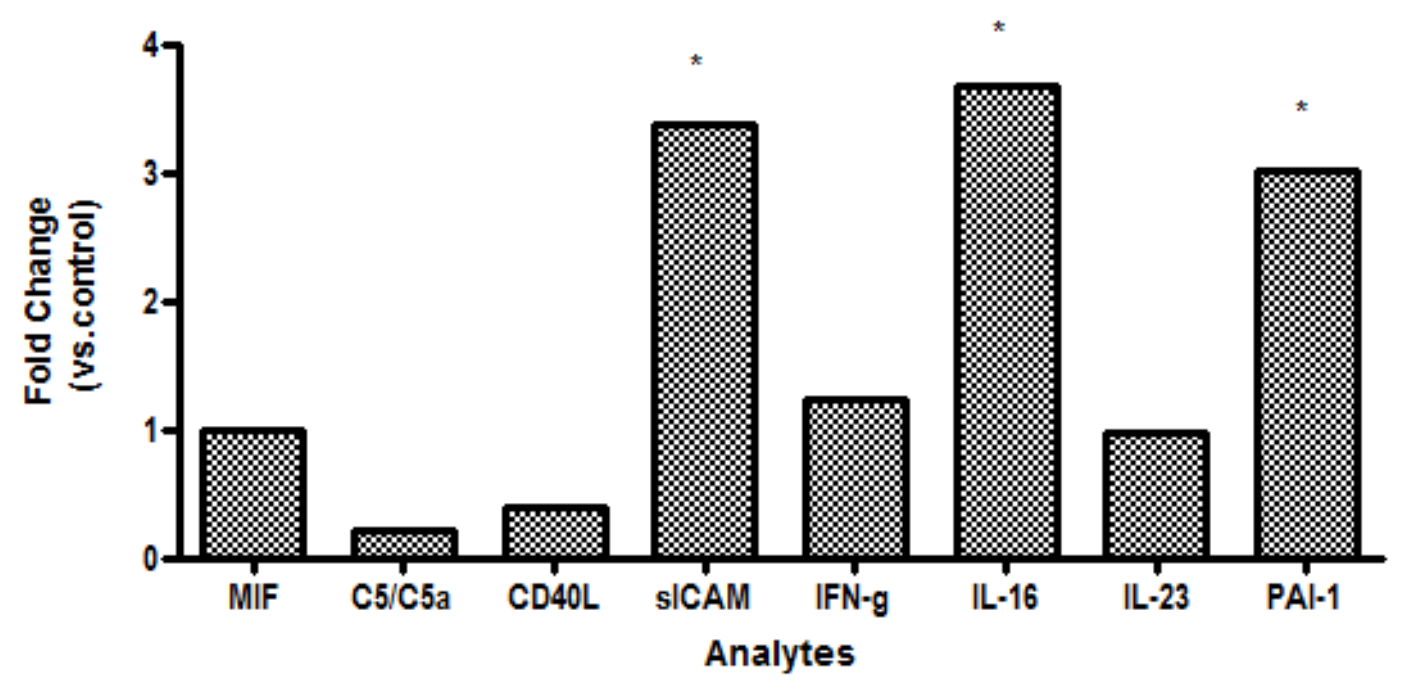

Figure 15: Molecule induction in Ramos B cells cocultured for $24 \mathrm{~h}$ with tumorderived exosomes. Analysis of coculture supernatant using a human antibody array revealed the increase of several molecules. Asterisks indicate changes $>2$ fold. 


\section{CHAPTER 5}

\section{CONCLUSION AND SIGNIFICANCE OF WORK}

In countless studies, tumor-derived exosomes (TDE) demonstrate their ability to orchestrate communication between the tumor cell and the microenvironment in order to facilitate antitumor and protumor responses. Previous investigations have analyzed TDE interactions with a number of immune cells including T cells, myeloid-derived suppressor cells, and dendritic cells, but little to no investigation is evident on the effects of TDE on B cells. This study began to explore the role that TDE may play in the efficacy of the humoral immune response by analyzing the exosome-associated humoral antitumor response and the impact of exosomes on humoral modulation through their interaction with B cells. In the ovarian cancer framework, humoral responses are evident by the presence of enhanced IgG in the circulation, yet the cancer continues on its aggressive course, all while presenting non-obvious symptoms. The presentation of symptoms that mimic other conditions and/or the lack of obvious symptoms contribute to the latent diagnosis of ovarian cancer.

Utilizing human ovarian cancer as the model cancer system, ovarian TDE were found to display some of the same antigenic proteins as their parent cells, and bound immunoreactive $\lg G$, primarily of the $\lg \mathrm{G} 1$ and $\lg G 2$ subclasses. These findings indicate that TDE may express immunogenic antigen as a mechanism to divert the humoral antitumor response away from the tumor and towards itself. In the diversion of the response, IgG1, which is one of the complement-fixing, opsonizing antibodies important in Th1 antitumor responses, binds to the antigen and sets the stage for mediating the 
antitumor response. Additionally, lgG2 antibodies are produced and also bind to the antigen on the exosome, which is believed to block the opsonization, phagocytosis, and antibody-dependent cell cytotoxicity (ADCC) of the IgG1 [281]. Therefore, the presence of IgG2 may counteract the immune response against the exosome-associated antigen, resulting in a decreased antitumor response, which would further benefit the ovarian cancer cell by allowing it to progress. Additionally, ovarian TDE were found to induce B cell apoptosis and promote increases in PAI-1, IL-16, and SICAM-1 to assist in promoting the survival of the ovarian tumor. Overall, this study indicates that ovarian TDE are able to modulate the humoral immune response at the anti- and protumorigenic levels through direct effects on the exosomes, and the effects of the exosomes on the B cells (Fig 16).

Taking all of these factors into consideration, the hyperexpressed but seemingly ineffective IgG in the ovarian cancer patient sera may be a direct result of this battle between protumorigenic and antitumorogenic responses mediated by ovarian TDE. Further biochemical analysis of this exosome-associated IgG may provide additional insight on potential structural modifications induced which could further interfere with the ability of IgG to adequately mediate an immune response. Much remains to be defined and elucidated regarding the mechanisms of the host immune response to ovarian cancer. However, this study does provide perspective on a different facet of the immune response which has previously been unexplored. Further consideration of the humoral immune response component of ovarian cancer may shed some light on this enigmatic disease and contribute an additional strategy to be utilized in the fight against ovarian cancer. 


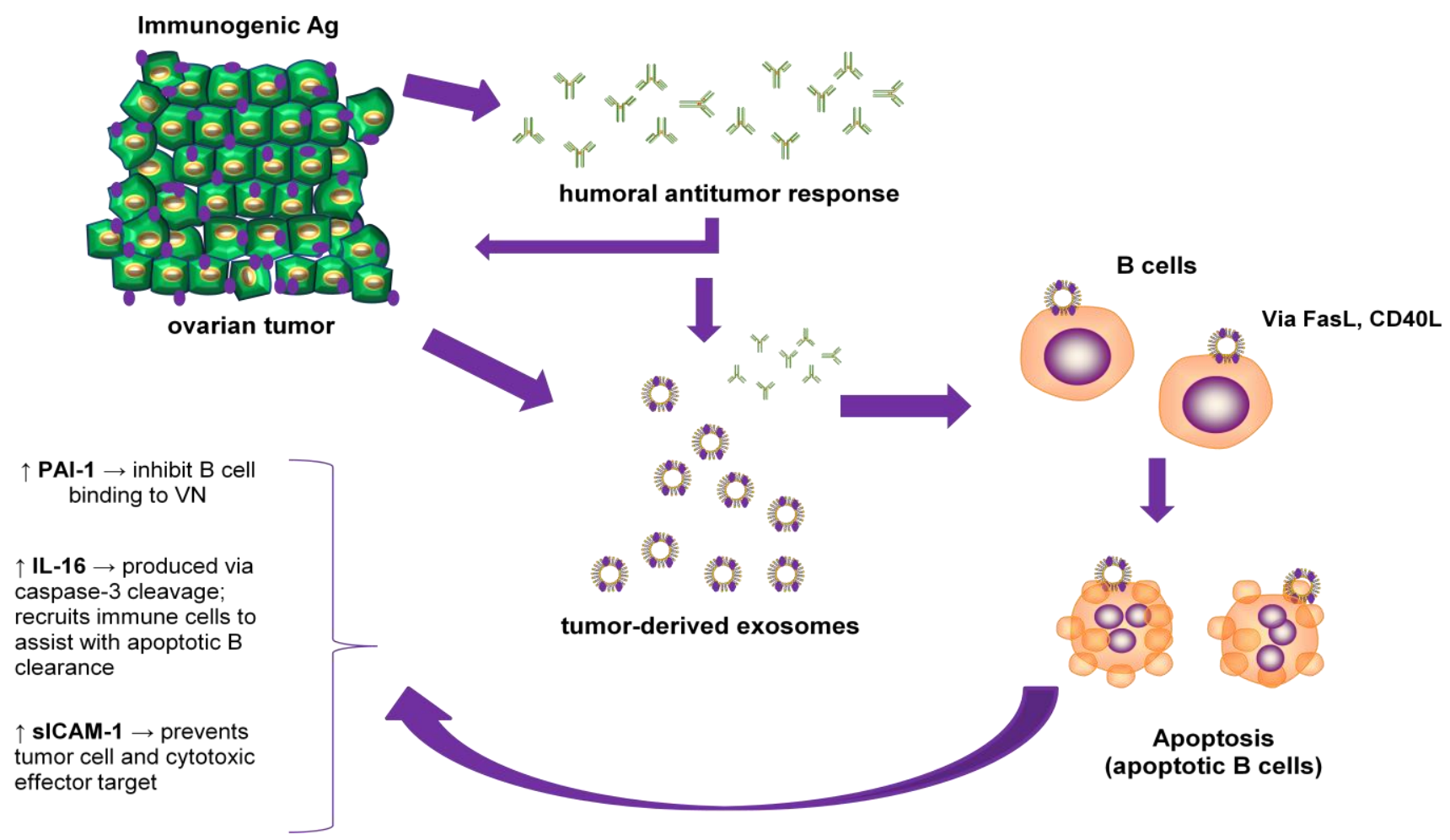

Figure 16: Proposed mechanism of TDE modulation in the ovarian cancer humoral response. Immunogenic antigen expressed by the ovarian tumor induces a humoral antitumor response, resulting in the production of immunoreactive antibodies. The ovarian tumor releases TDE which may also express immunogenic antigen, thereby allowing the secreted antitumor antibodies to bind to both the tumor and the TDE. Intercommunication between TDE and B cells through Fas and CD40 ligation may induce B cell apoptosis in an effort to reduce production of more 
antitumor antibodies. In the interaction between B cells and TDE, relative expression of plasminogen activator

inhibitor-1 (PAI-1), IL-16, and soluble intercellular adhesion molecule-1 (sICAM-1) is enhanced to potentially contribute to immune escape of the ovarian tumor. 


\section{REFERENCES}

1. Sankaranarayanan, R. and J. Ferlay, Worldwide burden of gynaecological cancer: the size of the problem. Best Pract Res Clin Obstet Gynaecol, 2006. 20(2): p. 207-25.

2. Jemal, A., et al., Cancer statistics, 2007. CA Cancer J Clin, 2007. 57(1): p. 43-66.

3. Chambers, S.K. and J.D. Martinez, The significance of p53 isoform expression in serous ovarian cancer. Future Oncol, 2012. 8(6): p. 683-6.

4. Siegel, R., et al., Cancer statistics, 2014. CA Cancer J Clin, 2014. 64(1): p. 9-29.

5. Cancer Facts and Figures, 2014, in American Cancer Society, A.C. Society, Editor. 2014: Atlanta.

6. Auersperg, N., et al., Ovarian surface epithelium: biology, endocrinology, and pathology. Endocr Rev, 2001. 22(2): p. 255-88.

7. Fathalla, M.F., Incessant ovulation--a factor in ovarian neoplasia? Lancet, 1971. 2(7716): p. 163.

8. Casagrande, J.T., et al., "Incessant ovulation" and ovarian cancer. Lancet, 1979. 2(8135): p. 170-3.

9. Jelovac, D. and D.K. Armstrong, Recent progress in the diagnosis and treatment of ovarian cancer. CA Cancer J Clin, 2011. 61(3): p. 183-203.

10. Titus-Ernstoff, L., et al., Menstrual and reproductive factors in relation to ovarian cancer risk. Br J Cancer, 2001. 84(5): p. 714-21.

11. Hinkula, M., et al., Incidence of ovarian cancer of grand multiparous women--a population-based study in Finland. Gynecol Oncol, 2006. 103(1): p. 207-11.

12. Booth, M., V. Beral, and P. Smith, Risk factors for ovarian cancer: a case-control study. Br J Cancer, 1989. 60(4): p. 592-8.

13. Choi, J.H., et al., Gonadotropins and ovarian cancer. Endocr Rev, 2007. 28(4): p. 440-61.

14. Risch, H.A., Hormonal etiology of epithelial ovarian cancer, with a hypothesis concerning the role of androgens and progesterone. J Natl Cancer Inst, 1998. 90(23): p. 1774-86.

15. Ness, R.B. and C. Cottreau, Possible role of ovarian epithelial inflammation in ovarian cancer. J Natl Cancer Inst, 1999. 91(17): p. 1459-67.

16. McNatty, K.P., et al., The microenvironment of the human antral follicle: interrelationships among the steroid levels in antral fluid, the population of granulosa cells, and the status of the oocyte in vivo and in vitro. $\mathrm{J}$ Clin Endocrinol Metab, 1979. 49(6): p. 851-60.

17. Edmondson, R.J., J.M. Monaghan, and B.R. Davies, The human ovarian surface epithelium is an androgen responsive tissue. Br J Cancer, 2002. 86(6): p. 87985.

18. Schildkraut, J.M., et al., Epithelial ovarian cancer risk among women with polycystic ovary syndrome. Obstet Gynecol, 1996. 88(4 Pt 1): p. 554-9.

19. Auersperg, N., et al., The biology of ovarian cancer. Semin Oncol, 1998. 25(3): p. 281-304. 
20. Subbaramaiah, K., et al., Inhibition of cyclooxygenase: a novel approach to cancer prevention. Proc Soc Exp Biol Med, 1997. 216(2): p. 201-10.

21. Aitokallio-Tallberg, A.M., L.U. Viinikka, and R.O. Ylikorkala, Increased synthesis of prostacyclin and thromboxane in human ovarian malignancy. Cancer Res, 1988. 48(9): p. 2396-8.

22. Auersperg, N., S.L. Maines-Bandiera, and H.G. Dyck, Ovarian carcinogenesis and the biology of ovarian surface epithelium. J Cell Physiol, 1997. 173(2): p. 261-5.

23. Brinton, L.A., \& Schiffman, M., Epidemiology of Gynecologic Cancers, in Principles and Practice of Gynecologic Oncology, R.R. Barakat, Markman, M., \& Randall, M.E., Editor. 2009, Lippincott Williams \& Wilkins: Philadelphia, PA. p. 329.

24. Pharoah, P.D. and B.A. Ponder, The genetics of ovarian cancer. Best Pract Res Clin Obstet Gynaecol, 2002. 16(4): p. 449-68.

25. Venkitaraman, A.R., Cancer susceptibility and the functions of BRCA1 and BRCA2. Cell, 2002. 108(2): p. 171-82.

26. Ford, D., et al., Risks of cancer in BRCA1-mutation carriers. Breast Cancer Linkage Consortium. Lancet, 1994. 343(8899): p. 692-5.

27. Easton, D.F., D. Ford, and D.T. Bishop, Breast and ovarian cancer incidence in BRCA1-mutation carriers. Breast Cancer Linkage Consortium. Am J Hum Genet, 1995. 56(1): p. 265-71.

28. Kobel, M., et al., Ovarian carcinoma subtypes are different diseases: implications for biomarker studies. PLoS Med, 2008. 5(12): p. e232.

29. Bowtell, D.D., The genesis and evolution of high-grade serous ovarian cancer. Nat Rev Cancer, 2010. 10(11): p. 803-8.

30. Faca, V.M., et al., Proteomic analysis of ovarian cancer cells reveals dynamic processes of protein secretion and shedding of extra-cellular domains. PLoS One, 2008. 3(6): p. e2425.

31. Kaku, T., et al., Histological classification of ovarian cancer. Med Electron Microsc, 2003. 36(1): p. 9-17.

32. Narod, S.A. and J. Boyd, Current understanding of the epidemiology and clinical implications of BRCA1 and BRCA2 mutations for ovarian cancer. Curr Opin Obstet Gynecol, 2002. 14(1): p. 19-26.

33. Shih le, M. and R.J. Kurman, Ovarian tumorigenesis: a proposed model based on morphological and molecular genetic analysis. Am J Pathol, 2004. 164(5): p. 1511-8.

34. Gilks, C.B., et al., Tumor cell type can be reproducibly diagnosed and is of independent prognostic significance in patients with maximally debulked ovarian carcinoma. Hum Pathol, 2008. 39(8): p. 1239-51.

35. Gilks, C.B., Subclassification of ovarian surface epithelial tumors based on correlation of histologic and molecular pathologic data. Int J Gynecol Pathol, 2004. 23(3): p. 200-5.

36. Wolfman, D.J., Ascher, S.M., Hricak, H., Cooper, C., \& Scoutt, L., Diagnostic Imaging Techniques in Gynecologic Oncology, in Principles and Practice of Gynecologic Oncology, R.R. Barakat, Markman, M., \& Randall, M.E., Editor. 2009, Lippincott Williams \& Wilkins: Philadelphia, PA. p. 197-230.

37. Society, A.C., Ovarian Cancer. 2013, American Cancer Society: Atlanta, GA.

38. Sormunen, C., Terminology for Health Professionals. 6th ed. 2010, Clifton Park, NY: Delmar Cengage Learning. 
39. Staging Classifications and Clinical Practice Guidelines for Gynaecological Cancers. A collaboration between FIGO and IGCS. 3rd ed. 2006, London: FIGO.

40. Bosze, P., Prognostic factors and staging: the role of molecular markers. CME J Gynecol Oncol, 2001. 6: p. 232-234.

41. Ovarian Cancer. 2013, American Cancer Society: Atlanta. p. 1-62.

42. Chen, L.-M., Berek, J.S. , Patient Information: Ovarian Cancer Diagnosis and Staging (Beyond the Basics), in UptoDate, S. Falk, Editor. 2014: Waltham, MA.

43. Prat, J. and F.C.o.G. Oncology, Staging classification for cancer of the ovary, fallopian tube, and peritoneum. Int J Gynaecol Obstet, 2014. 124(1): p. 1-5.

44. Bast, R.C., Jr., B. Hennessy, and G.B. Mills, The biology of ovarian cancer: new opportunities for translation. Nat Rev Cancer, 2009. 9(6): p. 415-28.

45. Naora, H. and D.J. Montell, Ovarian cancer metastasis: integrating insights from disparate model organisms. Nat Rev Cancer, 2005. 5(5): p. 355-66.

46. Feldman, G.B. and R.C. Knapp, Lymphatic drainage of the peritoneal cavity and its significance in ovarian cancer. Am J Obstet Gynecol, 1974. 119(7): p. 991-4.

47. Feldman, G.B., et al., The role of lymphatic obstruction in the formation of ascites in a murine ovarian carcinoma. Cancer Res, 1972. 32(8): p. 1663-6.

48. Woopen, $\mathrm{H}$. and J. Sehouli, Current and future options in the treatment of malignant ascites in ovarian cancer. Anticancer Res, 2009. 29(8): p. 3353-9.

49. Landen, C.N., Jr., M.J. Birrer, and A.K. Sood, Early events in the pathogenesis of epithelial ovarian cancer. J Clin Oncol, 2008. 26(6): p. 995-1005.

50. Rauh-Hain, J.A., et al., Ovarian cancer screening and early detection in the general population. Rev Obstet Gynecol, 2011. 4(1): p. 15-21.

51. Luborsky, J.L., et al., Anti-tumor antibodies in ovarian cancer. Am J Reprod Immunol, 2005. 54(2): p. 55-62.

52. Goff, B.A., et al., Ovarian carcinoma diagnosis. Cancer, 2000. 89(10): p. 206875.

53. Berkenblit, A. and S.A. Cannistra, Advances in the management of epithelial ovarian cancer. J Reprod Med, 2005. 50(6): p. 426-38.

54. Bast, R.C., Jr., et al., A radioimmunoassay using a monoclonal antibody to monitor the course of epithelial ovarian cancer. N Engl J Med, 1983. 309(15): p. 883-7.

55. Jacobs, I. and R.C. Bast, Jr., The CA 125 tumour-associated antigen: a review of the literature. Hum Reprod, 1989. 4(1): p. 1-12.

56. Woolas, R.P., et al., Elevation of multiple serum markers in patients with stage I ovarian cancer. J Natl Cancer Inst, 1993. 85(21): p. 1748-51.

57. Fritsche, H.A. and R.C. Bast, CA 125 in ovarian cancer: advances and controversy. Clin Chem, 1998. 44(7): p. 1379-80.

58. Mol, B.W., et al., Distinguishing the benign and malignant adnexal mass: an external validation of prognostic models. Gynecol Oncol, 2001. 80(2): p. 162-7.

59. Swartz, M.A., et al., Tumor microenvironment complexity: emerging roles in cancer therapy. Cancer Res, 2012. 72(10): p. 2473-80.

60. Wilkie, K.P. and P. Hahnfeldt, Modeling the Dichotomy of the Immune Response to Cancer: Cytotoxic Effects and Tumor-Promoting Inflammation. arXiv preprint arXiv:1305.3634, 2013.

61. Schreiber, R.D., L.J. Old, and M.J. Smyth, Cancer immunoediting: integrating immunity's roles in cancer suppression and promotion. Science, 2011. 331(6024): p. 1565-70.

62. Kim, R., M. Emi, and K. Tanabe, Cancer immunoediting from immune surveillance to immune escape. Immunology, 2007. 121(1): p. 1-14. 
63. Matzinger, P., Tolerance, danger, and the extended family. Annu Rev Immunol, 1994. 12: p. 991-1045.

64. Smyth, M.J., D.I. Godfrey, and J.A. Trapani, $A$ fresh look at tumor immunosurveillance and immunotherapy. Nat Immunol, 2001. 2(4): p. 293-9.

65. Sinha, P., et al., Tumor immunity: a balancing act between $T$ cell activation, macrophage activation and tumor-induced immune suppression. Cancer Immunol Immunother, 2005. 54(11): p. 1137-42.

66. Shankaran, V., et al., IFNgamma and lymphocytes prevent primary tumour development and shape tumour immunogenicity. Nature, 2001. 410(6832): p. 1107-11.

67. Suckow, M.A., Cancer vaccines: harnessing the potential of anti-tumor immunity. Vet J, 2013. 198(1): p. 28-33.

68. Pillai, S., H. Mattoo, and A. Cariappa, B cells and autoimmunity. Curr Opin Immunol, 2011. 23(6): p. 721-31.

69. Scott, A.M., J.D. Wolchok, and L.J. Old, Antibody therapy of cancer. Nat Rev Cancer, 2012. 12(4): p. 278-87.

70. Graziano, D.F. and O.J. Finn, Tumor antigens and tumor antigen discovery. Cancer Treat Res, 2005. 123: p. 89-111.

71. Fonseca, C. and G. Dranoff, Capitalizing on the immunogenicity of dying tumor cells. Clin Cancer Res, 2008. 14(6): p. 1603-8.

72. Finn, O.J., Cancer immunology. N Engl J Med, 2008. 358(25): p. 2704-15.

73. Reuschenbach, M., M. von Knebel Doeberitz, and N. Wentzensen, A systematic review of humoral immune responses against tumor antigens. Cancer Immunol Immunother, 2009. 58(10): p. 1535-44.

74. von Mensdorff-Pouilly, S., et al., Human MUC1 mucin: a multifaceted glycoprotein. Int J Biol Markers, 2000. 15(4): p. 343-56.

75. Mattioni, M., et al., Serum anti-p53 antibodies as a useful marker for prognosis of gastric carcinoma. Int J Biol Markers, 2007. 22(4): p. 302-6.

76. Goodell, V., et al., Antibody immunity to the p53 oncogenic protein is a prognostic indicator in ovarian cancer. J Clin Oncol, 2006. 24(5): p. 762-8.

77. Fossa, A., et al., NY-ESO-1 protein expression and humoral immune responses in prostate cancer. Prostate, 2004. 59(4): p. 440-7.

78. Volkmann, M., et al., Anti-p53 in breast cancer: concordance of different assay procedures and association with p53 antigen expression. Oncology, 2002. 63(3): p. 297-305.

79. Tang, R., et al., Humoral response to $p 53$ in human colorectal tumors: a prospective study of 1,209 patients. Int J Cancer, 2001. 94(6): p. 859-63.

80. Ran, Y., et al., Profiling tumor-associated autoantibodies for the detection of colon cancer. Clin Cancer Res, 2008. 14(9): p. 2696-700.

81. Mayerhofer, K., et al., P53 antibody response in patients with vulvar cancer. Anticancer Res, 1999. 19(3B): p. 2323-6.

82. Mayerhofer, K., et al., Humoral p53 antibody response is a prognostic parameter in ovarian cancer. Anticancer Res, 1999. 19(1B): p. 875-8.

83. Abendstein, B., et al., Clinical significance of serum and ascitic p53 autoantibodies in epithelial ovarian carcinoma. Cancer, 2000. 88(6): p. 1432-7.

84. Kocer, B., J. McKolanis, and A. Soran, Humoral immune response to MUC5AC in patients with colorectal polyps and colorectal carcinoma. BMC Gastroenterol, 2006. 6: p. 4.

85. Dunn, G.P., L.J. Old, and R.D. Schreiber, The immunobiology of cancer immunosurveillance and immunoediting. Immunity, 2004. 21(2): p. 137-48. 
86. Dunn, G.P., C.M. Koebel, and R.D. Schreiber, Interferons, immunity and cancer immunoediting. Nat Rev Immunol, 2006. 6(11): p. 836-48.

87. Vesely, M.D., et al., Natural innate and adaptive immunity to cancer. Annu Rev Immunol, 2011. 29: p. 235-71.

88. Catlett-Falcone, R., et al., Constitutive activation of Stat3 signaling confers resistance to apoptosis in human U266 myeloma cells. Immunity, 1999. 10(1): p. 105-15.

89. Wrzesinski, S.H., Y.Y. Wan, and R.A. Flavell, Transforming growth factor-beta and the immune response: implications for anticancer therapy. Clin Cancer Res, 2007. 13(18 Pt 1): p. 5262-70.

90. Uyttenhove, C., et al., Evidence for a tumoral immune resistance mechanism based on tryptophan degradation by indoleamine 2,3-dioxygenase. Nat Med, 2003. 9(10): p. 1269-74.

91. Radoja, S., et al., Mice bearing late-stage tumors have normal functional systemic T cell responses in vitro and in vivo. J Immunol, 2000. 164(5): p. 261928.

92. Baniyash, M., Chronic inflammation, immunosuppression and cancer: new insights and outlook. Semin Cancer Biol, 2006. 16(1): p. 80-8.

93. Lawrence, T. and D.W. Gilroy, Chronic inflammation: a failure of resolution? Int J Exp Pathol, 2007. 88(2): p. 85-94.

94. Kanterman, J., M. Sade-Feldman, and M. Baniyash, New insights into chronic inflammation-induced immunosuppression. Semin Cancer Biol, 2012. 22(4): p. 307-18.

95. Kalluri, R. and M. Zeisberg, Fibroblasts in cancer. Nat Rev Cancer, 2006. 6(5): p. 392-401.

96. Skokos, D., et al., Mast cell-derived exosomes induce phenotypic and functional maturation of dendritic cells and elicit specific immune responses in vivo. J Immunol, 2003. 170(6): p. 3037-45.

97. Raposo, G., et al., Accumulation of major histocompatibility complex class II molecules in mast cell secretory granules and their release upon degranulation. Mol Biol Cell, 1997. 8(12): p. 2631-45.

98. Zitvogel, L., et al., Eradication of established murine tumors using a novel cellfree vaccine: dendritic cell-derived exosomes. Nat Med, 1998. 4(5): p. 594-600.

99. Bhatnagar, S., et al., Exosomes released from macrophages infected with intracellular pathogens stimulate a proinflammatory response in vitro and in vivo. Blood, 2007. 110(9): p. 3234-44.

100. Peters, P.J., et al., Molecules relevant for T cell-target cell interaction are present in cytolytic granules of human T lymphocytes. Eur J Immunol, 1989. 19(8): p. 1469-75.

101. Blanchard, N., et al., TCR activation of human T cells induces the production of exosomes bearing the TCR/CD3/zeta complex. J Immunol, 2002. 168(7): p. 3235-41.

102. Raposo, G., et al., B lymphocytes secrete antigen-presenting vesicles. J Exp Med, 1996. 183(3): p. 1161-72.

103. van Niel, G., et al., Intestinal epithelial cells secrete exosome-like vesicles. Gastroenterology, 2001. 121(2): p. 337-49.

104. Faure, J., et al., Exosomes are released by cultured cortical neurones. Mol Cell Neurosci, 2006. 31(4): p. 642-8.

105. Ratajczak, J., et al., Membrane-derived microvesicles: important and underappreciated mediators of cell-to-cell communication. Leukemia, 2006. 20(9): p. 1487-95. 
106. Camussi, G., et al., Exosomes/microvesicles as a mechanism of cell-to-cell communication. Kidney Int, 2010. 78(9): p. 838-48.

107. Al-Nedawi, K., et al., Intercellular transfer of the oncogenic receptor EGFRvIII by microvesicles derived from tumour cells. Nat Cell Biol, 2008. 10(5): p. 619-24.

108. Simons, M. and G. Raposo, Exosomes--vesicular carriers for intercellular communication. Curr Opin Cell Biol, 2009. 21(4): p. 575-81.

109. Mathivanan, S., H. Ji, and R.J. Simpson, Exosomes: extracellular organelles important in intercellular communication. J Proteomics, 2010. 73(10): p. 1907-20.

110. Graner, M.W., et al., Proteomic and immunologic analyses of brain tumor exosomes. FASEB J, 2009. 23(5): p. 1541-57.

111. Huber, V., et al., Human colorectal cancer cells induce T-cell death through release of proapoptotic microvesicles: role in immune escape. Gastroenterology, 2005. 128(7): p. 1796-804.

112. Bard, M.P., et al., Proteomic analysis of exosomes isolated from human malignant pleural effusions. Am J Respir Cell Mol Biol, 2004. 31(1): p. 114-21.

113. Andre, F., et al., Malignant effusions and immunogenic tumour-derived exosomes. Lancet, 2002. 360(9329): p. 295-305.

114. Taylor, D.D. and C. Gercel-Taylor, Exosomes/microvesicles: mediators of cancer-associated immunosuppressive microenvironments. Semin Immunopathol, 2011. 33(5): p. 441-54.

115. Taylor, D.D. and P.H. Black, Shedding of plasma membrane fragments. Neoplastic and developmental importance. Dev Biol (N Y 1985), 1986. 3: p. 3357.

116. Taylor, D.D., K.S. Lyons, and C. Gercel-Taylor, Shed membrane fragmentassociated markers for endometrial and ovarian cancers. Gynecol Oncol, 2002. 84(3): p. 443-8.

117. Chen, W., et al., Efficient induction of antitumor $T$ cell immunity by exosomes derived from heat-shocked lymphoma cells. Eur J Immunol, 2006. 36(6): p. 1598607.

118. Cho, J.A., et al., MHC independent anti-tumor immune responses induced by Hsp70-enriched exosomes generate tumor regression in murine models. Cancer Lett, 2009. 275(2): p. 256-65.

119. Tanchot, C., et al., Tumor-infiltrating regulatory T cells: phenotype, role, mechanism of expansion in situ and clinical significance. Cancer Microenviron, 2013. 6(2): p. 147-57.

120. de Visser, K.E., L.V. Korets, and L.M. Coussens, De novo carcinogenesis promoted by chronic inflammation is B lymphocyte dependent. Cancer Cell, 2005. 7(5): p. 411-23.

121. Taylor, D.D., H.D. Homesley, and G.J. Doellgast, "Membrane-associated" immunoglobulins in cyst and ascites fluids of ovarian cancer patients. Am J Reprod Immunol, 1983. 3(1): p. 7-11.

122. Vlock, D.R., et al., Incidence of serum antibody reactivity to autologous head and neck cancer cell lines and augmentation of antibody reactivity following acid dissociation and ultrafiltration. Cancer Res, 1989. 49(6): p. 1361-5.

123. Merimsky, O., et al., Antigens and antibodies in malignant melanoma. Tumour Biol, 1994. 15(4): p. 188-202.

124. Barbouche, M.R., et al., Prognostic significance of autoantibodies to laminin in the sera of breast cancer patients: a preliminary report. Eur J Clin Chem Clin Biochem, 1994. 32(7): p. 511-4.

125. Conroy, S.E., et al., Autoantibodies to $90 \mathrm{kD}$ heat-shock protein in sera of breast cancer patients. Lancet, 1995. 345(8942): p. 126. 
126. Taylor, D.D., H.D. Homesley, and G.J. Doellgast, Identification of antigenic components recognized by "membrane-bound" antibodies from ovarian cancer patients. Am J Reprod Immunol, 1984. 6(4): p. 179-84.

127. Kutteh, W.H., D.S. Miller, and J.M. Mathis, Immunologic characterization of tumor markers in human ovarian cancer cell lines. J Soc Gynecol Investig, 1996. 3(4): p. 216-22.

128. lero, M., et al., Tumour-released exosomes and their implications in cancer immunity. Cell Death Differ, 2008. 15(1): p. 80-8.

129. Valenti, R., et al., Human tumor-released microvesicles promote the differentiation of myeloid cells with transforming growth factor-beta-mediated suppressive activity on T lymphocytes. Cancer Res, 2006. 66(18): p. 9290-8.

130. Parolini, I., et al., Microenvironmental $\mathrm{pH}$ is a key factor for exosome traffic in tumor cells. J Biol Chem, 2009. 284(49): p. 34211-22.

131. Dolo, V., et al., Matrix-degrading proteinases are shed in membrane vesicles by ovarian cancer cells in vivo and in vitro. Clin Exp Metastasis, 1999. 17(2): p. 13140.

132. Dolo, V., et al., Shed membrane vesicles and selective localization of gelatinases and MMP-9/TIMP-1 complexes. Ann N Y Acad Sci, 1999. 878: p. 497-9.

133. Frey, A.B., Myeloid suppressor cells regulate the adaptive immune response to cancer. J Clin Invest, 2006. 116(10): p. 2587-90.

134. Serafini, P., I. Borrello, and V. Bronte, Myeloid suppressor cells in cancer: recruitment, phenotype, properties, and mechanisms of immune suppression. Semin Cancer Biol, 2006. 16(1): p. 53-65.

135. Taylor, D.D., et al., T-cell apoptosis and suppression of T-cell receptor/CD3-zeta by Fas ligand-containing membrane vesicles shed from ovarian tumors. Clin Cancer Res, 2003. 9(14): p. 5113-9.

136. Klibi, J., et al., Blood diffusion and Th1-suppressive effects of galectin-9containing exosomes released by Epstein-Barr virus-infected nasopharyngeal carcinoma cells. Blood, 2009. 113(9): p. 1957-66.

137. Vallhov, $\mathrm{H}$., et al., Exosomes containing glycoprotein 350 released by EBVtransformed $B$ cells selectively target $B$ cells through $C D 21$ and block EBV infection in vitro. J Immunol, 2011. 186(1): p. 73-82.

138. Denzer, K., et al., Follicular dendritic cells carry MHC class II-expressing microvesicles at their surface. J Immunol, 2000. 165(3): p. 1259-65.

139. Admyre, C., et al., B cell-derived exosomes can present allergen peptides and activate allergen-specific $T$ cells to proliferate and produce TH2-like cytokines. $\mathrm{J}$ Allergy Clin Immunol, 2007. 120(6): p. 1418-24.

140. Aung, T., et al., Exosomal evasion of humoral immunotherapy in aggressive Bcell lymphoma modulated by ATP-binding cassette transporter A3. Proc Natl Acad Sci U S A, 2011. 108(37): p. 15336-41.

141. Clayton, A., et al., Adhesion and signaling by $B$ cell-derived exosomes: the role of integrins. FASEB J, 2004. 18(9): p. 977-9.

142. Yang, C., et al., Exosomes released from Mycoplasma infected tumor cells activate inhibitory B cells. PLoS One, 2012. 7(4): p. e36138.

143. Anderson, K.S. and J. LaBaer, The sentinel within: exploiting the immune system for cancer biomarkers. J Proteome Res, 2005. 4(4): p. 1123-33.

144. Pieretti, M., et al., Heterogeneity of ovarian cancer: relationships among histological group, stage of disease, tumor markers, patient characteristics, and survival. Cancer Invest, 2002. 20(1): p. 11-23. 
145. Ferris, R.L., T.L. Whiteside, and S. Ferrone, Immune escape associated with functional defects in antigen-processing machinery in head and neck cancer. Clin Cancer Res, 2006. 12(13): p. 3890-5.

146. Greenwald, R.J., G.J. Freeman, and A.H. Sharpe, The B7 family revisited. Annu Rev Immunol, 2005. 23: p. 515-48.

147. Kalinski, P., et al., T-cell priming by type-1 and type-2 polarized dendritic cells: the concept of a third signal. Immunol Today, 1999. 20(12): p. 561-7.

148. Shurin, M.R., et al., Th1/Th2 balance in cancer, transplantation and pregnancy. Springer Semin Immunopathol, 1999. 21(3): p. 339-59.

149. Fruh, K. and Y. Yang, Antigen presentation by MHC class I and its regulation by interferon gamma. Curr Opin Immunol, 1999. 11(1): p. 76-81.

150. Hung, K., et al., The central role of CD4(+) T cells in the antitumor immune response. J Exp Med, 1998. 188(12): p. 2357-68.

151. Mantovani, A., et al., Tumour immunity: effector response to tumour and role of the microenvironment. Lancet, 2008. 371(9614): p. 771-83.

152. Taylor, D.D. and C. Gercel-Taylor, Tumor-reactive immunoglobulins in ovarian cancer: diagnostic and therapeutic significance? (review). Oncol Rep, 1998. 5(6): p. 1519-24.

153. Ramirez-Montagut, T., et al., Immunity to melanoma: unraveling the relation of tumor immunity and autoimmunity. Oncogene, 2003. 22(20): p. 3180-7.

154. Imafuku, Y., G.S. Omenn, and S. Hanash, Proteomics approaches to identify tumor antigen directed autoantibodies as cancer biomarkers. Dis Markers, 2004. 20(3): p. 149-53.

155. Sahin, U., et al., Human neoplasms elicit multiple specific immune responses in the autologous host. Proc Natl Acad Sci U S A, 1995. 92(25): p. 11810-3.

156. Stockert, E., et al., A survey of the humoral immune response of cancer patients to a panel of human tumor antigens. J Exp Med, 1998. 187(8): p. 1349-54.

157. Janeway, C., Immunobiology : the immune system in health and disease. 6th ed. 2005, New York: Garland Science. xxiii, 823 p.

158. Nesterova, M., et al., Autoantibody biomarker opens a new gateway for cancer diagnosis. Biochim Biophys Acta, 2006. 1762(4): p. 398-403.

159. Taylor, D.D., et al., Characterization of humoral responses of ovarian cancer patients: antibody subclasses and antigenic components. Gynecol Oncol, 2010. 116(2): p. 213-21.

160. Sounni, N.E. and A. Noel, Targeting the tumor microenvironment for cancer therapy. Clin Chem, 2013. 59(1): p. 85-93.

161. Fidler, I.J. and G. Poste, The "seed and soil" hypothesis revisited. Lancet Oncol, 2008. 9(8): p. 808.

162. Taylor, D.D., et al., Modulation of TCR/CD3-zeta chain expression by a circulating factor derived from ovarian cancer patients. Br J Cancer, 2001. 84(12): p. 16249.

163. Cocucci, E., G. Racchetti, and J. Meldolesi, Shedding microvesicles: artefacts no more. Trends Cell Biol, 2009. 19(2): p. 43-51.

164. Yang, C. and P.D. Robbins, The roles of tumor-derived exosomes in cancer pathogenesis. Clin Dev Immunol, 2011. 2011: p. 842849.

165. Webber, J., et al., Cancer exosomes trigger fibroblast to myofibroblast differentiation. Cancer Res, 2010. 70(23): p. 9621-30.

166. Otranto, M., et al., The role of the myofibroblast in tumor stroma remodeling. Cell Adh Migr, 2012. 6(3): p. 203-19.

167. Groh, V., et al., Tumour-derived soluble MIC ligands impair expression of NKG2D and T-cell activation. Nature, 2002. 419(6908): p. 734-8. 
168. Peinado, H., et al., Melanoma exosomes educate bone marrow progenitor cells toward a pro-metastatic phenotype through MET. Nat Med, 2012. 18(6): p. 88391.

169. Gagnon, A., et al., Use of a combination of approaches to identify and validate relevant tumor-associated antigens and their corresponding autoantibodies in ovarian cancer patients. Clin Cancer Res, 2008. 14(3): p. 764-71.

170. Murphy, K., et al., Janeway's immunobiology. 8th ed. 2012, New York: Garland Science. xix, $868 \mathrm{p}$.

171. Zhang, J.Y., K.S. Looi, and E.M. Tan, Identification of tumor-associated antigens as diagnostic and predictive biomarkers in cancer. Methods Mol Biol, 2009. 520: p. 1-10.

172. Sawyers, C.L., The cancer biomarker problem. Nature, 2008. 452(7187): p. 54852.

173. Tyers, M. and M. Mann, From genomics to proteomics. Nature, 2003. 422(6928): p. 193-7.

174. Gygi, S.P., et al., Evaluation of two-dimensional gel electrophoresis-based proteome analysis technology. Proc Natl Acad Sci U S A, 2000. 97(17): p. 93905.

175. Rabilloud, T., Two-dimensional gel electrophoresis in proteomics: old, old fashioned, but it still climbs up the mountains. Proteomics, 2002. 2(1): p. 3-10.

176. Quinones, Q.J., G.G. de Ridder, and S.V. Pizzo, GRP78: a chaperone with diverse roles beyond the endoplasmic reticulum. Histol Histopathol, 2008. 23(11): p. 1409-16.

177. Delie, F., P. Petignat, and M. Cohen, GRP78 Protein Expression in Ovarian Cancer Patients and Perspectives for a Drug-Targeting Approach. J Oncol, 2012. 2012: p. 468615.

178. Gonzalez-Gronow, M., et al., GRP78: a multifunctional receptor on the cell surface. Antioxid Redox Signal, 2009. 11(9): p. 2299-306.

179. Wang, M., et al., Role of the unfolded protein response regulator GRP78/BiP in development, cancer, and neurological disorders. Antioxid Redox Signal, 2009. 11(9): p. 2307-16.

180. Misra, U.K., R. Deedwania, and S.V. Pizzo, Activation and cross-talk between Akt, NF-kappaB, and unfolded protein response signaling in 1-LN prostate cancer cells consequent to ligation of cell surface-associated GRP78. J Biol Chem, 2006. 281(19): p. 13694-707.

181. Misra, U.K., et al., Ligation of cancer cell surface GRP78 with antibodies directed against its $\mathrm{COOH}$-terminal domain up-regulates $p 53$ activity and promotes apoptosis. Mol Cancer Ther, 2009. 8(5): p. 1350-62.

182. Gonzalez-Gronow, M., et al., Prostate cancer cell proliferation in vitro is modulated by antibodies against glucose-regulated protein 78 isolated from patient serum. Cancer Res, 2006. 66(23): p. 11424-31.

183. Chinni, S.R., et al., Humoral immune responses to cathepsin $D$ and glucoseregulated protein 78 in ovarian cancer patients. Clin Cancer Res, 1997. 3(9): p. 1557-64.

184. Lu, D., et al., Comparison of candidate serologic markers for type I and type II ovarian cancer. Gynecol Oncol, 2011. 122(3): p. 560-6.

185. Shin, B.K., et al., Global profiling of the cell surface proteome of cancer cells uncovers an abundance of proteins with chaperone function. J Biol Chem, 2003. 278(9): p. 7607-16.

186. Bankowska, A., et al., Biological and diagnostic role of cathepsin D. Rocz Akad Med Bialymst, 1997. 42 Suppl 1: p. 79-85. 
187. Bird, J.W., W.N. Schwartz, and A.M. Spanier, Degradation of myofibrillar proteins by cathepsins B and D. Acta Biol Med Ger, 1977. 36(11-12): p. 1587-604.

188. Takei, Y., et al., Mitogenic activity toward human breast cancer cell line MCF-7 of two bFGFs purified from sera of breast cancer patients: co-operative role of cathepsin D. Breast Cancer Res Treat, 1997. 43(1): p. 53-63.

189. Wolf, M., et al., Cathepsin D specifically cleaves the chemokines macrophage inflammatory protein-1 alpha, macrophage inflammatory protein-1 beta, and SLC that are expressed in human breast cancer. Am J Pathol, 2003. 162(4): p. 118390.

190. Nishimura, Y., T. Kawabata, and K. Kato, Identification of latent procathepsins $B$ and $L$ in microsomal lumen: characterization of enzymatic activation and proteolytic processing in vitro. Arch Biochem Biophys, 1988. 261(1): p. 64-71.

191. Nicotra, G., et al., The dilemma: does tissue expression of cathepsin $D$ reflect tumor malignancy? The question: does the assay truly mirror cathepsin $D$ misfunction in the tumor? Cancer Biomark, 2010. 7(1): p. 47-64.

192. Bidere, N., et al., Cathepsin D triggers Bax activation, resulting in selective apoptosis-inducing factor (AIF) relocation in T lymphocytes entering the early commitment phase to apoptosis. J Biol Chem, 2003. 278(33): p. 31401-11.

193. Kirana, C., et al., Cathepsin D Expression in Colorectal Cancer: From Proteomic Discovery through Validation Using Western Blotting, Immunohistochemistry, and Tissue Microarrays. Int J Proteomics, 2012. 2012: p. 245819.

194. Berchem, G., et al., Cathepsin-D affects multiple tumor progression steps in vivo: proliferation, angiogenesis and apoptosis. Oncogene, 2002. 21(38): p. 5951-5.

195. Chang, G.C., et al., Identification of alpha-enolase as an autoantigen in lung cancer: its overexpression is associated with clinical outcomes. Clin Cancer Res, 2006. 12(19): p. 5746-54.

196. Jiang, B.H., et al., V-SRC induces expression of hypoxia-inducible factor 1 (HIF1) and transcription of genes encoding vascular endothelial growth factor and enolase 1: involvement of HIF-1 in tumor progression. Cancer Res, 1997. 57(23): p. 5328-35.

197. Gitlits, V.M., B.H. Toh, and J.W. Sentry, Disease association, origin, and clinical relevance of autoantibodies to the glycolytic enzyme enolase. J Investig Med, 2001. 49(2): p. 138-45.

198. Holland, J.P., et al., Homologous nucleotide sequences at the 5' termini of messenger RNAs synthesized from the yeast enolase and glyceraldehyde-3phosphate dehydrogenase gene families. The primary structure of a third yeast glyceraldehyde-3-phosphate dehydrogenase gene. J Biol Chem, 1983. 258(8): p. 5291-9.

199. Giallongo, A., et al., Structure of the human gene for alpha-enolase. Eur J Biochem, 1990. 190(3): p. 567-73.

200. Feo, S., et al., ENO1 gene product binds to the c-myc promoter and acts as a transcriptional repressor: relationship with Myc promoter-binding protein 1 (MBP1). FEBS Lett, 2000. 473(1): p. 47-52.

201. Subramanian, A. and D.M. Miller, Structural analysis of alpha-enolase. Mapping the functional domains involved in down-regulation of the c-myc protooncogene. J Biol Chem, 2000. 275(8): p. 5958-65.

202. Dang, C.V., A. Le, and P. Gao, MYC-induced cancer cell energy metabolism and therapeutic opportunities. Clin Cancer Res, 2009. 15(21): p. 6479-83.

203. Miller, D.M., et al., c-Myc and cancer metabolism. Clin Cancer Res, 2012. 18(20): p. 5546-53. 
204. Pal, P., et al., 2-D gel electrophoresis-based proteomic analysis reveals that ormeloxifen induces G0-G1 growth arrest and ERK-mediated apoptosis in chronic myeloid leukemia cells K562. Proteomics, 2011. 11(8): p. 1517-29.

205. Ghosh, A.K., et al., Tumor-suppressive effects of MBP-1 in non-small cell lung cancer cells. Cancer Res, 2006. 66(24): p. 11907-12.

206. Ejeskar, K., et al., Introduction of in vitro transcribed ENO1 mRNA into neuroblastoma cells induces cell death. BMC Cancer, 2005. 5: p. 161.

207. Ghosh, A.K., et al., MBP-1 mediated apoptosis involves cytochrome $c$ release from mitochondria. Oncogene, 2002. 21(18): p. 2775-84.

208. Mussunoor, S. and G.I. Murray, The role of annexins in tumour development and progression. J Pathol, 2008. 216(2): p. 131-40.

209. Lokman, N.A., et al., The role of annexin A2 in tumorigenesis and cancer progression. Cancer Microenviron, 2011. 4(2): p. 199-208.

210. Hajjar, K.A., et al., Interaction of the fibrinolytic receptor, annexin II, with the endothelial cell surface. Essential role of endonexin repeat 2. J Biol Chem, 1996. 271(35): p. 21652-9.

211. Mai, J., D.M. Waisman, and B.F. Sloane, Cell surface complex of cathepsin B/annexin II tetramer in malignant progression. Biochim Biophys Acta, 2000. 1477(1-2): p. 215-30.

212. Ao, W., et al., Anti-annexin II antibody is associated with thrombosis and/or pregnancy morbidity in antiphospholipid syndrome and systemic lupus erythematosus with thrombosis. Rheumatol Int, 2011. 31(7): p. 865-9.

213. Brichory, F.M., et al., An immune response manifested by the common occurrence of annexins I and II autoantibodies and high circulating levels of IL-6 in lung cancer. Proc Natl Acad Sci U S A, 2001. 98(17): p. 9824-9.

214. Erikson, E. and R.L. Erikson, Identification of a cellular protein substrate phosphorylated by the avian sarcoma virus-transforming gene product. Cell, 1980. 21(3): p. 829-36.

215. Zhao, H. and R.W. Hardy, Long-chain saturated fatty acids induce annexin II translocation to detergent-resistant membranes. Biochem J, 2004. 381(Pt 2): p. 463-9.

216. Babiychuk, E.B., et al., Modulating signaling events in smooth muscle: cleavage of annexin 2 abolishes its binding to lipid rafts. FASEB J, 2002. 16(10): p. 117784.

217. Ranson, M. and N.M. Andronicos, Plasminogen binding and cancer: promises and pitfalls. Front Biosci, 2003. 8: p. s294-304.

218. Ahn, S.H., et al., Differential expression of annexin I in human mammary ductal epithelial cells in normal and benign and malignant breast tissues. Clin Exp Metastasis, 1997. 15(2): p. 151-6.

219. Vishwanatha, J.K., et al., Enhanced expression of annexin II in human pancreatic carcinoma cells and primary pancreatic cancers. Carcinogenesis, 1993. 14(12): p. 2575-9.

220. Sharma, M.R., et al., Angiogenesis-associated protein annexin II in breast cancer: selective expression in invasive breast cancer and contribution to tumor invasion and progression. Exp Mol Pathol, 2006. 81(2): p. 146-56.

221. Chetcuti, A., et al., Loss of annexin II heavy and light chains in prostate cancer and its precursors. Cancer Res, 2001. 61(17): p. 6331-4.

222. Banerjee, A.G., et al., Expression of biomarkers modulating prostate cancer angiogenesis: differential expression of annexin II in prostate carcinomas from India and USA. Mol Cancer, 2003. 2: p. 34. 
223. Shiozawa, Y., et al., Annexin II/annexin II receptor axis regulates adhesion, migration, homing, and growth of prostate cancer. J Cell Biochem, 2008. 105(2): p. 370-80.

224. Bao, H., et al., Overexpression of Annexin II affects the proliferation, apoptosis, invasion and production of proangiogenic factors in multiple myeloma. Int $\mathrm{J}$ Hematol, 2009. 90(2): p. 177-85.

225. Zhang, Q., et al., Upregulated expression of annexin II is a prognostic marker for patients with gastric cancer. World J Surg Oncol, 2012. 10: p. 103.

226. Tatenhorst, L., et al., Knockdown of annexin 2 decreases migration of human glioma cells in vitro. Neuropathol Appl Neurobiol, 2006. 32(3): p. 271-7.

227. Meimaridou, E., S.B. Gooljar, and J.P. Chapple, From hatching to dispatching: the multiple cellular roles of the Hsp70 molecular chaperone machinery. J Mol Endocrinol, 2009. 42(1): p. 1-9.

228. Kodiha, M., et al., Stress inhibits nucleocytoplasmic shuttling of heat shock protein hsc70. Am J Physiol Cell Physiol, 2005. 289(4): p. C1034-41.

229. Nirde, P., et al., Heat shock cognate 70 protein secretion as a new growth arrest signal for cancer cells. Oncogene, 2010. 29(1): p. 117-27.

230. Kornguth, S.E., et al., Occurrence of anti-retinal ganglion cell antibodies in patients with small cell carcinoma of the lung. Cancer, 1982. 50(7): p. 1289-93.

231. Thirkill, C.E., et al., Cancer-associated retinopathy (CAR syndrome) with antibodies reacting with retinal, optic-nerve, and cancer cells. N Engl J Med, 1989. 321(23): p. 1589-94.

232. Polans, A.S., et al., A photoreceptor calcium binding protein is recognized by autoantibodies obtained from patients with cancer-associated retinopathy. J Cell Biol, 1991. 112(5): p. 981-9.

233. Garcia, M., et al., Overexpression of transfected cathepsin D in transformed cells increases their malignant phenotype and metastatic potency. Oncogene, 1990. 5(12): p. 1809-14.

234. Xu, S., et al., Discovery of an orally active small-molecule irreversible inhibitor of protein disulfide isomerase for ovarian cancer treatment. Proc Natl Acad Sci U S A, 2012. 109(40): p. 16348-53.

235. Ko, H.S., T. Uehara, and Y. Nomura, Role of ubiquilin associated with proteindisulfide isomerase in the endoplasmic reticulum in stress-induced apoptotic cell death. J Biol Chem, 2002. 277(38): p. 35386-92.

236. Yokoi, T., et al., Identification of protein disulfide isomerase and calreticulin as autoimmune antigens in LEC strain of rats. Biochim Biophys Acta, 1993. 1158(3): p. 339-44.

237. Meek, B., et al., IgA antibodies to Toxoplasma gondii in human tears. Invest Ophthalmol Vis Sci, 2000. 41(9): p. 2584-90.

238. Meek, B., et al., Protein disulfide isomerase of Toxoplasma gondii is targeted by mucosal IgA antibodies in humans. FEBS Lett, 2002. 522(1-3): p. 104-8.

239. Kaiser, B.K., et al., Disulphide-isomerase-enabled shedding of tumourassociated NKG2D ligands. Nature, 2007. 447(7143): p. 482-6.

240. Lopez-Larrea, C., et al., The NKG2D receptor: sensing stressed cells. Trends Mol Med, 2008. 14(4): p. 179-89.

241. Ashiru, O., et al., Natural killer cell cytotoxicity is suppressed by exposure to the human NKG2D ligand MICA*008 that is shed by tumor cells in exosomes. Cancer Res, 2010. 70(2): p. 481-9.

242. Clayton, A. and Z. Tabi, Exosomes and the MICA-NKG2D system in cancer. Blood Cells Mol Dis, 2005. 34(3): p. 206-13. 
243. Neville, A.M., et al., Human tumour-associated and tumour-specific antigens: some concepts in relation to clinical oncology. J Clin Pathol Suppl (Assoc Clin Pathol), 1975. 6: p. 102-12.

244. Black, P.H., Shedding from the cell surface of normal and cancer cells. Adv Cancer Res, 1980. 32: p. 75-199.

245. Baker, M.A., et al., Characterization of compounds shed from the surface of human leukemic myeloblasts in vitro. Blood, 1982. 60(2): p. 412-9.

246. Hochst, B. and L. Diehl, Antigen shedding into the circulation contributes to tumor immune escape. Oncoimmunology, 2012. 1(9): p. 1620-1622.

247. Romero, P., J.C. Cerottini, and D.E. Speiser, The human T cell response to melanoma antigens. Adv Immunol, 2006. 92: p. 187-224.

248. Preuss, K.D., et al., Analysis of the B-cell repertoire against antigens expressed by human neoplasms. Immunol Rev, 2002. 188: p. 43-50.

249. Guevara-Patino, J.A., et al., Immunity to cancer through immune recognition of altered self: studies with melanoma. Adv Cancer Res, 2003. 90: p. 157-77.

250. Kobold, S., et al., Autoantibodies against tumor-related antigens: incidence and biologic significance. Hum Immunol, 2010. 71(7): p. 643-51.

251. Hamilton, R.G., Human IgG subclass measurements in the clinical laboratory. Clin Chem, 1987. 33(10): p. 1707-25.

252. French, M., Serum IgG subclasses in normal adults. Monogr Allergy, 1986. 19: p. 100-7.

253. Gonzalez-Quintela, A., et al., Serum levels of immunoglobulins (IgG, $\lg A$, $\lg M)$ in a general adult population and their relationship with alcohol consumption, smoking and common metabolic abnormalities. Clin Exp Immunol, 2008. 151(1): p. $42-50$.

254. Buckley, R.H., Humoral immunodeficiency. Clin Immunol Immunopathol, 1986. 40(1): p. 13-24.

255. Dispenzieri, A., et al., Retrospective cohort study of 148 patients with polyclonal gammopathy. Mayo Clin Proc, 2001. 76(5): p. 476-87.

256. Liu, Y. and J. Li, Preferentially immunoglobulin (IgG) subclasses production in primary Sjogren's syndrome patients. Clin Chem Lab Med, 2011.

257. Papadea, C., C.B. Reimer, and I.J. Check, IgG subclass distribution in patients with multiple myeloma or with monoclonal gammopathy of undetermined significance. Ann Clin Lab Sci, 1989. 19(1): p. 27-37.

258. Finn, O.J., Immune response as a biomarker for cancer detection and a lot more. N Engl J Med, 2005. 353(12): p. 1288-90.

259. Taylor, D.D. and G.J. Doellgast, Quantitation of peroxidase-antibody binding to membrane fragments using column chromatography. Anal Biochem, 1979. 98(1): p. 53-9.

260. Taylor, D.D., H.D. Homesley, and G.J. Doellgast, Binding of specific peroxidaselabeled antibody to placental-type phosphatase on tumor-derived membrane fragments. Cancer Res, 1980. 40(11): p. 4064-9.

261. Taylor, D.D., et al., Characterization of plasma membrane shedding from murine melanoma cells. Int J Cancer, 1988. 41(4): p. 629-35.

262. Chaput, N., et al., Exosomes for immunotherapy of cancer. Adv Exp Med Biol, 2003. 532: p. 215-21.

263. Whiteside, T.L., Tumour-derived exosomes or microvesicles: another mechanism of tumour escape from the host immune system? Br J Cancer, 2005. 92(2): p. 209-11.

264. Valenti, R., et al., Tumor-released microvesicles as vehicles of immunosuppression. Cancer Res, 2007. 67(7): p. 2912-5. 
265. Koga, K., et al., Purification, characterization and biological significance of tumorderived exosomes. Anticancer Res, 2005. 25(6A): p. 3703-7.

266. Taylor, D.D. and C. Gercel-Taylor, MicroRNA signatures of tumor-derived exosomes as diagnostic biomarkers of ovarian cancer. Gynecol Oncol, 2008. 110(1): p. 13-21.

267. Peoples, G.E., et al., TCR $V$ beta $3+$ and $V$ beta $6+C T L$ recognize tumorassociated antigens related to HER2/neu expression in HLA-A2+ ovarian cancers. J Immunol, 1994. 152(10): p. 4993-9.

268. Peoples, G.E., et al., $T$ cell receptor $V$ beta 2 and $V$ beta 6 mediate tumorspecific cytotoxicity by tumor-infiltrating lymphocytes in ovarian cancer. J Immunol, 1993. 151(10): p. 5472-80.

269. Disis, M.L., et al., Generation of T-cell immunity to the HER-2/neu protein after active immunization with HER-2/neu peptide-based vaccines. J Clin Oncol, 2002. 20(11): p. 2624-32.

270. Vlad, A.M., et al., MUC1 immunobiology: from discovery to clinical applications. Adv Immunol, 2004. 82: p. 249-93.

271. Kenemans, P., CA 125 and OA 3 as target antigens for immunodiagnosis and immunotherapy in ovarian cancer. Eur J Obstet Gynecol Reprod Biol, 1990. 36(3): p. 221-8.

272. Odunsi, K., et al., NY-ESO-1 and LAGE-1 cancer-testis antigens are potential targets for immunotherapy in epithelial ovarian cancer. Cancer Res, 2003. 63(18): p. 6076-83.

273. Burton, D.R., L. Gregory, and R. Jefferis, Aspects of the molecular structure of IgG subclasses. Monogr Allergy, 1986. 19: p. 7-35.

274. Pan, Q. and L. Hammarstrom, Molecular basis of IgG subclass deficiency. Immunol Rev, 2000. 178: p. 99-110.

275. Walport, M.J., Complement. First of two parts. N Engl J Med, 2001. 344(14): p. 1058-66.

276. Walport, M.J., Complement. Second of two parts. N Engl J Med, 2001. 344(15): p. 1140-4.

277. Lemmon, J.K.a.K., A.P., IgG Subclasses: Physical properties, genetics, and biologic functions., in UpToDate, E.R. Stiehm, Editor. 2012.

278. Fasler, S., F. Skvaril, and H.U. Lutz, Electrophoretic properties of human IgG and its subclasses on sodium dodecyl-sulfate-polyacrylamide gel electrophoresis and immunoblots. Anal Biochem, 1988. 174(2): p. 593-600.

279. Bouharoun-Tayoun, H. and P. Druilhe, Antibodies in falciparum malaria: what matters most, quantity or quality? Mem Inst Oswaldo Cruz, 1992. 87 Suppl 3: p. 229-34.

280. Aucan, C., et al., Familial correlation of immunoglobulin $\mathrm{G}$ subclass responses to Plasmodium falciparum antigens in Burkina Faso. Infect Immun, 2001. 69(2): p. 996-1001.

281. Bouharoun-Tayoun, H. and P. Druilhe, Plasmodium falciparum malaria: evidence for an isotype imbalance which may be responsible for delayed acquisition of protective immunity. Infect Immun, 1992. 60(4): p. 1473-81.

282. Groux, H. and J. Gysin, Opsonization as an effector mechanism in human protection against asexual blood stages of Plasmodium falciparum: functional role of IgG subclasses. Res Immunol, 1990. 141(6): p. 529-42.

283. Pillai, S. and A. Cariappa, The follicular versus marginal zone B lymphocyte cell fate decision. Nat Rev Immunol, 2009. 9(11): p. 767-77.

284. Lopes-Carvalho, T. and J.F. Kearney, Development and selection of marginal zone B cells. Immunol Rev, 2004. 197: p. 192-205. 
285. Hardy, R.R., et al., Demonstration of B-cell maturation in X-linked immunodeficient mice by simultaneous three-colour immunofluorescence. Nature, 1983. 306(5940): p. 270-2.

286. Nieuwenhuis, P. and D. Opstelten, Functional anatomy of germinal centers. Am J Anat, 1984. 170(3): p. 421-35.

287. Cyster, J.G., Shining a light on germinal center B cells. Cell, 2010. 143(4): p. 503-5.

288. MacLennan, I.C., Germinal centers. Annu Rev Immunol, 1994. 12: p. 117-39.

289. Li, Z., et al., The generation of antibody diversity through somatic hypermutation and class switch recombination. Genes Dev, 2004. 18(1): p. 1-11.

290. Panayi, G.S., B cells: a fundamental role in the pathogenesis of rheumatoid arthritis? Rheumatology (Oxford), 2005. 44 Suppl 2: p. ii3-ii7.

291. Kim, H.J. and C. Berek, B cells in rheumatoid arthritis. Arthritis Res, 2000. 2(2): p. 126-31.

292. Gause, A. and C. Berek, Role of B cells in the pathogenesis of rheumatoid arthritis: potential implications for treatment. BioDrugs, 2001. 15(2): p. 73-9.

293. McLaughlin, K.A. and K.W. Wucherpfennig, B cells and autoantibodies in the pathogenesis of multiple sclerosis and related inflammatory demyelinating diseases. Adv Immunol, 2008. 98: p. 121-49.

294. Lipsky, P.E., Systemic lupus erythematosus: an autoimmune disease of B cell hyperactivity. Nat Immunol, 2001. 2(9): p. 764-6.

295. Gumus, E., et al., Association of positive serum anti-p53 antibodies with poor prognosis in bladder cancer patients. Int J Urol, 2004. 11(12): p. 1070-7.

296. Tan, T.T. and L.M. Coussens, Humoral immunity, inflammation and cancer. Curr Opin Immunol, 2007. 19(2): p. 209-16.

297. Dass, T.K., et al., Clinical utility and monitoring of breast cancer by circulating immune complexes. Indian J Pathol Microbiol, 1992. 35(4): p. 298-307.

298. Das, T.K., et al., Prognostic significance of circulating immune complexes in malignant tumours of head and neck. J Indian Med Assoc, 1995. 93(1): p. 3-7.

299. Aziz, M., T.K. Das, and A. Rattan, Role of circulating immune complexes in prognostic evaluation and management of genitourinary cancer patients. Indian $\mathrm{J}$ Cancer, 1997. 34(3): p. 111-20.

300. Clayton, A. and M.D. Mason, Exosomes in tumour immunity. Curr Oncol, 2009. 16(3): p. 46-9.

301. Navabi, H., et al., Preparation of human ovarian cancer ascites-derived exosomes for a clinical trial. Blood Cells Mol Dis, 2005. 35(2): p. 149-52.

302. Andreola, G., et al., Induction of lymphocyte apoptosis by tumor cell secretion of FasL-bearing microvesicles. J Exp Med, 2002. 195(10): p. 1303-16.

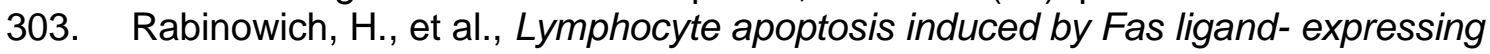
ovarian carcinoma cells. Implications for altered expression of $T$ cell receptor in tumor-associated lymphocytes. J Clin Invest, 1998. 101(11): p. 2579-88.

304. Whiteside, T.L., Tumor-induced death of immune cells: its mechanisms and consequences. Semin Cancer Biol, 2002. 12(1): p. 43-50.

305. Taylor, D.D. and C. Gercel-Taylor, Tumour-derived exosomes and their role in cancer-associated T-cell signalling defects. Br J Cancer, 2005. 92(2): p. 305-11.

306. Kasibhatla, S., et al., Analysis of DNA fragmentation using agarose gel electrophoresis. CSH Protoc, 2006. 2006(1).

307. Guinan, E.C., et al., Pivotal role of the B7:CD28 pathway in transplantation tolerance and tumor immunity. Blood, 1994. 84(10): p. 3261-82. 
308. Applequist, S.E., R.P. Wallin, and H.G. Ljunggren, Variable expression of Tolllike receptor in murine innate and adaptive immune cell lines. Int Immunol, 2002. 14(9): p. 1065-74.

309. Bourke, E., et al., The toll-like receptor repertoire of human B lymphocytes: inducible and selective expression of TLR9 and TLR10 in normal and transformed cells. Blood, 2003. 102(3): p. 956-63.

310. Hua, Z. and B. Hou, TLR signaling in B-cell development and activation. Cell Mol Immunol, 2013. 10(2): p. 103-6.

311. Roosnek, E. and A. Lanzavecchia, Efficient and selective presentation of antigen-antibody complexes by rheumatoid factor B cells. J Exp Med, 1991. 173(2): p. 487-9.

312. Lee, J.R. and G.A. Koretzky, Production of reactive oxygen intermediates following CD40 ligation correlates with c-Jun N-terminal kinase activation and IL6 secretion in murine B lymphocytes. Eur J Immunol, 1998. 28(12): p. 4188-97.

313. Oksvold, M.P., et al., Expression of B-cell surface antigens in subpopulations of exosomes released from B-cell lymphoma cells. Clin Ther, 2014. 36(6): p. 847862.e1.

314. Knight, A.M., Regulated release of B cell-derived exosomes: do differences in exosome release provide insight into different $A P C$ function for $B$ cells and $D C$ ? Eur J Immunol, 2008. 38(5): p. 1186-9.

315. Sabin, K.Z., Induction of T cell apoptosis by glioblastoma multiforme, in Biology. 2013, Northern Michigan University: Ann Arbor. p. 70.

316. Wieckowski, E.U., et al., Tumor-derived microvesicles promote regulatory $T$ cell expansion and induce apoptosis in tumor-reactive activated CD8+ $T$ lymphocytes. J Immunol, 2009. 183(6): p. 3720-30.

317. Brauns, S.C., et al., Caspase-3 activation and induction of PARP cleavage by cyclic dipeptide cyclo(Phe-Pro) in HT-29 cells. Anticancer Res, 2005. 25(6B): p. 4197-202.

318. Mcllwain, D.R., T. Berger, and T.W. Mak, Caspase functions in cell death and disease. Cold Spring Harb Perspect Biol, 2013. 5(4): p. a008656.

319. Lindahl, T., et al., Post-translational modification of poly(ADP-ribose) polymerase induced by DNA strand breaks. Trends Biochem Sci, 1995. 20(10): p. 405-11.

320. Los, M., et al., Activation and caspase-mediated inhibition of PARP: a molecular switch between fibroblast necrosis and apoptosis in death receptor signaling. Mol Biol Cell, 2002. 13(3): p. 978-88.

321. D'Amours, D., et al., Gain-of-function of poly(ADP-ribose) polymerase-1 upon cleavage by apoptotic proteases: implications for apoptosis. J Cell Sci, 2001. 114(Pt 20): p. 3771-8.

322. Bortner, C.D., N.B. Oldenburg, and J.A. Cidlowski, The role of DNA fragmentation in apoptosis. Trends Cell Biol, 1995. 5(1): p. 21-6.

323. Kim, J.W., et al., Fas ligand-positive membranous vesicles isolated from sera of patients with oral cancer induce apoptosis of activated T lymphocytes. Clin Cancer Res, 2005. 11(3): p. 1010-20.

324. Peng, P., Y. Yan, and S. Keng, Exosomes in the ascites of ovarian cancer patients: origin and effects on anti-tumor immunity. Oncol Rep, 2011. 25(3): p. 749-62.

325. Abusamra, A.J., et al., Tumor exosomes expressing Fas ligand mediate CD8+ Tcell apoptosis. Blood Cells Mol Dis, 2005. 35(2): p. 169-73.

326. Suda, T., et al., Molecular cloning and expression of the Fas ligand, a novel member of the tumor necrosis factor family. Cell, 1993. 75(6): p. 1169-78. 
327. Suda, T., et al., Membrane Fas ligand kills human peripheral blood T lymphocytes, and soluble Fas ligand blocks the killing. J Exp Med, 1997. 186(12): p. 2045-50.

328. Tanaka, M., et al., Downregulation of Fas ligand by shedding. Nat Med, 1998. 4(1): p. 31-6.

329. Schneider, P., et al., Conversion of membrane-bound Fas(CD95) ligand to its soluble form is associated with downregulation of its proapoptotic activity and loss of liver toxicity. J Exp Med, 1998. 187(8): p. 1205-13.

330. Waring, P. and A. Mullbacher, Cell death induced by the Fas/Fas ligand pathway and its role in pathology. Immunol Cell Biol, 1999. 77(4): p. 312-7.

331. Boldin, M.P., et al., Self-association of the "death domains" of the p55 tumor necrosis factor (TNF) receptor and Fas/APO1 prompts signaling for TNF and Fas/APO1 effects. J Biol Chem, 1995. 270(1): p. 387-91.

332. Chinnaiyan, A.M., et al., FADD, a novel death domain-containing protein, interacts with the death domain of Fas and initiates apoptosis. Cell, 1995. 81(4): p. 505-12.

333. Medema, J.P., et al., FLICE is activated by association with the CD95 deathinducing signaling complex (DISC). Embo j, 1997. 16(10): p. 2794-804.

334. Thornberry, N.A. and Y. Lazebnik, Caspases: enemies within. Science, 1998. 281(5381): p. 1312-6.

335. Enari, M., et al., A caspase-activated DNase that degrades DNA during apoptosis, and its inhibitor ICAD. Nature, 1998. 391(6662): p. 43-50.

336. Mcllroy, D., et al., Involvement of caspase 3-activated DNase in internucleosomal DNA cleavage induced by diverse apoptotic stimuli. Oncogene, 1999. 18(31): p. 4401-8.

337. van Kooten, C. and J. Banchereau, CD40-CD40 ligand. J Leukoc Biol, 2000. 67(1): p. 2-17.

338. Grassme, $\mathrm{H}$., et al., Clustering of CD40 ligand is required to form a functional contact with CD40. J Biol Chem, 2002. 277(33): p. 30289-99.

339. Faris, M., et al., CD40 signaling pathway: anti-CD40 monoclonal antibody induces rapid dephosphorylation and phosphorylation of tyrosine-phosphorylated proteins including protein tyrosine kinase Lyn, Fyn, and Syk and the appearance of a 28-kD tyrosine phosphorylated protein. J Exp Med, 1994. 179(6): p. 1923-31.

340. Durie, F.H., et al., The role of CD40 in the regulation of humoral and cellmediated immunity. Immunol Today, 1994. 15(9): p. 406-11.

341. Yellin, M.J., et al., T lymphocyte $T$ cell-B cell-activating molecule/CD40-L molecules induce normal $B$ cells or chronic lymphocytic leukemia $B$ cells to express CD80 (B7/BB-1) and enhance their costimulatory activity. J Immunol, 1994. 153(2): p. 666-74.

342. Berberich, I., G.L. Shu, and E.A. Clark, Cross-linking CD40 on B cells rapidly activates nuclear factor-kappa B. J Immunol, 1994. 153(10): p. 4357-66.

343. Splawski, J.B., S.M. Fu, and P.E. Lipsky, Immunoregulatory role of CD40 in human B cell differentiation. J Immunol, 1993. 150(4): p. 1276-85.

344. Rothstein, T.L., Inducible resistance to Fas-mediated apoptosis in B cells. Cell Res, 2000. 10(4): p. 245-66.

345. Rothstein, T.L., et al., Protection against Fas-dependent Th1-mediated apoptosis by antigen receptor engagement in B cells. Nature, 1995. 374(6518): p. 163-5.

346. Foote, L.C., et al., Intracellular signaling for inducible antigen receptor-mediated Fas resistance in B cells. J Immunol, 1996. 157(5): p. 1878-85. 
347. Schattner, E.J., et al., CD40 ligation induces Apo-1/Fas expression on human $B$ lymphocytes and facilitates apoptosis through the Apo-1/Fas pathway. J Exp Med, 1995. 182(5): p. 1557-65.

348. Dano, K., et al., Plasminogen activators, tissue degradation, and cancer. Adv Cancer Res, 1985. 44: p. 139-266.

349. Schneider, D.J., Y. Chen, and B.E. Sobel, The effect of plasminogen activator inhibitor type 1 on apoptosis. Thromb Haemost, 2008. 100(6): p. 1037-40.

350. Andreasen, P.A., et al., The urokinase-type plasminogen activator system in cancer metastasis: a review. Int J Cancer, 1997. 72(1): p. 1-22.

351. Zhao, H., et al., Immunohistochemical expression of UPA, PAl-1, cathepsin D and apoptotic cells in ductal carcinoma in situ of the breast. Breast Cancer, 2002. 9(2): p. 118-26.

352. Sugiura, Y., et al., The plasminogen-plasminogen activator (PA) system in neuroblastoma: role of PA inhibitor-1 in metastasis. Cancer Res, 1999. 59(6): p. 1327-36.

353. Gutierrez, L.S., et al., Tumor development is retarded in mice lacking the gene for urokinase-type plasminogen activator or its inhibitor, plasminogen activator inhibitor-1. Cancer Res, 2000. 60(20): p. 5839-47.

354. Zhou, A., et al., How vitronectin binds PAl-1 to modulate fibrinolysis and cell migration. Nat Struct Biol, 2003. 10(7): p. 541-4.

355. Ohguro, S. and H. Tsubota, Expressions of very late antigen-6 and vitronectin receptor, and their interactions to laminin and vitronectin during tonsillar $B$-cell activation. Auris Nasus Larynx, 1996. 23: p. 111-20.

356. Salcedo, R. and M. Patarroyo, Constitutive alpha V beta 3 integrin-mediated adhesion of human lymphoid B cells to vitronectin substrate. Cell Immunol, 1995. 160(2): p. 165-72.

357. Savill, J., et al., Vitronectin receptor-mediated phagocytosis of cells undergoing apoptosis. Nature, 1990. 343(6254): p. 170-3.

358. Zhang, Y., et al., Processing and activation of pro-interleukin-16 by caspase-3. J Biol Chem, 1998. 273(2): p. 1144-9.

359. Cruikshank, W.W., H. Kornfeld, and D.M. Center, Interleukin-16. J Leukoc Biol, 2000. 67(6): p. 757-66.

360. Elssner, A., et al., IL-16 is constitutively present in peripheral blood monocytes and spontaneously released during apoptosis. J Immunol, 2004. 172(12): $\mathrm{p}$. 7721-5.

361. Kaser, A., et al., B lymphocyte-derived IL-16 attracts dendritic cells and Th cells. J Immunol, 2000. 165(5): p. 2474-80.

362. Kovacs, E., The serum levels of IL-12 and IL-16 in cancer patients. Relation to the tumour stage and previous therapy. Biomed Pharmacother, 2001. 55(2): $p$. 111-6.

363. Chupp, G.L., et al., Tissue and T cell distribution of precursor and mature IL-16. J Immunol, 1998. 161(6): p. 3114-9.

364. Abbas, A.K.e.a., Cellular and Molecular Immunology. 2007, Philadelphia, PA: Saunders Elsevier. 566.

365. Rothlein, R., et al., A form of circulating ICAM-1 in human serum. J Immunol, 1991. 147(11): p. 3788-93.

366. Seth, R., F.D. Raymond, and M.W. Makgoba, Circulating ICAM-1 isoforms: diagnostic prospects for inflammatory and immune disorders. Lancet, 1991. 338(8759): p. 83-4. 
367. Alexiou, D., et al., Serum levels of E-selectin, ICAM-1 and VCAM-1 in colorectal cancer patients: correlations with clinicopathological features, patient survival and tumour surgery. Eur J Cancer, 2001. 37(18): p. 2392-7.

368. Giavazzi, R., et al., Soluble intercellular adhesion molecule 1 is released by human melanoma cells and is associated with tumor growth in nude mice. Cancer Res, 1992. 52(9): p. 2628-30.

369. Becker, J.C., et al., Soluble intercellular adhesion molecule-1 inhibits MHCrestricted specific T cell/tumor interaction. J Immunol, 1993. 151(12): p. 7224-32.

370. Becker, J.C., et al., Shedding of ICAM-1 from human melanoma cell lines induced by IFN-gamma and tumor necrosis factor-alpha. Functional consequences on cell-mediated cytotoxicity. J Immunol, 1991. 147(12): p. 4398401.

371. O'Hanlon, D.M., et al., Soluble adhesion molecules (E-selectin, ICAM-1 and VCAM-1) in breast carcinoma. Eur J Cancer, 2002. 38(17): p. 2252-7.

372. Mills, P.J., et al., The effects of standard anthracycline-based chemotherapy on soluble ICAM-1 and vascular endothelial growth factor levels in breast cancer. Clin Cancer Res, 2004. 10(15): p. 4998-5003.

373. De Wever, O., et al., Soluble cadherins as cancer biomarkers. Clin Exp Metastasis, 2007. 24(8): p. 685-97.

374. Gogali, A., et al., Soluble adhesion molecules E-cadherin, intercellular adhesion molecule-1, and E-selectin as lung cancer biomarkers. Chest, 2010. 138(5): p. 1173-9.

375. Lee, H.M., et al., A membranous form of ICAM-1 on exosomes efficiently blocks leukocyte adhesion to activated endothelial cells. Biochem Biophys Res Commun, 2010. 397(2): p. 251-6.

376. Koyama, S., Immunosuppressive effect of shedding intercellular adhesion molecule 1 antigen on cell-mediated cytotoxicity against tumor cells. Jpn J Cancer Res, 1994. 85(2): p. 131-4. 
University of Louisville

CURRICULUM VITAE

\section{Carolyn D. Roberson}

Department of Microbiology and Immunology

319 Abraham Flexner Way

(502) 852-6979

Bldg 55A, Rm. 311

cdrobe04@louisville.edu

Louisville, KY 40202

\section{EDUCATION}

Ph.D. Candidate. Immunology, University of Louisville, Louisville, KY. 2009-present Dissertation Title: Modulation of the Ovarian Cancer Humoral Response by TumorDerived Exosomes. Mentor: Dr. Douglas D. Taylor (2009-2013); Mentor: Dr. Jill Suttles.

Master of Science, Microbiology and Immunology, University of Louisville, Louisville, KY. 2011.

Master of Science. Biological Sciences, Mississippi State University, Mississippi State, MS. 1999. Thesis: Analysis of Melanophore Differentiation in Embryonic Zebrafish Under Normal and Treated Conditions. Advisor: Dr. Giselle Thibaudeau

Bachelor of Science. Biology (Pre-Med), Stillman College, Tuscaloosa, AL. 1994.

\section{ACADEMIC/TEACHING EXPERIENCE}

Associate Professor of Biology. Roane State Community College, Cumberland County Campus, Crossville, TN. 2000-2009.

- Taught lectures and labs

- Courses taught: General Biology I, General Biology II, Human Anatomy and Physiology I, Human Anatomy and Physiology II, Microbiology Lab, Biology for Education Majors

- Organized and prepared materials for all biology labs

- Advised and assisted students in determining their course of study

- Mentored two adjunct professors

- Participated regularly in interviewing process for hiring of Math/Science faculty

- Developed a one-semester biology course for education majors 
Lecturer. Mississippi State University, Mississippi State, MS. 1999-2000

- Courses taught: Human Anatomy Lab, Anatomy and Physiology, Animal Biology

Graduate Teaching Assistant. Mississippi State University, Mississippi State, MS. 1996-1999.

- Courses taught: Anatomy and Physiology Lab, Animal Biology Lab

- Guest lecturer: Human Anatomy (2 lectures)

\section{RESEARCH EXPERIENCE}

Graduate Research Assistant/Ph.D. Research. Department of Microbiology and Immunology, University of Louisville, Louisville, KY. 2009-present.

- Conduct experiments to analyze the human humoral response to ovarian cancer

Graduate Research Assistant/M.S. Developmental Biology, Mississippi State University, Mississippi State, MS. 1996-1999.

- Conducted experiments to analyze melanophore differentiation in embryonic zebrafish under normal and treated conditions

- Maintained an in-house adult zebrafish colony (150+ zebrafish) for breeding

Research Assistant. Emergency Department, Children's Hospital of Alabama, University of Alabama at Birmingham, Birmingham, AL. Summer 1993.

- Co-conducted patient satisfaction surveys (via parents) on the quality and satisfaction of care received in the emergency department

- Co-constructed, designed, and updated informational pamphlets on the emergency department's triage system

Research Assistant. Anesthesia Research Department, University of Alabama at Birmingham, Birmingham, AL. Summer 1992.

- Conducted experiments on surface tension of artificial surfactant

\section{TEACHING SERVICE ACTIVITIES}

Instructor for Summer Minority Science Workshop. Oak Ridge Branch Campus, Roane State Community College, Oak Ridge, TN. 2002-2007.

- Designed and facilitated the biology component of a week-long workshop for local students (middle school-high school) to generate greater interest and success in the sciences 
Assistant Facilitator for Freshman Experience. Cumberland County Campus, Roane State Community College, Crossville, TN. Fall 2003-2004.

- Designed and facilitated activities to assist incoming freshmen with acclimation to the community college environment

Campus Tour Assistant. Cumberland County Campus, Roane State Community College, Crossville, TN. 2002-2005.

- Conducted tours of the biology lab for local students (middle school-high school)

Instructor For GearUP GradKids Summer Academy. Scott County Campus, Roane State Community College, Huntsville, TN. 2003.

- Conducted a one-day science experience for students participating in GearUp GradKids, a federally-funded program designed to encourage Scott and Cocke county (TN) students to pursue higher education.

\section{Biology Textbook Reviewer}

- Krough, D. Biology: A Guide to the Natural World. 3rd ed. Prentiss Hall, 2004.

- Complete text

- Raven, P.H., Johnson, G.B., Losos, J. and S. Singer. Biology. $7^{\text {th }}$ ed. McGraw-Hill, 2004.

- 3-chapter review

- Russell, P.J., Wolfe, S.L., Starr, C., Hertz, P.E. and B. McMillan. Biology: The Dynamic Science. Brooks-Cole, 2007.

- 3-chapters plus preface

Co-Facilitator for Gateway Workshop. Roane County Campus, Roane State Community College, Harriman, TN. April 2001.

- Co-designed and facilitated a week-long workshop for local high school science teachers to assist them in preparing their students for the biology component of the Gateway exam (exam formerly required for graduation)

\section{PROFESSIONAL DEVELOPMENT}

Teacher Preparation Grant Workshop (Pellissippi State Technical Community College (PSTCC), Knoxville, TN): May 2006, February 2007, October 2007, February 2008, May 2008

- NSF funded Partnership grant (TBR-TPP) with PSTCC and TBR Schools in East TN

- Includes reviewing of, making changes to, and development of new courses needed for Elementary Education degree (K-6) and Associates of Science in Teaching (AST) degree

WebCT Academy (RSCC): May 2004, 2005

- In depth look at the purpose, capabilities, and use of WebCT in course management and enhancement 
Day at Mercer (Atlanta, GA): March 2003, 2005

- One-day workshop providing Pharmacy and Pharmacy Tech advisors with information about Mercer University Southern School of Pharmacy

NCSI Summer Workshop (High Point, NC): July 2003

- Follow-up workshop to SC2002

SC2002 Education Program (Baltimore, MD): November 2002

- Supercomputing Education Program focusing on use of computer visualization as a tool in teaching

\section{FUNDING}

Integrated Programs in Biomedical Sciences (IPIBS) Fellowship. University of Louisville, 2009-2011.

Technology Access Fee (TAF) Fund Award. Roane State Community College, 16-bay Mobile Cart (Dell wireless laptops), 2003.

Institutional Effectiveness Planning (IEP) Fund Award. Roane State Community College, Dell laptop (for instructor), lab projector, ADAM Interactive Anatomy Software, and projection screen, 2001.

Departmental Travel Award. Mississippi State University. Association of Southeastern Biologists (ASB) meeting. Wilmington, NC, 1999.

Departmental Travel Award. Mississippi State University. Pan American Society for Pigment Cell Research (PASPCR) meeting. Snowmass, CO, 1998.

\section{COMMITTEES AND ORGANIZATIONS}

American Association for Cancer Research (AACR). Member. 2012-present.

American Society for Exosomes and Microvesicles (ASEMV). Member. 2013.

Microbiology and Immunology Student Organization (MISO), Member. University of Louisville, 2009-present.

Black Biomedical Graduate Student Organization (BBGSO), Vice-President, Secretary. University of Louisville, 2010-present.

Anatomical Sciences and Neurobiology Department (ASNB) Chair Search Committee, Graduate Student Representative. University of Louisville, 2011. 
Math/Science Faculty Interview Committee. Roane State Community College, 20052008.

President Search Committee, Faculty Representative. Roane State Community College, 2005.

Pan-American Society for Pigment Cell Research (PASPCR). Member. 1998-1999.

Association for Southeastern Biologists (ASB). Member. 1998-1999.

\section{PUBLICATIONS}

Roberson, C.D., Qi, Y., Gercel-Taylor, C., Schey, K.L., and D.D. Taylor. Identification of Immunoreactive Tumor Antigens Using Free and Exosome-Associated Humoral Responses. Exosomes Microvesicles, 2013, 1:8. doi: 10.5772/57524.

Atay, S., Roberson, C.D., Gercel-Taylor, C., and D.D. Taylor. Ovarian Cancer-Derived Exosomal Fibronectin Induces Pro-Inflammatory IL-1beta. Exosomes Microvesicles, 2013, 1:2. doi: 10.5772/56180.

Roberson, C.D., Atay, S., Gercel-Taylor, C. and D.D. Taylor. (2010). Tumor-Derived Exosomes as Mediators of Disease and Potential Diagnostic Biomarkers. Cancer Biomarkers (7):1-11.

Roberson, Carolyn Denise (1999). Analysis of Melanophore Differentiation in Embryonic Zebrafish Under Normal and Treated Conditions. M.S. thesis, Mississippi State University, United States--Mississippi. ProQuest Dissertation Database (Publication number AAT 1396482).

Roberson, C., Jin, E-J., and G. Thibaudeau (1999). Analysis of Melanophore Differentiation in Zebrafish Under Normal and Treated Conditions (Abstract). ASB Bulletin 46:174.

\section{PRESENTATIONS}

Roberson, C., Gowan, J., Rudolph, J., Shaffer, A. and V. Buck (2003). Analysis of Cystic Fibrosis Inheritance Using Computational Modeling (When Eve Met Steve...). National Computational Science Institute (NCSI) Summer Workshop. High Point, NC.

Roberson, C., Jin, E-J., and G. Thibaudeau (1999). Analysis of Melanophore Differentiation in Zebrafish Under Normal and Treated Conditions. Association of Southeastern Biologists (ASB) Meeting. Wilmington, NC. 


\section{POSTER PRESENTATIONS}

Roberson, C.D., Gercel-Taylor, C. and D.D. Taylor (2012). Characterization of Humoral Response Profiles of Ovarian Cancer Patients as Diagnostic Biomarkers. American Association for Cancer Research (AACR), Chicago, IL.

Roberson, C.D., Gercel-Taylor, C. and D.D. Taylor (2011). Characterization of the Humoral Response to Ovarian Cancer Antigenic Protein. Poster presentation at the James Graham Brown Center $10^{\text {th }}$ Annual Retreat. Louisville, KY.

Roberson, C., Jin, E-J., and G. Thibaudeau (1998). Melanophore Differentiation in Zebrafish. Pan American Society for Pigment Cell Research (PASPCR), Snowmass, co. 